\title{
Temperature Influence and Heat Management Requirements of Microalgae Cultivation in Photobioreactors
}

\author{
A Thesis \\ presented to \\ the Faculty of California Polytechnic State University,
}

San Luis Obispo

\author{
In Partial Fulfillment \\ of the Requirements for the Degree \\ Master of Science in Agriculture, with Specialization in: \\ Agricultural Engineering Technology
}

by

Thomas Hagen Mehlitz

February 2009 
(C) 2009

Thomas Hagen Mehlitz

ALL RIGHTS RESERVED 


\section{COMMITTEE MEMBERSHIP}

TITLE:

AUTHOR:

DATE SUBMITTED:

COMMITTEE CHAIR: Ilhami Yildiz, Ph.D.

COMMITTEE MEMBER: Richard Cavaletto, Ph.D.

COMMITTEE MEMBER: Brian Hampson, Ph.D.

COMMITTEE MEMBER: Shaun Kelly, Ph.D.

COMMITTEE MEMBER: Shikha Rahman, Ph.D. 


\begin{abstract}
Temperature Influence and Heat Management Requirements of Microalgae Cultivation in Photobioreactors.
\end{abstract}

Thomas Hagen Mehlitz

Microalgae are considered one of the most promising feedstocks for biofuel production for the future. The most efficient way to produce vast amounts of algal biomass is the use of closed tubular photobioreactors (PBR). The heat requirement for a given system is a major concern since the best algae growth rates are obtained between 25-30 ${ }^{\circ} \mathrm{C}$, depending on the specific strain. A procedure to determine temperature influence on algal growth rates was developed for a lab-scale PBR system using the species Chlorella. A maximum growth rate of 1.44 doublings per day at $29{ }^{\circ} \mathrm{C}$ (optimal temperature) was determined. In addition, a dynamic mathematical model was developed to simulate heating and cooling energy requirements of tubular PBRs for any desired location. Operating the model with hourly weather data as input, heating and cooling loads can be calculated early in the planning stage of a project. Furthermore, the model makes it possible to compare the operation inside a greenhouse to the outdoor operations, and consequently provides fundamental information for an economic feasibility study. The best configuration for a specific location can be evaluated easily. The model was exemplary tested for a hypothetical 100,000 1 photobioreactor located in San Luis Obispo, California, U.S.A. Average algae productivity rates of $23 \%$ and $67 \%$ for outdoor and indoor PBR operations, respectively, were obtained. Actual energy loads (heating and cooling) needed to maintain the PBR at optimal temperature were determined and 
compared. Sensitivity analyses had been performed for abrupt temperature and solar radiation steps, PBR row distances, ground reflectivities, and ventilation rates of the greenhouse. An optimal row distance of $0.75 \mathrm{~m}$ was determined for the specific PBR. The least amount of energy was needed for a ground reflectivity of $20 \%$. The ventilation rate had no major influence on the productivity rate of the system. Results demonstrated the importance of a simulation model as well as the economic impact of a sophisticated heat management system. Energy savings due to an optimized heat management system will eventually increase proficiency of the systems, which will support a new sustainable industry and future developmental potential.

Keywords: Microalgae, photobioreactor, temperature influence, heat management, biodiesel, ethanol, biofuel, algal biomass 


\section{ACKNOWLEDGMENTS}

I would like to thank my faculty advisors for their support while working on this thesis. I would like to thank Dr. Ilhami Yildiz for his inspiration, hard work and friendship throughout my time at Cal Poly. Thank you for dozens of meetings, hundreds of coffees and thousands of laughs. Please keep your high standards and amazing ways of energizing people. Dr. Yildiz, I thank you for your great influence and shaping me to the person I am now. I have had nothing but a great time, and am grateful for this lifetime friendship.

I would also like to thank Dr. Richard Cavaletto, Dr. Brian Hampson, Dr. Shaun Kelly and Dr. Shikha Rahman for their unlimited support and constant belief in me as well as the project.

Furthermore, I would like to thank my co-workers and green-friends here at Cal Poly: Bryan Brooker, Diana Durany and John Karamanlis for their enthusiasm and support, their contributions to this thesis and for continuing the Algae-to-Biofuels project at Cal Poly.

Finally, I would like to thank Burkhard, Elke, Linda, Kathrin and Sandra for their love, support and sacrifice throughout my time on the other side of the world. 


\section{TABLE OF CONTENTS}

Page

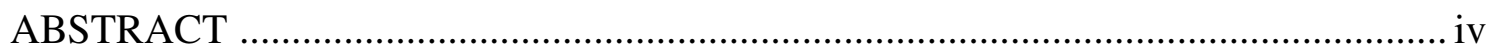

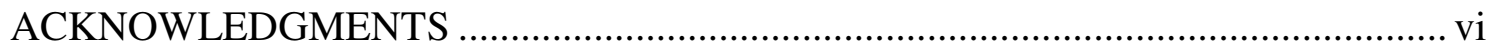

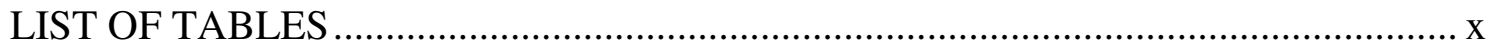

LIST OF FIGURES ....................................................................................

LIST OF SYMBOLS ..................................................................................

CHAPTER

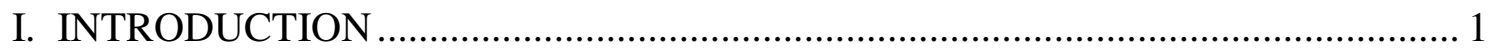

II. BACKGROUND ...................................................................................... 7

2.1 Overview .................................................................................... 7

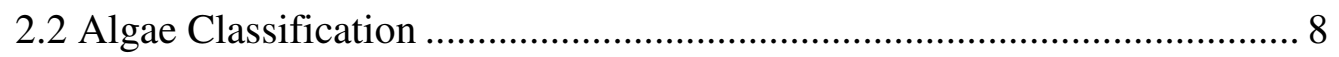

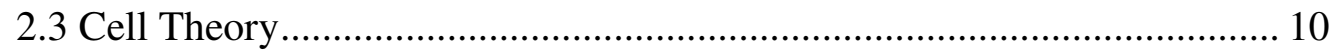

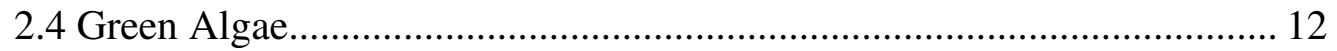

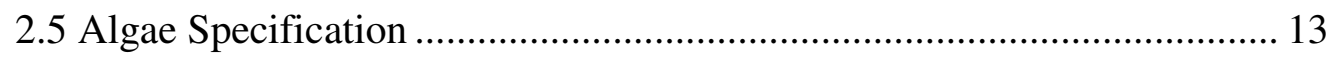

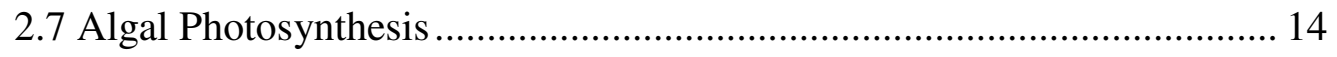

2.7 Growth Kinetics ....................................................................... 16

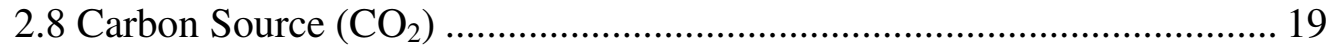

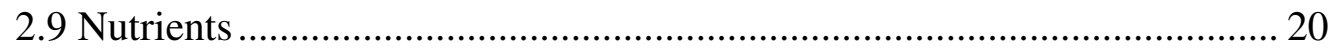


2.11.1 Function of a Photobioreactor............................................................ 30

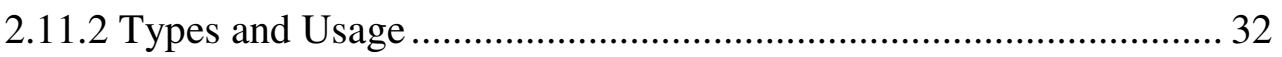

2.11.3 The PBR used for Simulation in this Study (BioFence) ................... 36

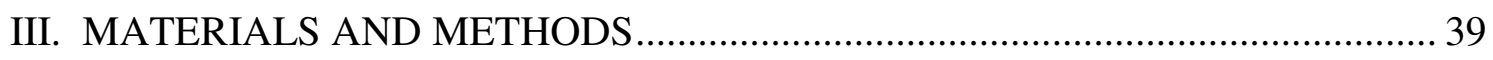

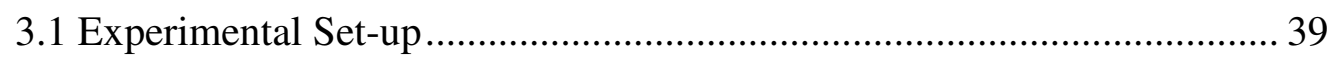

3.1.1 Culturing Techniques....................................................................... 40

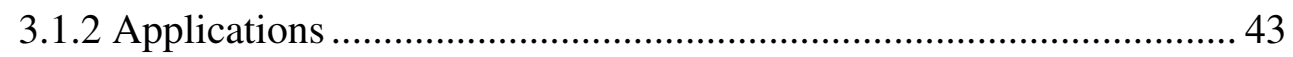

3.1.3 Data Collection and Analyses ...................................................... 49

3.2 Heat Management Simulation Model …………….................................. 51

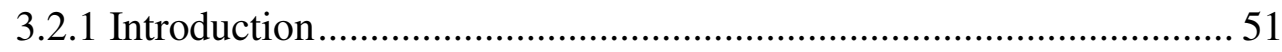

3.2.2 Physical Model and Photobioreactor Architecture ……….................. 54

3.2.3 Energy Balances.................................................................................. 54

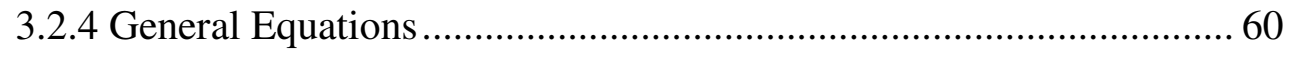

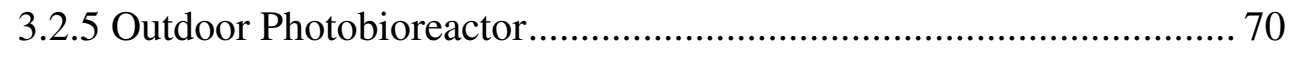

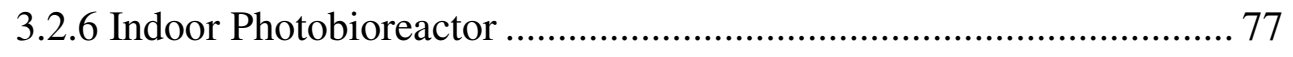

3.2.7 Sensitivity Analyses and Evaluations ……………………................ 82 
IV. RESULTS AND DISCUSSION 83

4.1 Temperature Experiments 83

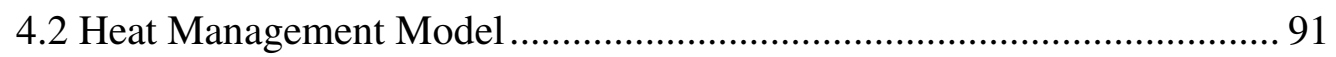

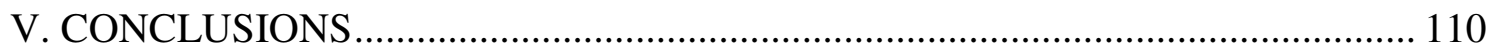

5.1 Temperature Experiments ………………………............................ 110

5.2 Heat Management Model ..................................................................... 112

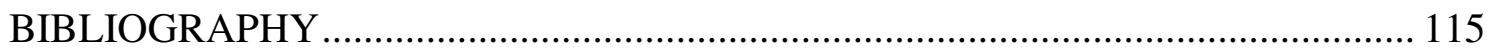

\section{APPENDICES}

A. Energy requirements per day for standard transmissivity............................ 123

B. Energy requirements per day for $60 \%$ transmissivity............................... 125

C. Energy requirements per day for $80 \%$ transmissivity................................ 127

D. Effects of different Nitrogen concentrations on the chemical composition of various algae strains. 


\section{LIST OF TABLES}

Table

Page

1. Chemical Composition of Different Algae Strains on a Dry Matter Basis (\%).....13

2. Basic fertilizer composition.......................................................4

3. Photobioreactor and greenhouse characteristics.....................................51

4. Key model parameters and their values used in the sensitivity analyses.............80

5. Mean growth rates at different growth medium temperatures ..........................86

6. Values incorporated into the heat management model ...............................86 


\section{LIST OF FIGURES}

Figure

Page

1. Schematic view of a photobioreactor system.................................................... 1

2. A tubular photobioreactor in outdoor environment. .............................................. 1

3. Algae paste freshly harvested through filter technology. .......................................... 1

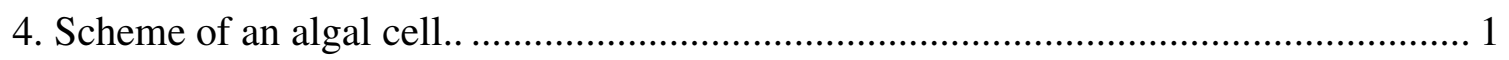

5. Green algae as seen under the microscope.. ................................................... 1

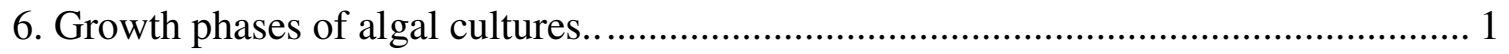

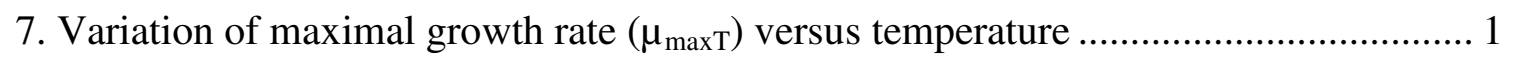

8. A horizontal tubular Photobioreactor................................................................ 1

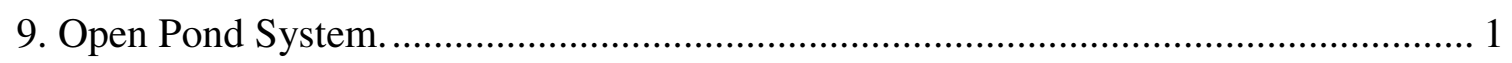

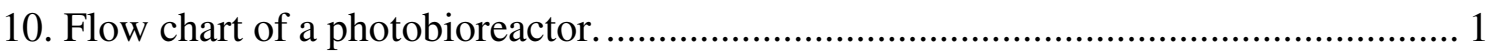

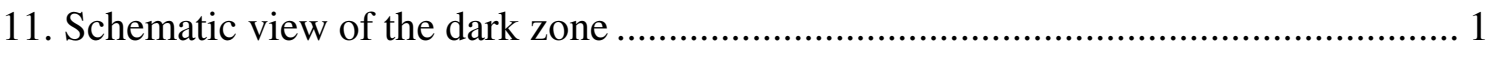

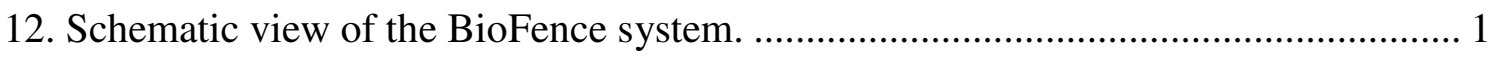

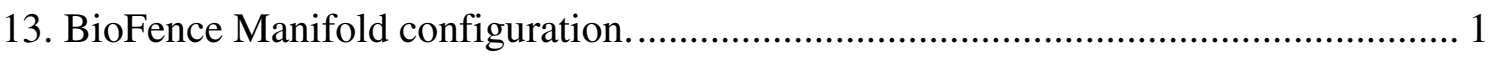

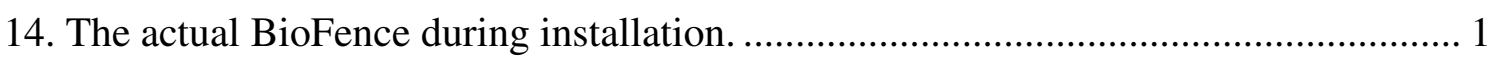

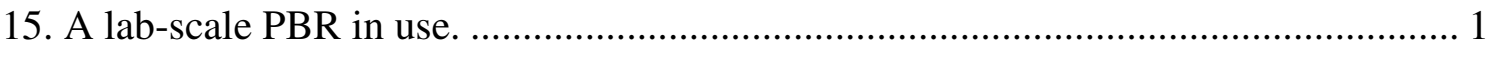

16. Schematic view of the photobioreactor set-up............................................... 1

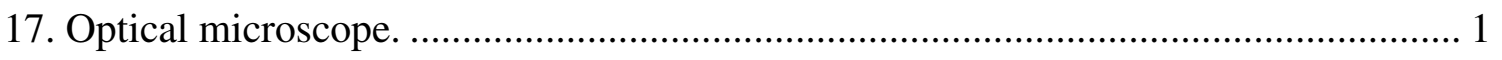

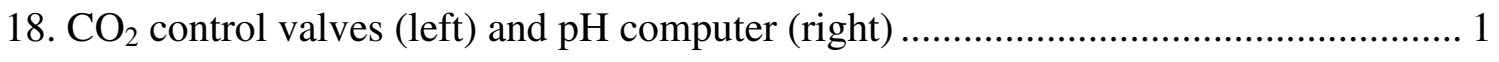

19. An older spectrophotometer with analog reading.............................................. 1

20. A modern spectrophotometer with PC control. ................................................. 1 
21. Hanna Instruments Multimeter. 1

22. Screen view of the online database where all available data were collected............... 1

23. Flow chart of the simulation model. .................................................................... 1

24. Dimensions of the photobioreactor..................................................................... 1

25. Heat losses and gains from an outdoor PBR .................................................... 1

26. Heat losses/gains from an indoor PBR and a greenhouse...................................... 1

27. Zenith angle, slope, surface azimuth angle, and solar azimuth angle for a tilted

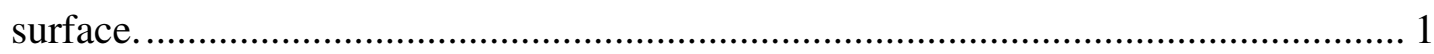

28. Photobioreactor tube configuration used in determining the critical sun angle, TC.

The upper tube shades the lower tube................................................................ 1

29. Angles of incidence and refraction in media with refractive indices $n 1$ and $n 2 \ldots \ldots \ldots 1$

30. Photobioreactors during operation ................................................................. 1

31. Online database where all observed data were collected......................................... 1

32. Sample size for each temperature experiment. ............................................... 1

33. Mean growth rates and standard deviations at different temperatures ..................... 1

34. Relative productivity rates with respect to growth medium temperature.................. 1

35. Chlorella growth curve with respect to growth medium temperature....................... 1

36. Sensitivity analyses on outside temperature (top) and solar radiation (bottom)......... 1

37. Responses to a step change in outdoor temperature. ............................................ 1

38. Responses to a step change in solar radiation................................................... 1

39. Energy requirements and average productivity for different ground reflectivities...... 1

40. Energy requirements and average productivity for different PBR distances.............. 1

41. Energy requirements and average productivity for ventilation rates. ........................ 1 
42. Energy requirements and average productivity for different shading material

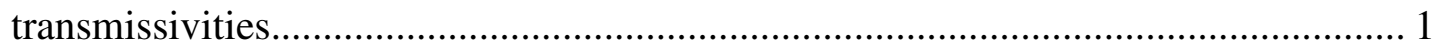

43. Temperature variations for outdoor (top) and indoor (bottom) PBR operations......... 1

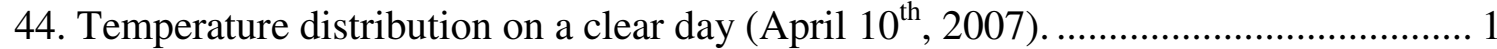

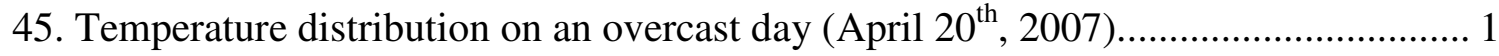

46. Algae productivity with respect to the temperature in each hour in the outdoor

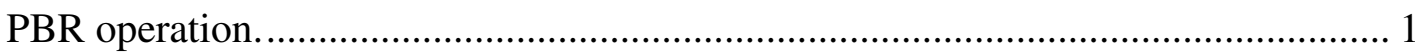

47. Algae productivity with respect to the temperature in each hour in the indoor

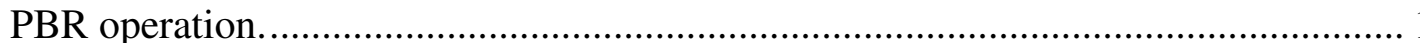

48. The hypothetical algae productivity with respect to the temperature in each hour for indoor PBR operation, when losses due to overheating were ignored. ......... 1

49. Required heating and cooling loads for the indoor PBR operation. .......................... 1 


\section{LIST OF SYMBOLS}

\begin{tabular}{|c|c|}
\hline $\mathrm{AEH}$ & Infiltration rate \\
\hline $\mathrm{A}_{\mathrm{GH}}$ & Total surface area of the greenhouse \\
\hline $\mathrm{A}_{\mathrm{GHSUR}}$ & Total surface area of the floor \\
\hline $\mathrm{A}_{\mathrm{TSUR}}$ & Total outside surface of the PBR tubes \\
\hline $\mathrm{A}_{\text {TSURPRO }}$ & Total projected surface area of the PBR \\
\hline $\mathrm{b}$ & Distance between ground \& first PBR tube \\
\hline $\mathrm{Cp}_{\mathrm{AIR}}$ & Specific heat of air \\
\hline $\mathrm{C} \mathrm{p}_{\mathrm{WAT}}$ & Specific heat of water \\
\hline $\mathrm{Cv}_{\mathrm{F}}$ & Specific volumetric heat capacity for the floor \\
\hline $\mathrm{D}$ & Dilution rate \\
\hline $\mathrm{D}_{\mathrm{AP}}$ & Specific testing vial diameter according to Bouguer's law \\
\hline $\mathrm{D}_{\mathrm{FLOOR} 1}$ & Floor layer thickness of the top layer \\
\hline $\mathrm{D}_{\mathrm{FLOOR} 2}$ & Floor layer thickness of the middle layer \\
\hline $\mathrm{D}_{\mathrm{FLOOR} 3}$ & Floor layer thickness of the bottom layer \\
\hline dt & Distance between PBR tube centers \\
\hline $\mathrm{dT}_{\mathrm{FL} 1}$ & Ground temperature change for top floor layer \\
\hline $\mathrm{dT}_{\mathrm{FL} 2}$ & Ground temperature change for middle floor layer \\
\hline $\mathrm{dT}_{\mathrm{FL} 3}$ & Ground temperature change for bottom floor layer \\
\hline $\mathrm{dT}_{\mathrm{GH}}$ & Greenhouse air temperature change \\
\hline $\mathrm{dT}_{\mathrm{PBR}}$ & Photobioreactor temperature change \\
\hline $\mathrm{dtt}$ & Distance between PBR twin tube centers \\
\hline $\mathrm{E}$ & Calculation parameter \\
\hline $\mathrm{EF}$ & Extinction factor according to Bouguer's law (also known as K) \\
\hline GHG & Greenhouse gable height \\
\hline GHL & Greenhouse length \\
\hline
\end{tabular}




\begin{tabular}{|c|c|}
\hline GHN & \# of greenhouse bays \\
\hline GHW & Greenhouse width \\
\hline GHWH & Greenhouse wall height \\
\hline $\mathrm{h}_{\text {HTC }}$ & Heat transfer coefficient \\
\hline $\mathrm{H}_{\mathrm{ILL} 1}$ & Illuminated height of a column $n$ \\
\hline $\mathrm{HS}_{\mathrm{PBR}}$ & Heat storage component of the PBR \\
\hline $\mathrm{IR}_{\mathrm{AIR}}$ & Index of refraction $\mathrm{n}$ for the air \\
\hline $\mathrm{IR}_{\mathrm{TUBE}}$ & Index of refraction $\mathrm{n}$ for the glass tube \\
\hline $\mathrm{I}_{\mathrm{S}}$ & Outside solar radiation \\
\hline $\mathrm{I}_{\mathrm{T}}$ & Total solar radiation reaching the tubes \\
\hline JD & Julian Day \\
\hline $\mathrm{K}_{\mathrm{FLOOR}}$ & Thermal conductivity of floor layers \\
\hline $\mathrm{K}_{\mathrm{s}}$ & Half-saturation constant \\
\hline lt & PBR tube length \\
\hline na & \# of PBR columns axial \\
\hline $\mathrm{nc}$ & \# of PBR parallel columns \\
\hline $\mathrm{P}_{\text {ERCNILL }}$ & $\begin{array}{l}\text { Percent shading of tubes illuminated in the } \mathrm{n}^{\text {th }} \text { column (fully } \\
\text { illuminated) }\end{array}$ \\
\hline$P_{\text {ERCNSHADE }}$ & Total percentage of shading received in column $n$ \\
\hline PERCNSHADE 1 & Percent shading of tubes in the $\mathrm{n}^{\text {th }}$ column (not fully illuminated height) \\
\hline PL & Actual pathlength in the algae medium \\
\hline $\operatorname{Pr}$ & Prandtl number \\
\hline $\mathrm{Q}_{10}$ & Temperature coefficient \\
\hline $\mathrm{Q}_{\text {сLвотғ }}$ & Conductive heat transfer of bottom floor layer \\
\hline$Q_{\text {CLMIDF }}$ & Conductive heat transfer of middle floor layer \\
\hline QCLTOPF & Conductive heat transfer of top floor layer \\
\hline $\mathrm{Q}_{\mathrm{GHCL}}$ & Heat transfer due to free convection between the inside air and PBR \\
\hline $\mathrm{Q}_{\mathrm{GHHG}}$ & Greenhouse heat gains due to solar radiation \\
\hline
\end{tabular}




\begin{tabular}{|c|c|}
\hline $\mathrm{Q}_{\mathrm{GHHLC}}$ & Greenhouse heat transfer due to conduction \\
\hline $\mathrm{Q}_{\mathrm{GHHLI}}$ & Greenhouse heat transfer due to infiltration \\
\hline $\mathrm{Q}_{\mathrm{GHHLR}}$ & Radiation exchange with the ground and sky \\
\hline $\mathrm{Q}_{\text {GHTSRA }}$ & Total solar radiation absorbed by the PBR in the greenhouse \\
\hline Qos & Outside longwave radiation exchange with the sky and the ground \\
\hline QoscL & Outside convective heat transfer due to convection \\
\hline $\mathrm{Q}_{\mathrm{RLF}}$ & Radiation exchange between the sky and floor \\
\hline $\mathrm{Q}_{\text {TSRA }}$ & Total solar radiation absorbed by the PBR \\
\hline $\mathrm{Q}_{\text {TSRAF }}$ & Total solar radiation absorbed by the floor \\
\hline $\mathrm{R}_{\mathrm{ALGAE}}$ & Reflectivity of the algae algae \\
\hline $\operatorname{Re}$ & Reynolds number \\
\hline $\mathrm{R}_{\mathrm{EFT}}$ & Total reflection of the PBR tube \\
\hline $\mathrm{R}_{\mathrm{GROUND}}$ & Reflectivity of the ground \\
\hline $\mathrm{R}_{\text {PARA }}$ & Parallel reflection of the PBR tube \\
\hline $\mathrm{R}_{\mathrm{PERP}}$ & Perpendicular reflection of the PBR tube \\
\hline SF & Shade factor \\
\hline $\mathrm{S}_{\mathrm{FR}}$ & Percent shading of the first PBR column \\
\hline $\mathrm{SF}_{\mathrm{tt}}$ & Overall shading factor for twin tube PBR \\
\hline $\mathrm{SF}_{\mathrm{tt} 1}$ & Shading factor for one twin tube column \\
\hline STIME & Solar time on a specific day of the year \\
\hline $\mathrm{t}$ & $\#$ of tubes per PBR column \\
\hline $\mathrm{T}$ & Temperature \\
\hline $\mathrm{T}_{\mathrm{ALG}}$ & PBR or algae temperature \\
\hline $\mathrm{T}_{\mathrm{ALGNEW}}$ & New PBR temperature \\
\hline $\mathrm{TC}$ & Critical sun angle \\
\hline $\mathrm{T}_{\mathrm{FLOOR}}$ & Floor temperature \\
\hline $\mathrm{T}_{\text {FLOORBOT }}$ & Bottom floor layer temperature \\
\hline
\end{tabular}




\begin{tabular}{|c|c|}
\hline $\mathrm{T}_{\mathrm{FLOORMID}}$ & Middle floor layer temperature \\
\hline $\mathrm{T}_{\text {FLOORNEW }}$ & New floor temperature \\
\hline $\mathrm{T}_{\mathrm{G}}$ & Deep ground temperature \\
\hline $\mathrm{T}_{\mathrm{GH}}$ & Greenhouse temperature \\
\hline TIME & Time on a specific day \\
\hline $\mathrm{T}_{\mathrm{inf}}$ & Temperature at $10 \%$ of maximum growth rate (lower end) \\
\hline $\mathrm{T}_{\mathrm{opt}}$ & Optimal temperature \\
\hline $\mathrm{T}_{\mathrm{OS}}$ & Outside air temperature \\
\hline $\mathrm{T}_{\mathrm{SKY}}$ & Sky temperature \\
\hline $\mathrm{T}_{\text {sup }}$ & Temperature at $10 \%$ of maximum growth rate (upper end) \\
\hline $\mathrm{tt}$ & $\begin{array}{l}\text { Switch to decide whether twin tubes }(1) \text { or single tubes }(0) \text { are used in } \\
\text { PBR columns }\end{array}$ \\
\hline $\mathrm{U}_{\mathrm{FL}}$ & Heat transfer coefficient - poured concrete $152 \mathrm{~mm}$ \\
\hline $\mathrm{U}_{\mathrm{G}}$ & Heat transfer coefficient - single layer glass \\
\hline $\mathrm{V}_{\mathrm{FL} 1}$ & Volume of the top floor layer \\
\hline $\mathrm{V}_{\mathrm{FL} 2}$ & Volume of the middle floor layer \\
\hline $\mathrm{V}_{\text {FL3 }}$ & Volume of the bottom floor layer \\
\hline $\mathrm{V}_{\mathrm{GH}}$ & Total greenhouse volume \\
\hline $\mathrm{V}_{\mathrm{PBR}}$ & Total photobioreactor volume \\
\hline WS & Wind speed \\
\hline $\mathrm{x}$ & Distance between PBR columns (parallel) \\
\hline $\mathrm{xa}$ & Distance between PBR columns (axial) \\
\hline
\end{tabular}

$\alpha_{\text {FLOOR }}$

$\beta$

$\gamma$

$\delta$

\author{
Absorptivity of the floor \\ Slope of virtual surface for beam incidence \\ Surface azimuth angle \\ Declination, the angular position of the sun at solar noon
}


$\mu_{\max }$

$\mu_{\max T}$

$\theta$

$\rho_{\text {AIR }}$

$\rho_{\mathrm{WAT}}$

$\tau$

$\tau_{\mathrm{GH}}$

$\tau_{\mathrm{A}}$

$\tau_{\mathrm{T}}$

$\Phi$

$\omega$
Emissivity of the glass/Plexiglass tubes

Flow rate photobioreactor

Maximum growth rate

Temperature dependent maximum growth rate

Angle of incidence

Density of air

Density of water

Total transmissivity PBR

Transmissivity of the greenhouse cover

Transmissivity of algae water

Transmissivity of PBR tubes

Latitude for location (San Luis Obispo)

Hour angle, the angular displacement of the sun 


\section{CHAPTER I}

\section{INTRODUCTION}

As we enter into the $21^{\text {st }}$ century, the world is faced with two major problems: the depletion of fossil fuels and the resulting dependency on fossil fuel exporting countries, as well as the aspect of global warming through emissions of greenhouse gases (Hinrichs and Kleinbach, 2006). Alternative, renewable, and environmentally friendly energy sources in combination with energy conservation practices are key elements in solving these problems. A lot of research has been done in various fields of alternative energy such as bioethanol and biodiesel production from crops, development of hydrogen as a

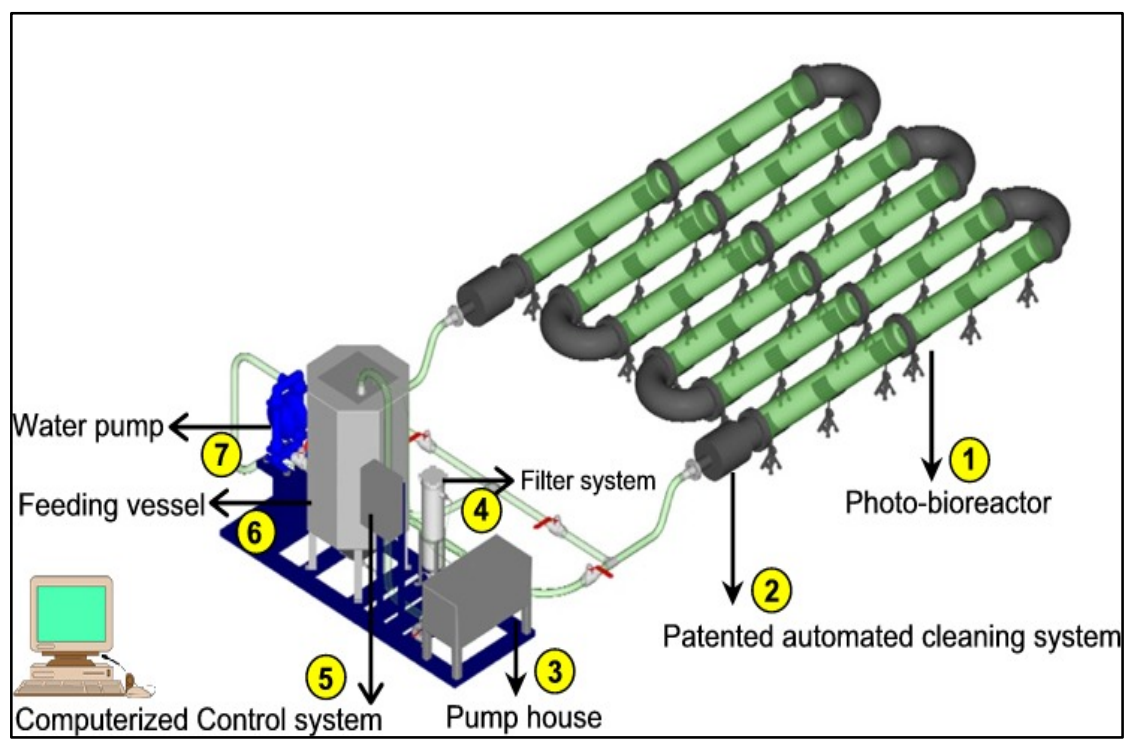

Figure 1. Schematic view of a photobioreactor system.

Source: After Algaelink, 2007.

fuel alternative, and biogas upgrades for use in gas fired vehicles. All of these new technologies however, have a number of disadvantages (Antoni et al., 2007). Thus far, 
they are either not productive enough, stand in contrast to public interests, or lack an abundance of a vital resource (mainly water and land). Therefore, several prudent questions need to be addressed. Can biomass be supplied without impacting the cost of agricultural land, competing with food production or harming the environment? Do we have sufficient land here or elsewhere?

Growing algae as a biofuel feedstock can be the solution to all of these problems. It has emerged as a viable resource for biodiesel and bioethanol production. Algae can be grown in two different systems, in photobioreactors (PBR) (Figure 1 and Figure 2) or in raceway ponds. Since the raceway ponds are less productive, land area extensive and uncontrollable, the PBRs will be the favorable application for the future (Chen, 1996). The PBR technology itself is quite new; therefore, much more research and improvements need to be done to optimize and enhance the existing systems for

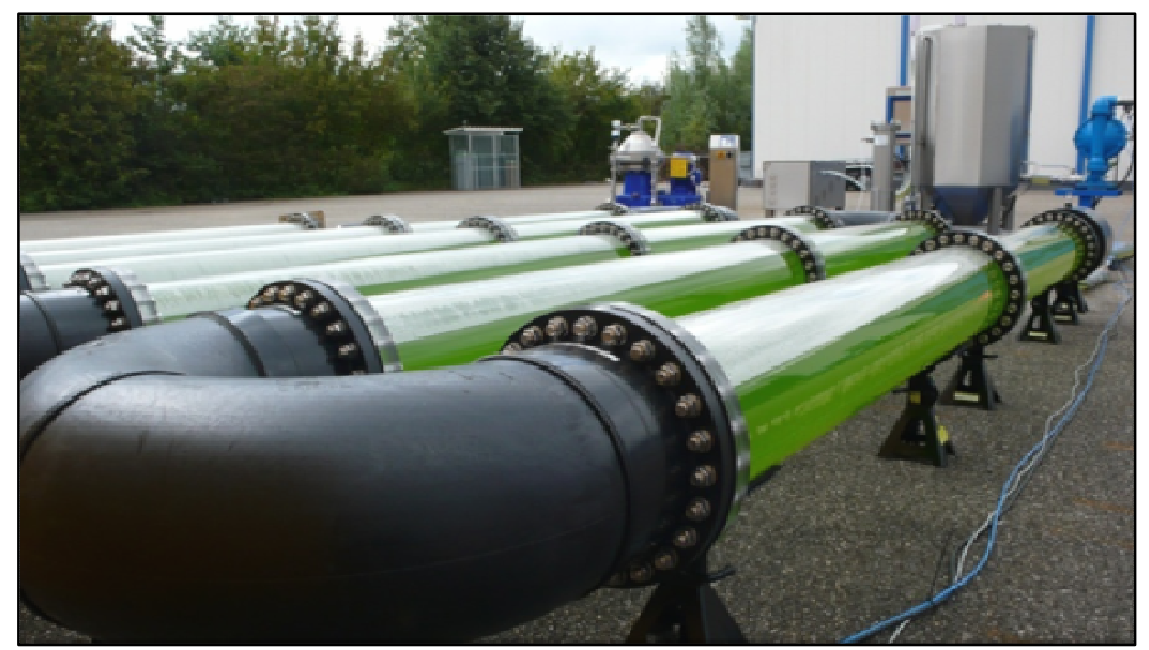

Figure 2. A tubular photobioreactor in outdoor environment.

Source: After Algaelink, 2007

commercial applications (NREL, 1998; Richmond, 2000; Pulz, 2001; Chisti, 2007; Huntley and Redalje, 2007). The major technical challenges are how to sustain the 
highest photosynthesis and biomass productivity levels, reduce cell damage due to hydrodynamic stress, reduce costs in fabrication and installation maintenance, and how to increase the capability of the system to expand to an industrial scale (Barbosa, 2003; AlgaeLink, 2007).

Unlike other crops that are currently being used for oil production such as soybean, oil palm, corn, and jatropha, some strains of algae contain as much as $70 \%$ oil. They are capable of producing more than 30-times the amount of oil (per year per unit area of land) when compared to oil seed crops (Chisti, 2007). Another advantage is that since algae use $\mathrm{CO}_{2}$ as a carbon source to grow, algae can extract the carbon dioxide from power plant exhausts or any other $\mathrm{CO}_{2}$ emitting process when the PBR is integrated into such a plant. A yield of 200 to 400 tons of oil/hectare/year can be considered reachable with a standard PBR system (Oilgae, 2006; Huntley and Redalje, 2007).

Theoretically, biodiesel produced from algae appears to be the only feasible solution today for replacing petrodiesel completely. No other feedstock has an oil yield high enough to be in a position to produce such large volumes of oil. It has been found that approximately 10 million acres of land would be needed for biodiesel production in order to produce enough biodiesel that could replace all the petrodiesel currently used in the U.S. (Oilgae, 2006). This is just 1 to $3 \%$ of the total land used today for both farming and grazing in the United States (about one billion acres). Clearly, algae biomass is a superior alternative as a feedstock for large-scale biodiesel production. One of the byproducts of the biofuels production from algae is a protein rich algae cake that can be used as an animal feed. Photobioreactors make it possible to supply biomass without 
impacting the cost of agricultural land, competing with food production and harming the environment. Co-production of biofuel and animal protein makes this resource efficient system a very attractive environmentally friendly alternative.

\section{Impacts}

Photobioreactors have two main functions: i) produce biomass in the form of algae, and ii) the use of carbon dioxide $\left(\mathrm{CO}_{2}\right)$ from the atmospheric environment in order for the algae to grow. $\mathrm{CO}_{2}$ is the most emitted greenhouse gas; and therefore, is widely considered responsible for global warming and its consequences. About $85 \%$ of the released $\mathrm{CO}_{2}$ in California comes from fuel combustion. Other sources of $\mathrm{CO}_{2}$ emission specific to California include the production of ethanol, cement, lime and waste combustion (Climatechange CA, 2005). Companies are not allowed to release as much $\mathrm{CO}_{2}$ as they would like to. Instead, they have to pay for every emitted ton of $\mathrm{CO}_{2}$. Different scenarios estimate a $\mathrm{CO}_{2}$ price of $\$ 15$ to $\$ 95$ per ton (Spicher, 2008) in the coming years. It is currently about $\$ 10$ per ton of $\mathrm{CO}_{2}$. Large systems are able to utilize about 150 tons of $\mathrm{CO}_{2}$ to produce 100 tons of dry biomass per day. The dry biomass is then pressed to obtain the end products: algae vegetable oil and algae cake. Vegetable oil can be converted to biodiesel. The market price for vegetable oil is currently about $\$ 3.00$ per gallon. The algae cake is worth about $\$ 0.50$ per $\mathrm{kg}$ and highly demanded by agricultural and food industry. Algae cake is highly nutritious and is used as food supplements and feedstock for animals (AlgaeLink, 2007).

The feasibility of photobioreactors is therefore mainly dependent on the algae productivity as well as energy consumption during the algae production and processing. 
Revenue is generated simply by operating the plant; from the biological sequestration of greenhouse gases, and marketing the value-added products (biodiesel, algae cake, and others).

The overall research goal in this field is the development and optimization of photobioreactors for microalgae cultivation to produce biofuels. The PBR technology is only a few years old; therefore, further research and improvements are needed to optimize and enhance the existing systems for commercial applications (NREL, 1998; Richmond, 2000; Pulz, 2001; Molina-Grima et al., 2004; Schulz, 2006; Chisti, 2007; Huntley and Redalje, 2007; Antoni, 2007). The major technical challenges are how to sustain highest photosynthesis and biomass productivity levels, reduce cell damage by hydrodynamic stress, reduce costs in fabrication and installation maintenance, and how to increase the capability of the system to expand to an industrial scale (Barbosa, 2003; AlgaeLink, 2007). The main goal is to make the systems economically feasible to produce algae on a large-scale.

The specific objective of this study was to evaluate temperature influences on algae cultivation in photobioreactors and the resulting heat management practices by developing a dynamic simulation tool. The simulation shall provide fundamental data for planning the best location and layout of commercial algae production plants. This study investigates the effects of location, local climate and algae strain yield to analyze the feasibility of a given PBR system. The results of this study are valuable for people planning a business and operators of algae production systems using photobioreactors. It answers the following questions: Where (geographically) can photobioreactors be 
placed? Are greenhouses necessary for housing photobioreactors? Is it feasible to heat the system to get a better yield? At what temperatures is heating (or cooling) necessary?

\section{General Approach}

An experimental study was executed using a lab-scale photobioreactor. While growing microalgae in the PBR, the system's temperature was varied. The algae yield differences due to temperature change was gathered and analyzed to find the optimal temperature for algae growth. A comprehensive dynamic mathematical model for a horizontal tubular PBR was developed and executed using the location of San Luis Obispo, California, USA. Heat requirements of a virtual commercial-scale system were calculated using the model and analyzed for indoor and outdoor growing conditions to study heat management practices and improve the system efficiency. 


\section{CHAPTER II}

\section{BACKGROUND}

\subsection{Overview}

Microalgae are single celled microscopic organisms, which (like plants) use photosynthesis to convert the sun's energy into chemical energy. They are much more efficient converters of solar energy than any known plant, because they grow in suspension where they have unlimited access to water and more efficient access to $\mathrm{CO}_{2}$ and dissolved nutrients.

Microalgae are the fastest growing photosynthesizing organism on earth (Figure 3). They can complete an entire growing cycle in as short as one day only. Over 100,000 different strains of algae are known and many are still not discovered (NREL, 1998). Three hundred species, mostly green algae and diatoms are winnowed and considered

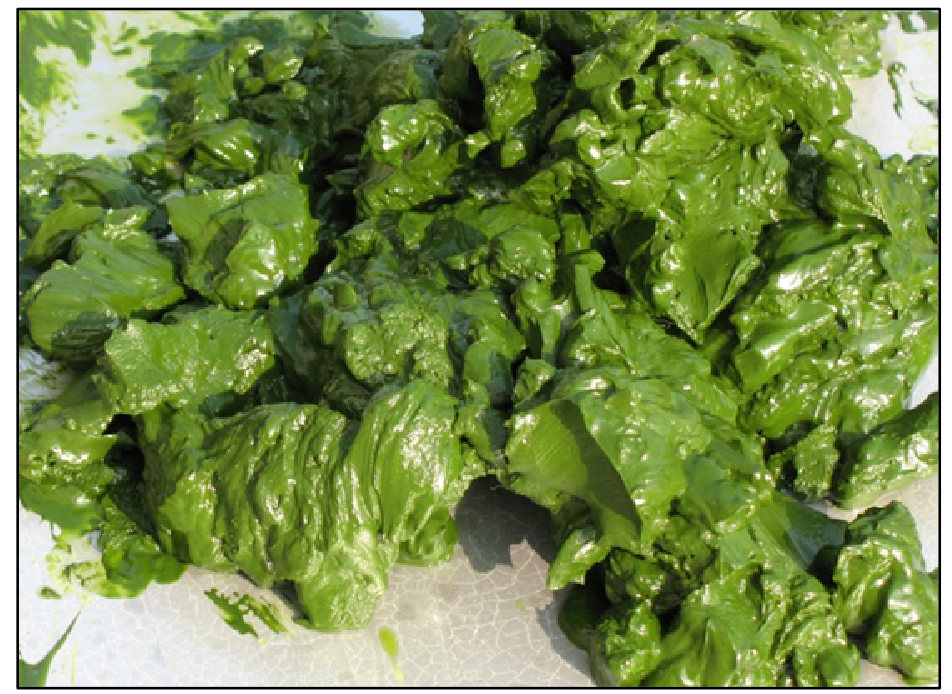

Figure 3. Algae paste freshly harvested through filter technology. Source: After Algaelink, 2007. 
viable for the production of biofuels. Some of those contain as much as $70 \%$ lipids (oil). Many species can grow in brackish water, that is, water that contains high levels of salt. Therefore, a competition with drinking water could be avoided by choosing the right algae strain (NREL, 1998).

The cultivation of algae is nevertheless a complex process. The nutrient level in the water must be in a specific range, the $\mathrm{pH}$ must always be under control. Nutrients must be controlled so algae will not be "starved", and so that nutrients will not be wasted either. Light must neither be too strong nor too weak. Algae only need $10 \%$ the amount of light they receive from direct sunlight (Barbosa, 2003).

\subsection{Algae Classification}

Algae are a diverse group of organisms. They vary in size from single-celled microalgae (as small as one micrometer) to several meter long seaweeds. Most algae are photoautotrophic, however, some are facultative or obligate heterotrophs (Darley, 1982; Becker, 1994). Photoautotrophs conduct photosynthesis, sequestering $\mathrm{CO}_{2}$, and using light as the energy source. Heterotrophs receive their energy from organic carbon compounds, instead. For the purpose of large-scale biofuel production, photoautotrophic microalgae are the favorable kind, unless large amounts of chemically bound energy is readily available for algae production (NREL, 1998).

Many different characteristics describe a single alga. The classification system is based on attributes like (Jonathan et al., 2007):

- Presence or absence of flagella (tail)

- Flagellar characteristics (length, number, hairs, point of insertion) 
- Cell-wall composition, and

- Type of stored photosynthetic product

Over 100,000 different microalgae are classified in a variety of classes. The most common classification of algae is shown below (NREL, 1998):

- BACILLARIOPHYTA (diatoms)

- CHAROPHYTA (stoneworts)

- CHLOROPHYTA (green algae)

- CHRYSOPHYTA (golden algae)

- CYANOBACTERIA (blue-green algae)

- DINOPHYTA (dinoflagellates)

- PHAEOPHYTA (brown algae)

- RHODOPHYTA (red algae)

About 300 species (mostly green algae and diatoms) show a potential (oil yield, growing parameters) for different biofuel applications (NREL, 1998). This work will therefore focus only on these two classes. Since they are single-celled organisms, some background about cell theory is necessary to understand the complex interrelations. 


\subsection{Cell Theory}

The cell is the fundamental building block of life. It is the structural and functional unit of all known living organisms. It is the smallest unit of an organism that is classified as living (Alberts, 2002). Some organisms, such as bacteria and microalgae are unicellular (consist of a single cell) (Figure 4). Other organisms, such as humans, are multicellular. The cell theory, first developed in 1839 by Matthias Jakob Schleiden and Theodor Schwann, states that all organisms are composed of one or more cells. All cells come from preexisting cells. Vital functions of an organism occur within cells, and all cells contain the hereditary information necessary for regulating cell functions and for transmitting information to the next generation of cells (Espinasse, 1962). Cells are:

- capable of growth and reproduction; that is, they can reproduce another entity essentially identical to themselves.

- highly organized and selectively restrict what crosses their boundaries. Thus, cells are at low entropy compared to their environment.

- composed of major elements $(\mathrm{C}, \mathrm{N}, \mathrm{O}$ and $\mathrm{S}$, in particular) that are chemically reduced.

- self-feeding. They take up necessary elements, electrons and energy from their external environment to create and maintain themselves, as reproducing, organized and reduced entities. They require sources of elemental building blocks that they use to reproduce themselves. They require a source of energy to fuel the chemical processes leading to all three properties. In addition, they require a 
source of electrons to reduce their major element. How cells obtain elements, energy and electrons is called metabolism, and is one essential way to characterize a cell.

Cells can be divided into two main groups: the Prokaryotes and the Eukaryotes. The main difference is that the Prokaryotes do not have a cell nucleus, and the DNA floats freely in the cell (Shuler and Kargi, 2002).

Microalgae are made up of eukaryotic cells. These are cells with nuclei and organelles. All algae have plastids, the bodies with chlorophyll that carry out photosynthesis. However, various lines of algae can have different combinations of chlorophyll molecules; some have just Chlorophyll A, some have a combination of A and B, or A and C (Becker, 1994; Degen, 2003).

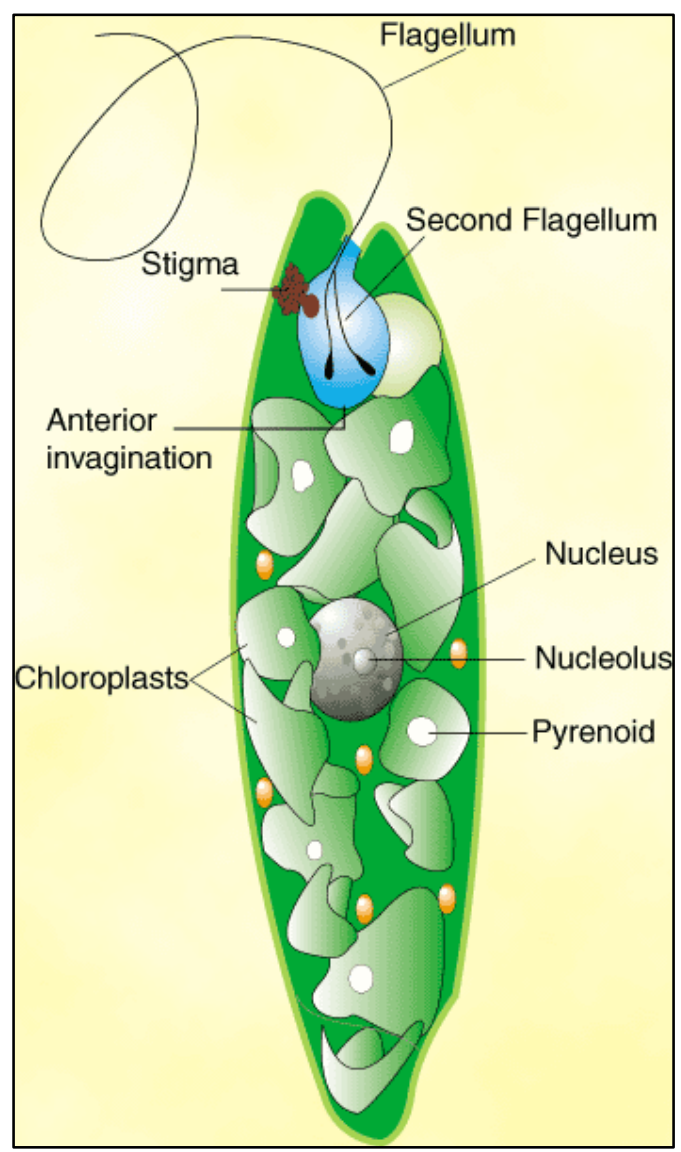

Figure 4. Scheme of an algal cell.

Source: After Sparknotes, 2007. 


\subsection{Green Algae}

The green algae are probably the most important class for the biofuel production (NREL, 1998). They are one of the larger groups of algae in terms of variety of species. Green algae (Figure 5) live mostly in fresh water. Some species can also live in moist soil or in brackish water.

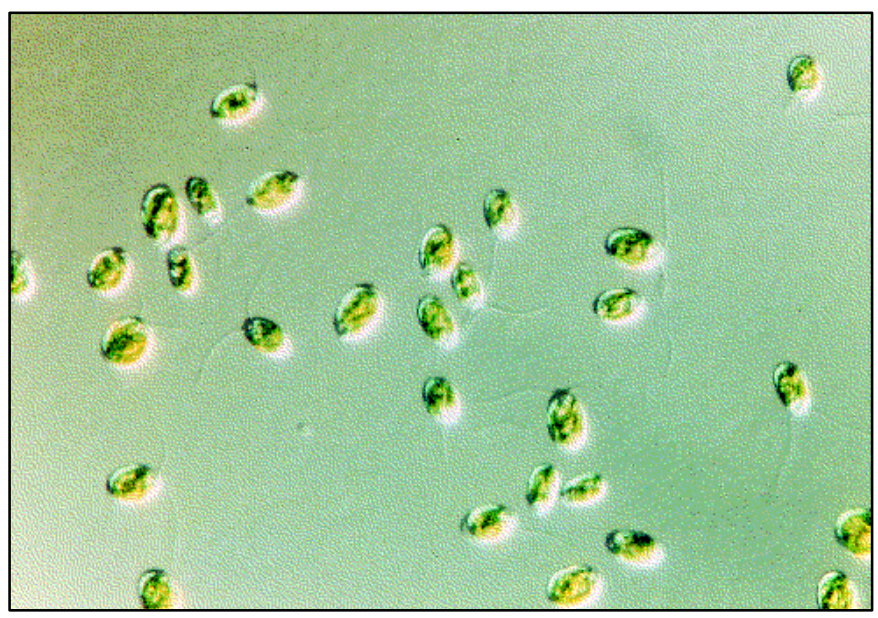

Figure 5. Green algae as seen under the microscope. Source: After Esapub, 2006.

The two main characteristics of green algae are i) the use of chlorophyll A and B in their photosynthesis (which gives them their green color), and ii) the enclosure of the chloroplast in a double membrane. These characteristics make green algae the most plantlike algae (Darley, 1982).

Green algae include unicellular and colonial flagellates, usually but not always with two flagella per cell, as well as various colonial, coccoid, and filamentous forms (Thomas, 2002). Many species live most of their lives as single-cells, other species form colonies or long filaments. All green algae have mitochondria with flat cristae. When present, flagella are typically anchored by a cross-shaped system of microtubules, but 
these are absent among the higher plants and charophytes. Flagella are used to propel the organism. Green algae usually have cell walls containing cellulose (Hoek et al., 1995).

\subsection{Algae Specification}

The typical chemical algae composition contains proteins, carbohydrates, fats (lipids), and nucleic acids in varying proportions. The percentages vary with the type of algae, but also within a specific strain based on the nutrient supply. Table 1shows a range of each compound for a number of important strains.

Table 1. Chemical composition of different algae strains on a dry matter basis (\%). Source: After Becker, 1994.

\begin{tabular}{|l|l|l|l|l|}
\hline Strain & Protein & Carbohydrates & Lipids & Nucleic acid \\
\hline Scenedesmus obliquus & $50-56$ & $10-17$ & $12-14$ & $3-6$ \\
\hline Scenedesmus quadricauda & 47 & - & 1.9 & - \\
\hline Scenedesmus dimorphus & $8-18$ & $21-52$ & $16-40$ & - \\
\hline Chlamydomonas rheinhardii & 48 & 17 & 21 & - \\
\hline Chlorella vulgaris & $51-58$ & $12-17$ & $14-22$ & $4-5$ \\
\hline Chlorella pyrenoidosa & 57 & 26 & 2 & - \\
\hline Spirogyra sp. & $6-20$ & $33-64$ & $11-21$ & - \\
\hline Dunaliella bioculata & 49 & 4 & 8 & - \\
\hline Dunaliella salina & 57 & 32 & 6 & - \\
\hline Euglena gracilis & $39-61$ & $14-18$ & $14-20$ & - \\
\hline Prymnesium parvum & $28-45$ & $25-33$ & $22-38$ & $1-2$ \\
\hline Tetraselmis maculata & 52 & 15 & 3 & - \\
\hline Porphyridium cruentum & $28-39$ & $40-57$ & $9-14$ & - \\
\hline Spirulina platensis & $46-63$ & $8-14$ & $4--9$ & $2-5$ \\
\hline Spirulina maxima & $60-71$ & $13-16$ & $6-7$ & $3-4.5$ \\
\hline Synechoccus sp. & 63 & 15 & 11 & 5 \\
\hline Anabaena cylindrica & $43-56$ & $25-30$ & $4-7$ & - \\
\hline
\end{tabular}




\subsection{Algal Photosynthesis}

Photosynthesis is the process by which plants utilize the energy of the sun's radiation to produce energy and new biomass. Photosynthesis is the base reaction supplying the vast majority of energy used by plants. Energy absorbed by chlorophyll from the sun is captured in the form of ATP (adenosine triphosphate) and NADPH (nicotinamide adenine dinucleotide phosphate), and later used to convert carbon dioxide to carbohydrates plus oxygen. The carbohydrate can then be converted to protein or fat (Hoek et al., 1995). The following simplified chemical reaction describes the process quantitatively:

$$
6 \mathrm{CO}_{2}+12 \mathrm{H}_{2} \mathrm{O}+\text { photons } \rightarrow \mathrm{C}_{6} \mathrm{H}_{12} \mathrm{O}_{6}+6 \mathrm{O}_{2}
$$

Solar energy is spread along a wide range of wavelengths, of which only a portion is useable for photosynthesis. The wavelengths useable by plants are known as Photosynthetically Active Radiation (PAR), covers the spectral range from 0.4 to 0.7 micrometers, which includes about 45 to $50 \%$ of the total solar energy. Energy requirements of the photosynthesis reaction reduce the usability of that 45 to $50 \%$ by

another factor of 4 . The theoretical energy use is therefore roughly $11 \%$ of the overall solar energy. This photosynthetic efficiency is translated into biomass including fats, proteins, simple and complex carbohydrates (cellulose, lignin, etc.) and simple carbohydrates (Luening, 1981; GreenFuel Technologies Corporation, 2008). 
Algae have been grown at a photosynthetic efficiency of approximately 5.4\% under natural sunlight. Crops in general grow at a photosynthetic efficiency of approximately $1 \%$. Algae can be grown much more efficiently because of the nature of the photobioreactor and the removal of factors that might limit growth such as lack of nutrients or $\mathrm{CO}_{2}$ (Luening, 1981; Pirt et al., 1983; Kirk, 1994; Ogbonna et al., 1995; GreenFuel Technologies Corp., 2008).

Understanding the basics, one can easily assume that the algae growth rate can be improved by using artificial lighting for 24 hours. However, this needs to be determined for each individual application. In most cases, it is not economically feasible due to high energy costs of artificial lighting.

The issue of lighting brings rise to the topic of photoinhibition. Algae must receive sufficient light to exceed their light compensation point for their net growth. Increasing light beyond the compensation point results in an increase in the growth rate until the culture becomes light saturated, and higher light intensities can lead to photoinhibition. Photoinhibition is a reduction in an alga's capacity for photosynthesis caused by exposure to strong light. Photoinhibition is not necessarily caused by intense light, but rather absorption of too much light energy compared with the photosynthetic capacity (Acien Fernandez et al., 1998; Yun and Park, 2001; Wu and Merchuk, 2002; Barbosa, 2003). 


\subsection{Growth Kinetics}

Unicellular microalgae do not grow in size or weight as regular plants or animal cells. Rather, the growth is accomplished by increasing the number of single cells. For filamentous algae, growth can also mean the elongation of the chain. However, since every alga could also live alone and functions in the same way whether on or off the chain, the elongation of the chain can be seen and measured by simply counting the number of cells.

Commonly, populations of unicellular algae can be measured by the number of single cells or by their mass. The former is then called "cell concentration", defined as the number of individual cells per unit volume; the latter is called "cell mass" or "cell density", defined as the weight of cells or biomass per unit volume. The growth kinetics can be determined in a homogenous batch culture, where the nutrient supply is limited and nothing is added or removed from the media. The algal growth passes through several different phases as given in Figure 6 (Becker, 1994; Shuler and Kargi, 2002):

1. Adaption (lag phase)

2. Accelerating growth phase

3. Exponential growth (log phase)

4. Decreasing log growth (linear growth)

5. Stationary phase

6. Accelerated death

7. Log death 


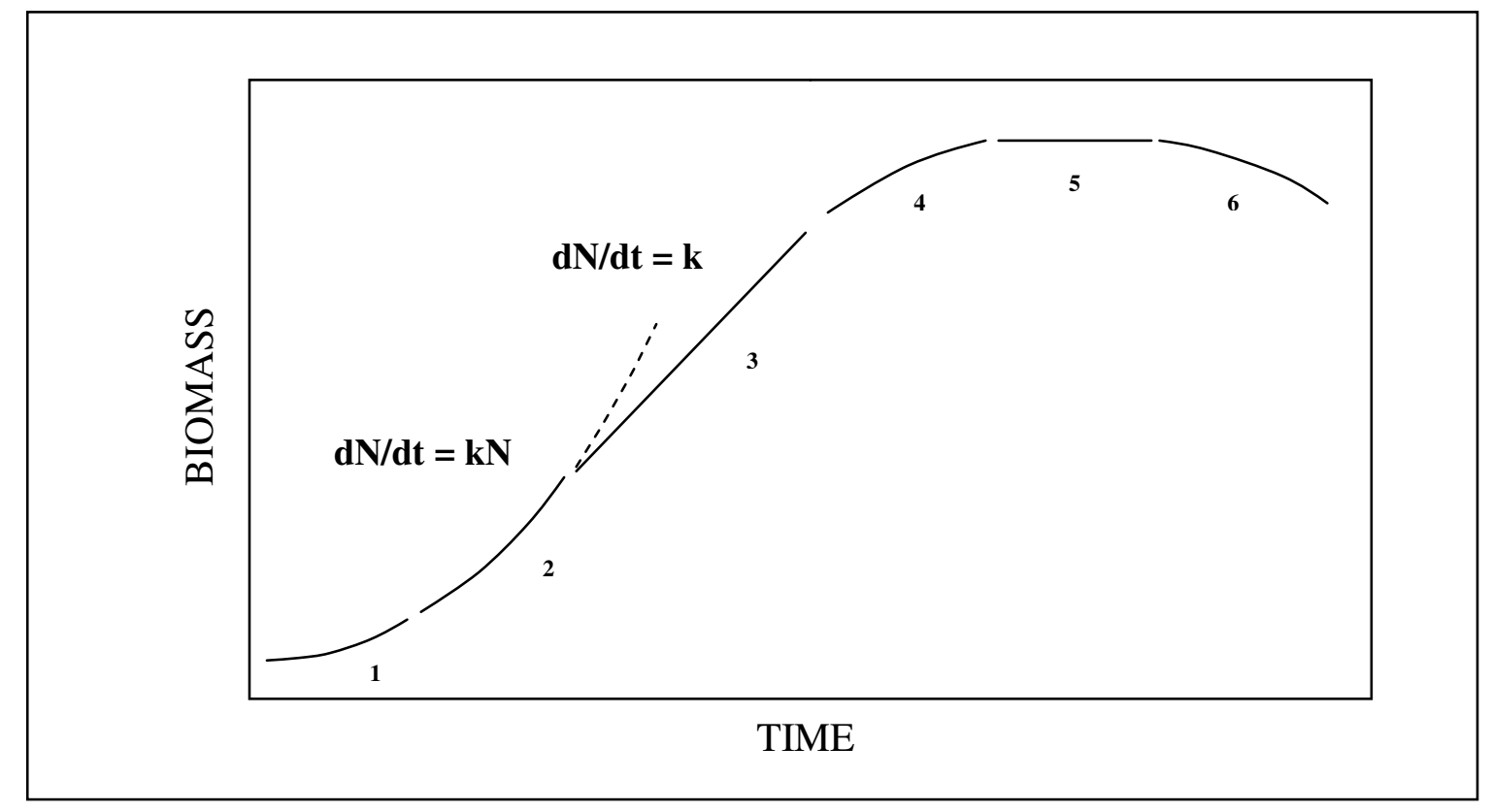

Figure 6. Growth phases of algal cultures. Source: After Shuler and Kargi, 2002.

The different phases are not always as clear as shown in the Figure 6. The slope may vary in magnitude, length or height. Also, the transitions from one phase to another may be shaped differently. The actual shape is based on the inoculation material, the nutrient concentration, and the environmental conditions such as light intensity, temperature, $\mathrm{pH}$, etc. (Shuler and Kargi, 2002).

Phase 1: When the medium is inoculated with the algae culture, the culture is not adapted to the new environment. It takes some time for the culture to adjust to the new conditions, before the algae can start growing.

Phase 2 and 3: After the cells have adapted themselves to the new environment, the exponential (logarithmic) growth begins. During this phase the increase in algal biomass per time is proportional to the biomass in the population at any given time, 
provided that neither light nor nutrient is limited. A steady-state is reached. The cells are divided at a constant rate.

Phase 4: The logarithmic growth declines at the point when nutrients get depleted, and even more significant, when the culture density reaches its critical point. Shading comes into play and a dark zone in the center of the bioreactor evolves. Light becomes the limiting factor to the growing conditions. The increase in algal biomass becomes almost linear. In well maintained, nutrient rich environments, this phase continues, however, when one of the nutrients gets depleted, respiration effects occur.

Phase 5: The light supply per algal cell becomes limited. Equilibrium is reached between the maximum concentration of biomass and loss due to degradation processes. The growth curve approaches a limiting value - the maximum attainable biomass concentration in a closed system.

Phase 6: Reduced viability in the cell population; the algal cells begin to release organic, growth-inhibiting, materials into the medium. The phase is caused by unfavorable conditions, over-age of the cultures and limited supply of light and nutrients, or infection by other microorganisms.

Phase 7: Death phase becomes exponential, leading to a complete breakdown of the population.

As already mentioned, the growth kinetics curve came from a batch culture. For mass production of algae, a continuous process is desirable (as realized in photobioreactors) to obtain a high productivity. In that case, the algal growth has to be kept at a steady-state (exponential) phase. Nutrients, therefore, have to be added 
continuously and biomass has to be removed respectively, to keep the cell density at an optimal level (avoid light limitation). The ratio of the flow rate $f$, at which the fresh medium (nutrients) is supplied to the culture volume, $V$ becomes important. This ratio is called dilution rate, $D=f / V$. Its reciprocal, $1 / D$ is called the mean residence time of an algal cell in the system. For the size of the algal population to remain constant in the system, the following equations have to be fulfilled: $\mathrm{d} N / \mathrm{d} t=0$ and $\mu=D$, meaning that a steady state is reached (Becker, 1994).

\subsection{Carbon Source $\left(\mathrm{CO}_{2}\right)$}

Like all autotrophic organisms, algae require an inorganic carbon source to perform photosynthesis. In the case of a photobioreactor, the easiest way would be the aeration with ambient air; however, the natural $\mathrm{CO}_{2}$ concentration $(0.03 \%)$ in air is too low to sustain optimal growth and high productivity. Freshwater algae, growing under low salinity and at near neutral $\mathrm{pH}$ conditions, must be supplied with additional $\mathrm{CO}_{2}$ to ensure satisfactory growth rates. Usually, $\mathrm{CO}_{2}$ enriched air is supplied to the systems. In water, $\mathrm{CO}_{2}$ appears in different forms, depending on the $\mathrm{pH}$, temperature and the concentration of nutrients (Becker, 1994):

$$
\mathrm{CO}_{2}+\mathrm{H}_{2} \mathrm{O}\left\langle-->\mathrm{H}_{2} \mathrm{CO}_{3}\left\langle->\mathrm{H}^{+}+\mathrm{HCO}_{3}^{-} \stackrel{-->}{ } 2 \mathrm{H}^{+}+\mathrm{CO}_{3}{ }^{2-}\right.\right.
$$

When growing algae in continuous flow, the $\mathrm{pH}$ tends to elevate due to the excretion of $\mathrm{OH}^{-}$ions by the algae into the water. A sophisticated $\mathrm{CO}_{2}$ dosing system will maintain the $\mathrm{pH}$ near neutral (Aqua Medic, 2007). 
Algal biomass consists of about $50 \%$ carbon, which means that about $1.8 \mathrm{~kg}$ of $\mathrm{CO}_{2}$ is required to produce $1 \mathrm{~kg}$ of biomass based on the chemical reaction described in Chapter 2.6. Since pure $\mathrm{CO}_{2}$ is expensive, a production plant would need to look for cheap alternatives. As already mentioned in the introduction, this is a good opportunity to utilize flue gas from power plants, combustion processes, or cement plants. Ethanol plants are considered to be the ideal carbon source for algal growth since it can be used without a costly purification process (Aqua Medic GmbH, 2007; GreenFuel Technologies Corp., 2008).

\subsection{Nutrients}

In addition to carbon, algae need some additional nutrients to grow and reproduce. The most critical elements are nitrogen, phosphorous and silicon due to the high amount required to produce the biomass. Trace elements are also important because they often are used as catalysts and therefore, accelerate the process significantly. General information about the uptake and limitation of nutrients are presented here, hoping to help in understanding principles to come later.

\section{Uptake kinetics}

The nutrient supply can affect the algal growth rate, especially when the nutrient concentration is low. Michaelis-Menten (1913) developed an empirical equation for enzyme kinetics that can also be used to describe the relationship between the nutrient concentration and the uptake rate (Darley, 1982). This relationship follows a hyperbolic function: 


$$
\mathrm{V}=\mathrm{V}_{\mathrm{m}}\left(\mathrm{S} /\left(\mathrm{K}_{\mathrm{S}}+\mathrm{S}\right)\right)
$$

where $\mathrm{V}$ is the nutrient uptake rate, $\mathrm{V}_{\mathrm{m}}$ is the maximum nutrient uptake rate, $\mathrm{S}$ is the concentration of nutrient, and $\mathrm{K}_{\mathrm{S}}$ is the the half-saturation constant or substrate concentration at which $\mathrm{V}=\mathrm{V}_{\mathrm{m}} / 2$. The half-saturation constants for nitrate, ammonia, phosphate and silicate are in the $\mu \mathrm{mol} \mathrm{l}^{-1}$ range $\left(0.1-5 \mu \mathrm{mol} \mathrm{l}^{-1}\right)$. It should also be noted that $K_{S}$ may vary with environmental parameters such as temperature (Darley, 1982).

\section{Nitrogen}

From a quantitative view, nitrogen is, beside carbon, the most important nutrient. It can be utilized by algae in organic (urea) or inorganic (nitrate, nitrite, ammonia) forms. Nitrite $\left(\mathrm{NO}_{2}{ }^{-}\right)$is toxic when used in larger amounts (higher concentrations) and thus not very convenient to use (Darley, 1982). The growth rate is generally the same for every nitrogen source. The best nitrogen assimilation can be reached using organic urea $\left(\left(\mathrm{NH}_{2}\right)_{2} \mathrm{CO}\right)$. Using inorganic sources, ammonia $\left(\mathrm{NH}_{4}^{+}\right)$is preferred over nitrate $\left(\mathrm{NO}_{3}^{-}\right)$. However, high ammonia concentrations (> 0.5 to $1.0 \mu \mathrm{mol} / \mathrm{l})$ will inhibit the uptake of nitrate. The assimilation of inorganic nitrogen is highly related to the $\mathrm{pH}$, since nitrogen

absorption changes the $\mathrm{pH}$. Ammonia as a source of nitrogen may decrease to a low $\mathrm{pH}$ of 3.0. The cells can only take up $\mathrm{NH}_{4}{ }^{+}$, so $\mathrm{NO}_{3}{ }^{-}$has to be reduced by an enzyme first before incorporation into amino acids is possible (Darley, 1982):

$$
\mathrm{NO}_{3}{ }^{-} \rightarrow \mathrm{NO}_{2}{ }^{-} \rightarrow \mathrm{NH}_{4}{ }^{+}
$$


The mean nitrogen requirement for many green algae is approximately 5 to $10 \%$ of the dry weight or 5 to $50 \mathrm{mM}$ (Millimolar) (Becker, 1994). Nitrogen deficiency results in a growth limitation, but also in a higher proportion of lipids in every cell (Appendix D). For biodiesel production, this is an opportunity to increase the oil yield per unit weight (Eppley and Renger, 1974).

\section{Phosphorous}

Phosphorous is another significant nutrient for algal growth; it is essential for almost all cellular processes. A limitation in phosphorous will also cause a decreased growth rate. The phosphate forms $\mathrm{PO}_{4}{ }^{3-}, \mathrm{H}_{2} \mathrm{PO}_{4}{ }^{-}$and $\mathrm{HPO}_{4}{ }^{2-}$ are the most important inorganic phosphorous sources for algae (Darley, 1982; Becker, 1994). However, algae can obtain phosphorous from organic compounds, which has to be hydrolyzed by extracellular phosphatases. This process is comparably slow and organic phosphorous is not available all the time. The ideal phosphorous concentration in the growth medium varies among the different species. The average concentration (tolerance) is in a range of $50 \mu \mathrm{g} / \mathrm{l}$ to $20 \mathrm{mg} / \mathrm{l}$ (Becker, 1994). The phosphorous uptake rate is influenced by factors

such as $\mathrm{pH}$ and the concentration of $\mathrm{Na}^{+}, \mathrm{K}^{+}, \mathrm{Mg}^{+}$and various heavy metals. Similar to the starvation of nitrogen, a phosphorous deficiency increases the proportion of produced lipids.

\section{Silicon}


Silicon is necessary for the growth of diatoms (silicon is part of the cell wall). Usually, the orthosilicic acid $\left(\mathrm{Si}(\mathrm{OH})_{4}\right)$ is used in artificial media. The assimilation takes place in the later phase of cell growth (when the cell walls are built) (Sullivan, 1977). 


\section{Trace Elements}

Only very small amounts (micro-, nano-, pictograms per liter medium) of trace nutrients are needed for optimal growth. The most important elements are manganese, nickel, zinc, boron, vanadium, cobalt, copper and molybdenum. Properties of essential trace elements are as follows (Becker, 1994):

- Influence algal growth in a representative number of species,

- Have a positive effect on total growth,

- Show a direct physiological effect on algal growth,

- Cannot be replaced by another element, and

- Show reversible signs of deficiency in cultures lacking this element.

\section{Vitamins}

Some algae require additional vitamins for optimal growth. The most common vitamins are B12, thiamine, and biotin. Concentrations may range from $1 / 10$ to $1 / 100 \mathrm{ng} / \mathrm{l}$ (Provasoli, 1974). 


\subsection{Temperature}

The yield of algae production can be described through the specific growth rate $\mu$. The specific growth rate declares the doubling of cells per day (1/day). The maximum specific growth rate, $\mu_{\max }$, describes the highest value of the specific growth rate, $\mu$, which also indicates the optimum algal growth rate under a specific condition.

Temperature is a widely measured environmental variable, and an important factor that affects the performance of algal growth (Raven and Geider, 1988; Shuler and Kargi, 2002). Determining the affect of strictly temperature on algal growth rate, can be identified by keeping all other variables constant. The growth rate reaches a maximum at a specific temperature. For microalgae, the growth rate, and therefore the yield, will

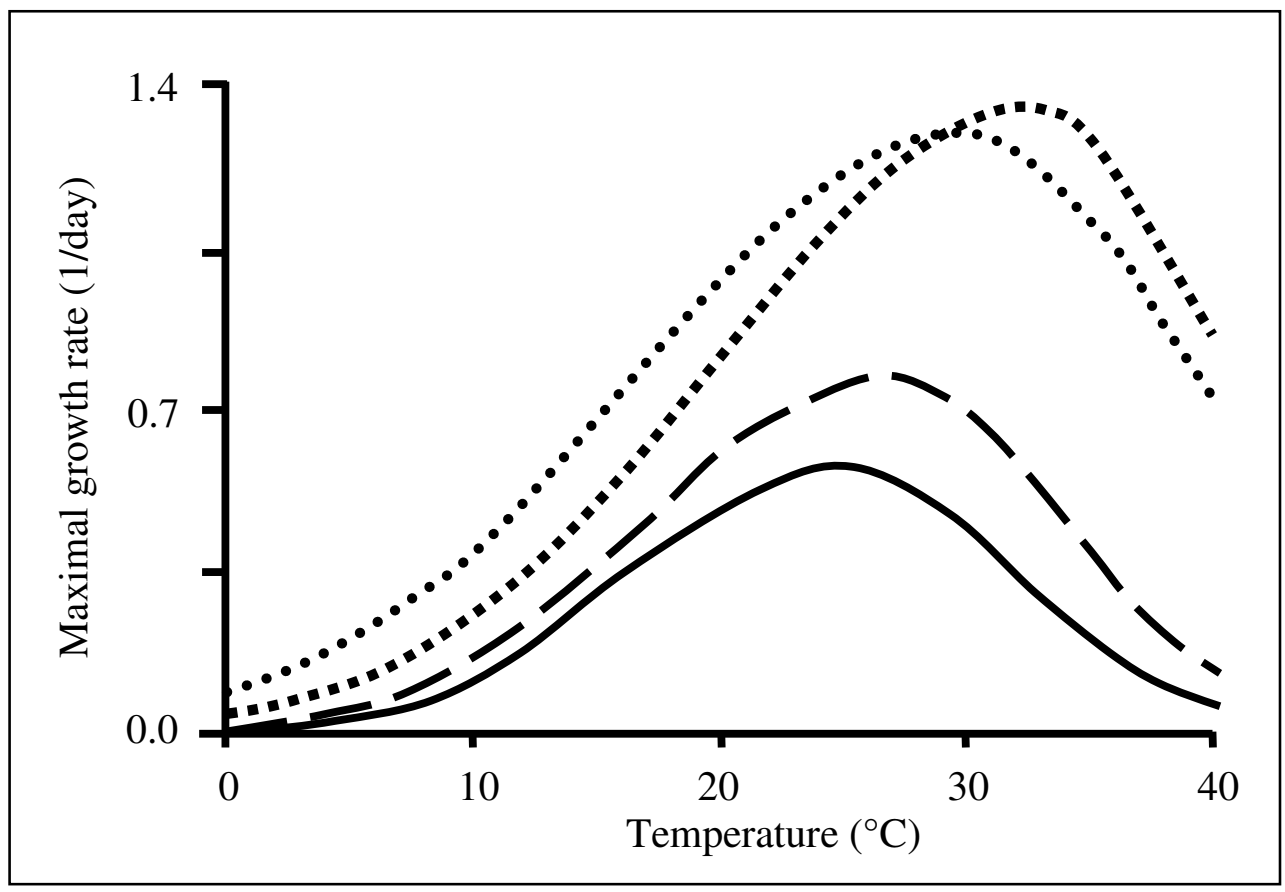

Figure 7. Variation of maximal growth rate $\left(\mu_{\operatorname{maxT}}\right)$ versus temperature for four different algae strains. Source: After Dauta et al., 1990. 
follow a skewed normal distribution (Lehman et al., 1975; Dauta et al., 1990), where $\mu_{\max }$ is the peak (Figure 7). Every single algae strain has a different specific growth rate, which needs to be determined. The skewed normal distribution can be described through the Eqn. 2.5 and 2.6, one for the specific growth rate below the maximum and one for the specific growth above the maximum. The temperature dependent growth rate $\left(\mu_{\operatorname{maxT}}\right)$ reaches a maximum at the optimal temperature $\left(\mathrm{T}_{\mathrm{opt}}\right)$. The growth rate declines therefore, when the temperature rises or falls. Temperature limits are reached when $\mu_{\operatorname{maxT}}=10 \%$ of the maximum growth rate $\mu_{\max }$ under optimal conditions. The lower temperature limit was expressed as $T_{\text {inf, }}$ whereas the upper limit was shown as $T_{\text {sup }}$ (Dauta et al., 1990):

$$
\begin{aligned}
\mu_{\operatorname{maxT}}= & \mu_{\max } * \operatorname{EXP}\left\{-2.3 *\left[\left(\mathrm{~T}-\mathrm{T}_{\mathrm{opt}}\right) /\left(\mathrm{T}_{\mathrm{sup}}-\mathrm{T}_{\mathrm{opt}}\right)\right]^{2}\right\} \\
& \text { for } \mathrm{T}>\mathrm{T}_{\mathrm{opt}} \\
\mu_{\max \mathrm{T}}= & \mu_{\max } * \operatorname{EXP}\left\{-2.3 *\left[\left(\mathrm{~T}-\mathrm{T}_{\mathrm{opt}}\right) /\left(\mathrm{T}_{\mathrm{inf}}-\mathrm{T}_{\mathrm{opt}}\right)\right]^{2}\right\} \\
& \text { for } \mathrm{T}<\mathrm{T}_{\mathrm{opt}}
\end{aligned}
$$

The temperature coefficient $\left(\mathrm{Q}_{10}\right)$ represents the factor by which the rate $(\mathrm{R})$ of a reaction increases for every 10-degree rise in the temperature $(T)$. The rate $(R)$ may represent any measure of the progress along the process. If the rate of the reaction is temperature independent, it can be seen in Eqn. 2.7 that the resulting $\mathrm{Q}_{10}$ will be equal to 1.0. If the reaction rate increases with increasing temperature, $\mathrm{Q}_{10}$ will equal greater than 1.0. Thus, the more temperature dependent a process is, the higher the $\mathrm{Q}_{10}$ value will be (Eskandari, 2008): 


$$
\mathrm{Q}_{10}=\left(\mathrm{R}_{2} / \mathrm{R}_{1}\right)^{\left(10 /\left(\mathrm{T}_{2}-\mathrm{T}_{1}\right)\right)}
$$

The $\mathrm{Q}_{10}$ value for microalgae grown in batch cultures is 1.88 at the maximum growth rate, $\mu_{\max }$. For continuous cultivation in large-scale photobioreactors, the $\mathrm{Q}_{10}$ value is between $2.08-2.19$ at $\mu_{\max }$. A number of researchers reported that the $\mathrm{Q}_{10}$ value becomes greater below the optimal growth rate (Eppley, 1972; Goldman and Carpenter, 1974; Raven and Geider, 1988).

\subsection{Photobioreactors}

A Photobioreactor (PBR) is a bioreactor that incorporates some type of light source. Photobioreactors are therefore fermenters in which phototrophic microorganisms such as microalgae are cultivated. This type of technology implements a closed system that introduces carbon dioxide to the algae in order to enhance its growth in the presence of light, water and nutrients. Closed photobioreactors are culture systems which restrict the exchange of gases, water, and contaminants between the culture and the outside environment (Figure 8). They have several advantages over open pond systems (Figure 9) for the cultivation of microalgae (Chen, 1996), such as

- higher biomass concentrations due to shorter light paths,

- reduced contamination, 
- better control of algae culture,

- large surface-to-volume-ratio,

- better control of gas transfer,

- reduction in evaporation of growth medium,

- uniform temperature, and

- $\quad$ higher cell densities possible.

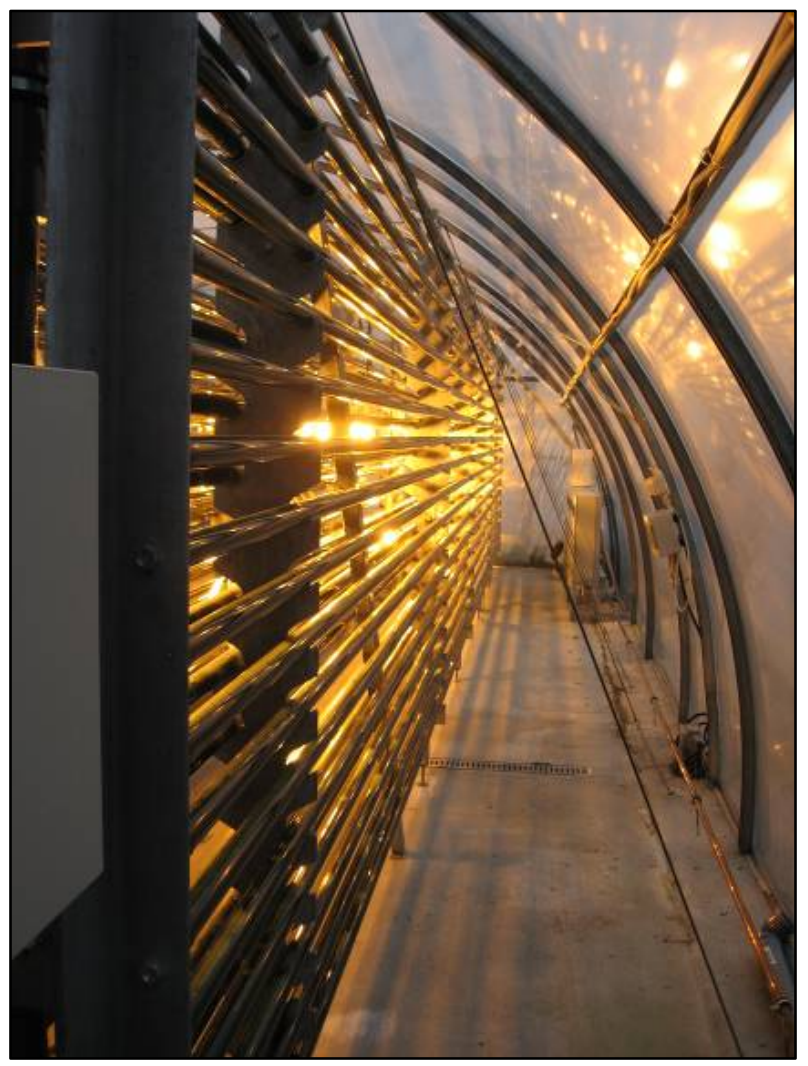

Figure 8. A horizontal tubular Photobioreactor. Source: After Mehlitz, 2008. 


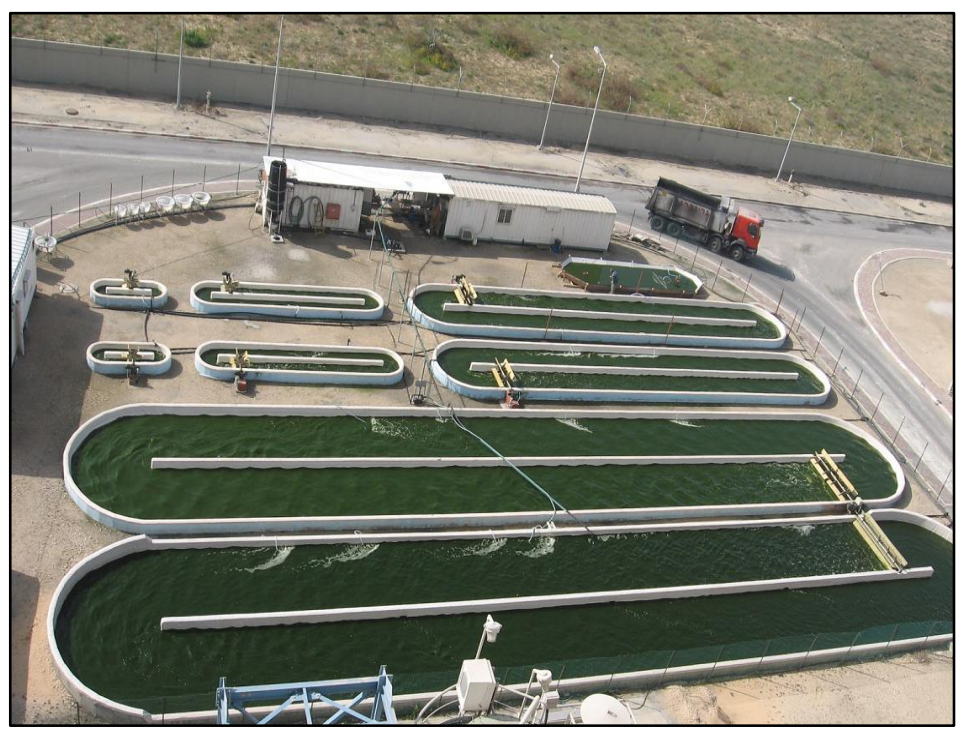

Figure 9. Open Pond System.

Source: After Seambiotic, 2008.

The ability of a pond to grow algae is limited by its surface area, not by its volume. Receiving just enough solar radiation, algae can only grow in the top $6 \mathrm{~mm}$ layer of the water (Chen, 1996).

The microalgae production can be divided into two main substrate usages: the so called "clean process" and the "wastewater process". The clean process uses fresh water with artificial fertilizers (nutrients) at specific concentrations. The wastewater process on the other hand uses filtered wastewater. The main advantage of wastewater use is the abundance of inexpensive substrate (avoiding the use of artificial fertilizers) and the synergies with wastewater treatment plants. The main disadvantage, however, is the uncontrollability due to the vast amount of different and unknown bacteria, viruses and algae. Thus, growing a single species in wastewater is almost impossible. 


\subsubsection{Function of a Photobioreactor}

A photobioreactor is a closed loop system. The algae grow in water, which is pumped through different stages (Figure 10). The heart of a PBR is where the photosynthesis occurs; where the algae is illuminated and absorbs solar radiation or artificial light through glass, transparent plastic tubes, bags or plates. The water is transported by a pump from the photosynthesis part of the PBR to the main feeding vessel. The vessel is usually manufactured from stainless steel or plastic to avoid corrosion and ensure a sanitary environment. The algae are not illuminated in the vessel, so that a natural light-dark cycle between the photosynthesis part and the vessel can occur. This enhances algal growth because the algae have time for respiration in the dark. The vessel also makes it possible to supply nutrients and initial algae strains (inoculation material) to the system. Also, a temperature control can be mounted in the feeding vessel. The $\mathrm{CO}_{2}$ /air mix is supplied through a valve connected on a tube right after the vessel. Harvesting takes place through a bypass in the system. When a critical cell density is reached, a valve flips over, and the algae water is directed through a filter or centrifuge system that extracts the algal biomass from the water. The water that now hardly contains algae is directed back to the system. The extracted algae mass can then be processed further by methods such as drying and pressing. 


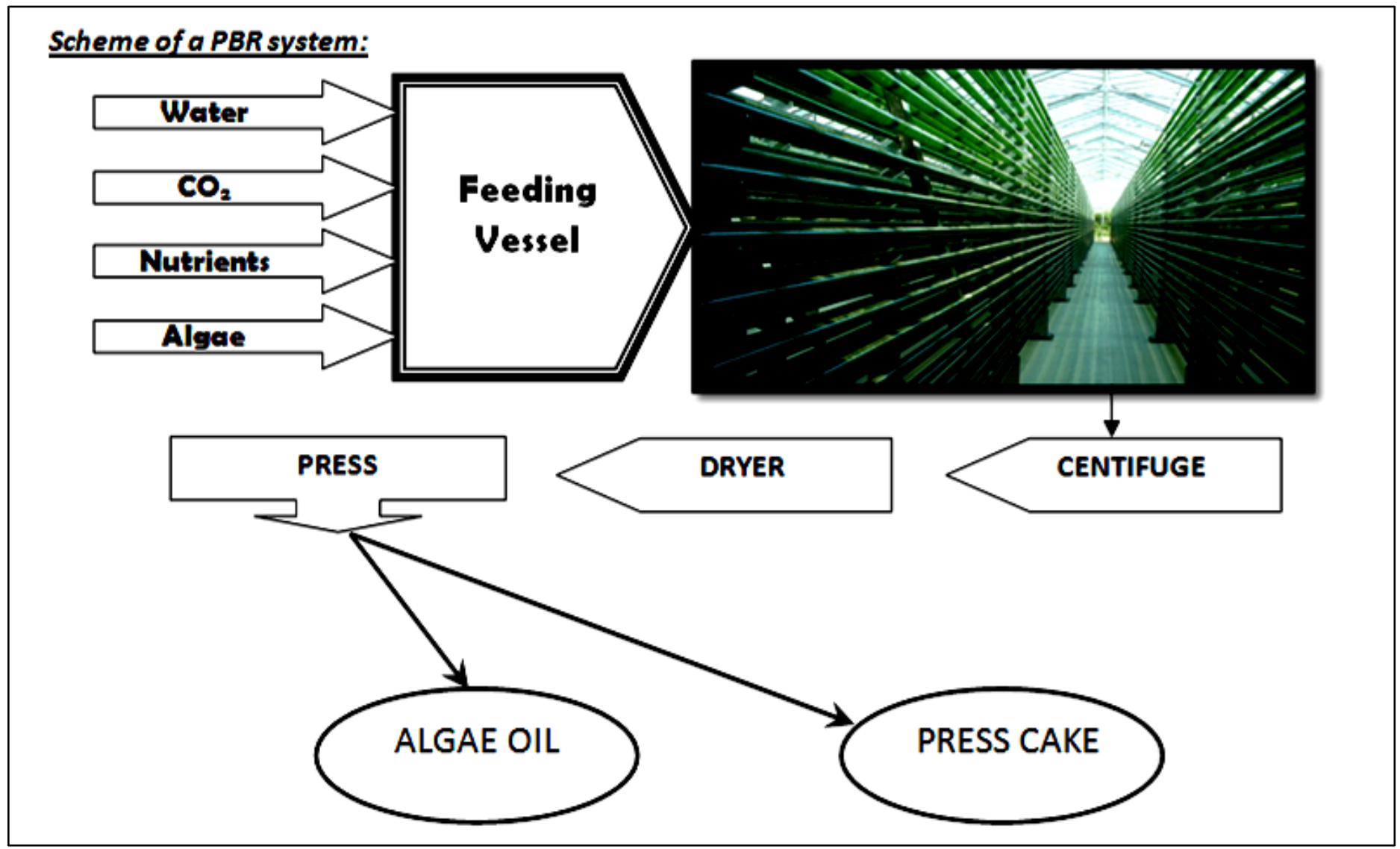

Figure 10. Flow chart of a photobioreactor. 


\subsubsection{Types and Usage}

Photobioreactors can be divided into five major groups: vertical tubular, horizontal tubular, plate, plastic bag system, and combinations of these.

\section{Tubular Systems}

There are numerous ways to construct tubular reactors although they all perform the same function. The tube is transparent and can be flexible, which is either laid out in a serpentine manner, coiled, or rigid structure. When laid out rigid, the tubes are either joined at the end by $\mathrm{U}$ joints or by manifolds. There is a substantial amount of literature that presents efficient ways of growing large quantities of various species of algae. An increasing number of hatcheries and algal production facilities are using tubular reactors because of their production benefits such as higher yield, better environmental control, and savings of labor.

Advantages of a tubular reactor include:

- Maximum light efficiency, and therefore, significantly improved productivity. Compared to bag cultures, the productivity is about 10-20 times higher.

- Self cleaning mechanisms can be implemented.

- Space saving. They can be mounted vertically, horizontally or at an angle, indoors or outdoors.

- Less labor requirements that reduces or eliminates handling problems.

- Systems can be operated for long periods of time without culture death. 
- Good controllability. They usually have automated systems where cultures can easily be kept hygienic. All environmental parameters are controlled.

One limitation of tubular systems is the dark zone in the center of the tubes as the diameter gets larger (Figure 11). Narrow diameter tubes avoid this problem since the light can penetrate all the way to the center of the tubes. This maximizes the available surface area for photosynthesis. Another system limitation is the pump. In order to reduce the problems of algae fouling as well as avoiding the tube cleaning, the flow rate through the tubing needs to be sufficient to induce appropriate turbulent flow. The AlgaeLink system avoids the need for this by having pig-like cleaners which are used frequently; however, the downside is the loss of productivity.

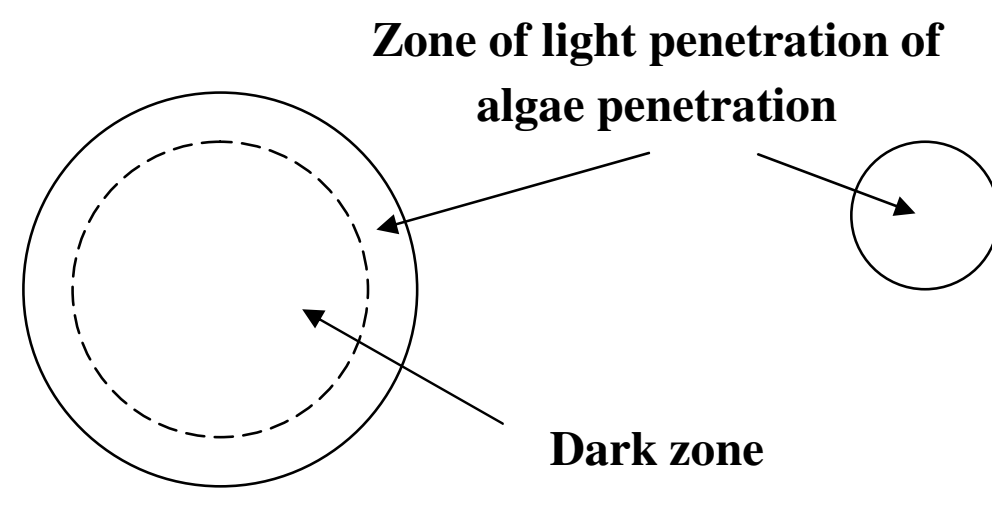

Tank or bag culture

Small diameter PBR tube 
The simplest and cheapest means of achieving turbulent flow is with a centrifugal pump. This has been shown very effective with tough cell walled algae such as Nannochloropsis and Chlorella (Varicon Aqua Solutions, 2004). These are probably the most successful species to grow in tubular reactors where they are able to grow to extremely high densities. A centrifugal pump will however act like a liquidizer on many algal species and could destroy them completely. Diaphragm pumps and very low shear pumps and good for pumping flagellate genera such as Ttetraselmis and Isochrysis (Varicon Aqua Solutions, 2004). Diaphragm pumps are cheap, but often require a high

Figure 11. Schematic view of the dark zone

pressure compressed air supply, which may not always be available. Low shear pumps need to be larger in size than a centrifugal pump, in order to produce the same flow, which means that Diaphragm pumps can therefore be expensive.

The system size is a critical measure as well and must be analyzed. As the length of tubes increase so does the friction of the liquid in the tubing. The head pressure required to pump the water, therefore, increases as well. For that reason, bigger and more expensive pumps are required in larger systems. In addition, as the amount of time the algae spends in the light increases, the carbon dioxide consumption increases, too. Oxygen poisoning combined with bleaching from the excess light can occur as a result (Varicon Aqua Solutions, 2004). 


\subsubsection{The PBR used for Simulation in this Study (BioFence)}

About a dozen or so firms have been developing and selling photobioreactors. The dynamic simulation tool developed in this Master's Thesis was based on a system known as "BioFence". The BioFence system was developed by Varicon Aqua Solutions Ltd, UK (Figure 12 and Figure 14). Horizontal plastic tubes are stacked in a rack to allow a high surface-to-volume ratio. The focus and benefit of this system is the easy to assemble modular and simple design. The expandability (for example by simple tube joiners) of the system allows a scale-up to basically all desired sizes. A sophisticated manifold assembly design reduces the size of the pump required, and therefore saves both cost and algal damage. Due to the manifold design shown in Figure 13, an inhibition of algal growth caused by water supersaturated with oxygen can be avoided. The BioFence

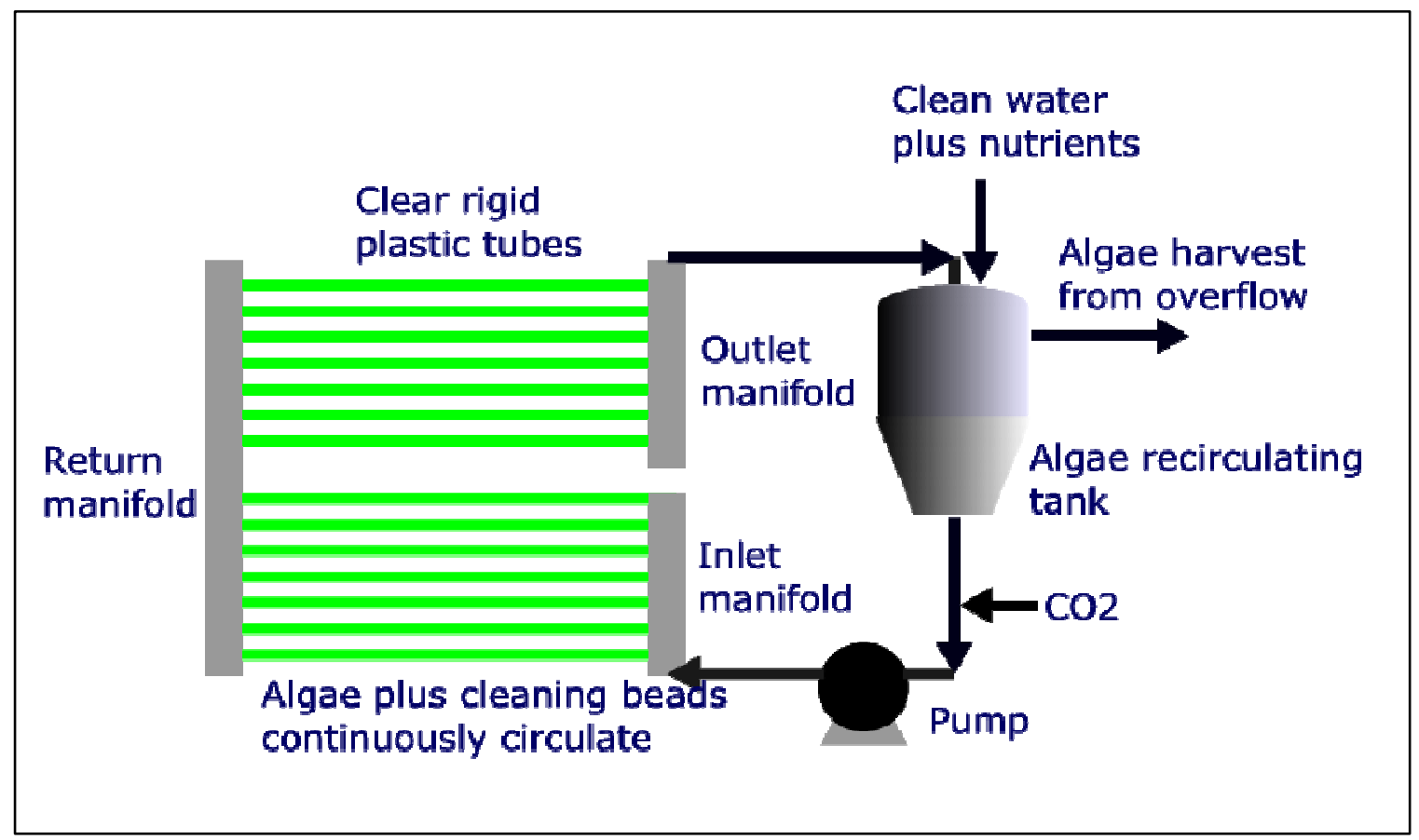

Figure 12. Schematic view of the BioFence system. Source: After Varicon Aqua Solutions Ltd., 2008. 
has the tubes arranged on manifolds which dramatically increase the path length that can be taken by the algae. For that reason, large systems can be built. Patented special cleaning beads that continuously circulate with the algae, clean the tubes from the inside and avoid algae sticking on the inside of the tubes.

Due to the beads, the process does not have to be stopped for cleaning purposes, thus higher productivity and a more stable process can be reached due to avoided cell crashes. According to Varicon Aqua Solutions Ltd., the BioFence can produce an equivalent of 20001 of bag grown algae per day in an array of tubes of $10 \mathrm{~m} \times 1.8 \mathrm{~m}$. Since the BioFence is automatically controlled and delivers algae either continuously or at set intervals, the equipment requires little attention. In addition, the algae can be delivered

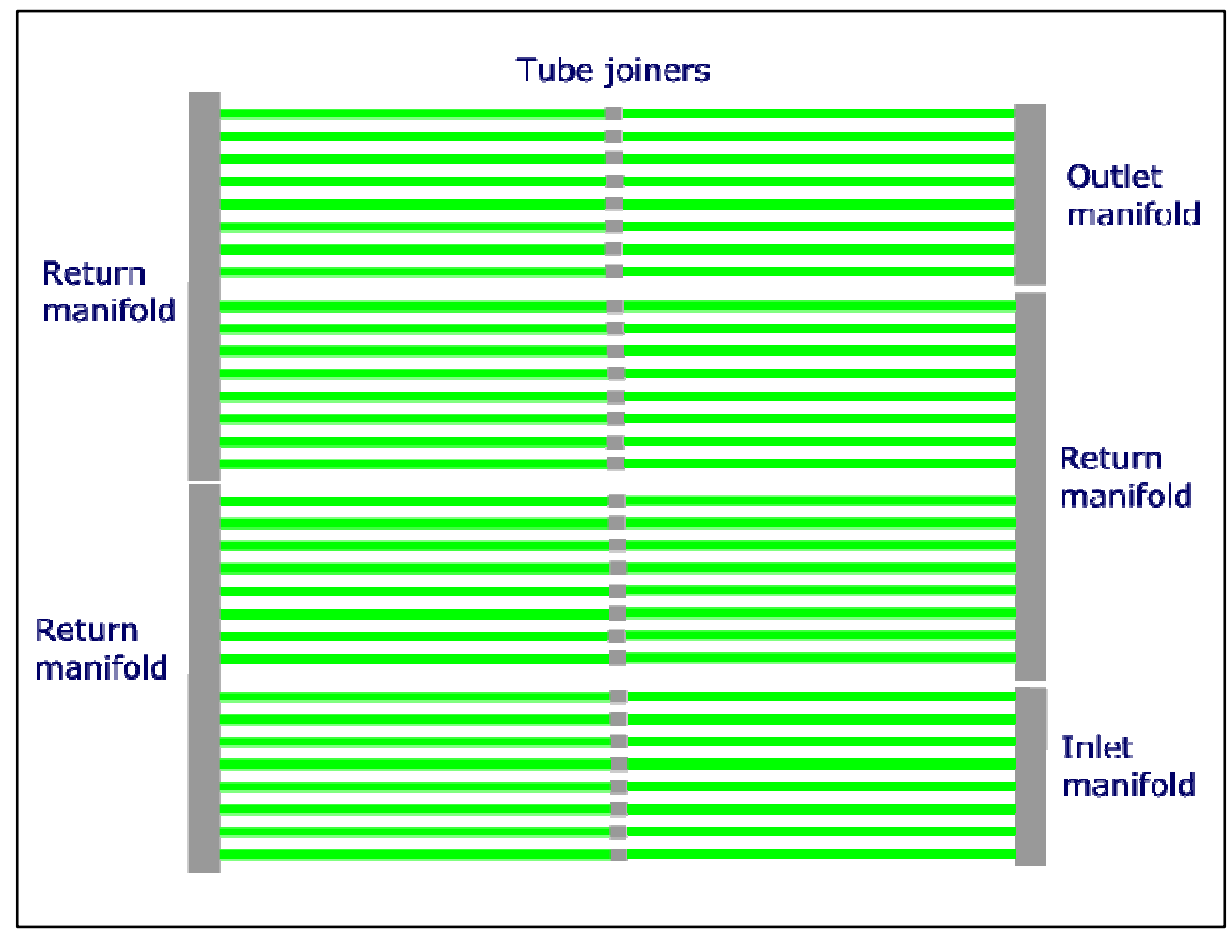

Figure 13. BioFence Manifold configuration. Source: After Varicon Aqua Solutions Ltd., 2008. 
either directly to where it will be used or into easy to handle containers. The system's volume can be easily calculated. Each meter of transparent tube has an internal volume of 0.66 liters and an internal surface area of 0.1 square meters. The BioFence is expandable in blocks of $16 \times 5$ m tubes, i.e. 53 liters. A light-to-dark ratio of at least $50 \%$ is recommended. The tank size required is therefore equal or greater than the internal tube volume. The total system volume is 100 liters per block of 16 tubes (Varicon Aqua Solutions, 2004).

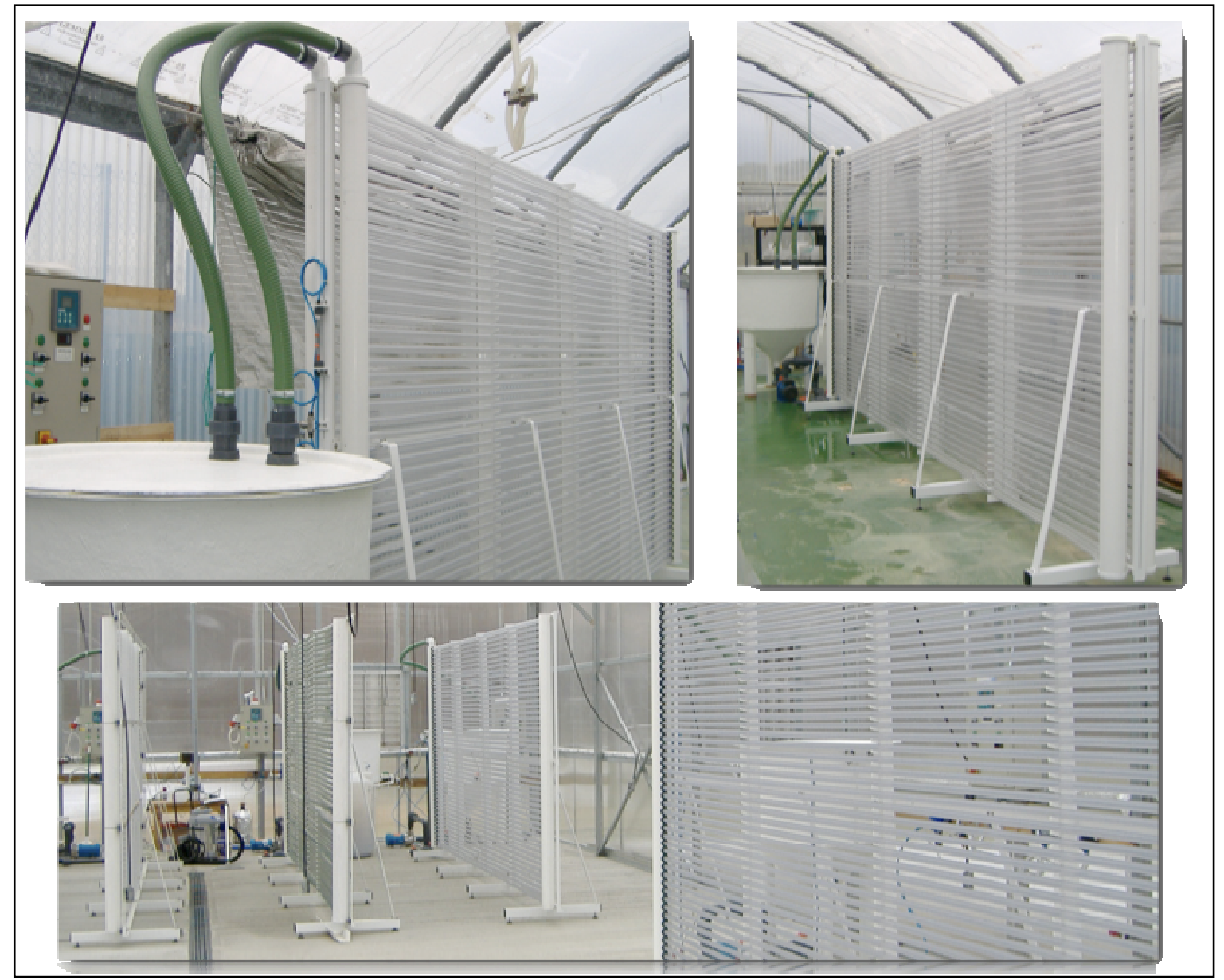

Figure 14. The actual BioFence during installation. Source: After Varicon Aqua Solutions, 2004. 


\section{CHAPTER III}

\section{MATERIALS AND METHODS}

\subsection{Experimental Set-up}

In this study, three lab-scale photobioreactors made by Aqua Medic GmbH were set-up, inoculated and operated over a period of 50 days. The temperature was varied from $9{ }^{\circ} \mathrm{C}$ to $39{ }^{\circ} \mathrm{C}$ by an off-the-shelf aquarium chiller and an aquarium heater.

Contamination with other algae strains as well as any sort of bacteria had to be avoided. Therefore, an optical microscope was used to ensure the purity of algae cultures. Samples were checked for purity once a week. In case of a contamination, the complete batch was eliminated, to ensure the work on a single strain.

The $\mathrm{CO}_{2}$ supply was controlled by an Aqua Medic $\mathrm{GmbH}$ pH meter, which was connected to an electric valve. An optimal $\mathrm{pH}$ of approximately 7.2 was maintained by supplying the right amount of $\mathrm{CO}_{2}$. As soon as the $\mathrm{pH}$ rose over 7.25, the valve opened and $\mathrm{CO}_{2}$ dosing was provided, which decreased the $\mathrm{pH}$ below 7.15. This procedure ensured an optimal $\mathrm{CO}_{2}$ supply as well as optimal $\mathrm{pH}$ in the algal growth medium.

A Bausch \& Lomb Spectronic 21 spectrophotometer was used to monitor algal growth. Samples from each PBR were taken twice a day. The optical density of each sample was determined by measuring the transmittance at $560 \mathrm{~nm}$. Since the density is a limiting growth factor (too high of a density can limit growth), the growth medium was diluted as soon as the transmittance reached $10 \%$. The danger of false readings and misinterpretable data was too high when going under $10 \%$, too. 
A Hanna instruments ${ }^{\circledR}$ multimeter was used to measure phosphate and nitrate concentration at each start of a new batch (approximately every forth day). In case of a lack of nutrients, the specific nutrient was supplied. This procedure avoided a growth inhibition due to a lack of nutrients. The minimum amount of phosphate was $10 \mathrm{ppm}$; the minimum amount of nitrate was $15 \mathrm{ppm}$.

\subsubsection{Culturing Techniques}

A vial with pure Chlorella cultures in a medium called "ALGGRO" was obtained from UTEX, the University of Texas, Austin, Texas, U.S.A. The vial was opened and put into the lab-scale photobioreactor (Figure 15) together with $100 \mathrm{ml}$ of distilled water and 5 drops of composed fertilizer called "PLANT FOOD", containing all important nutrients with a N-P-K ratio of 10-15-10 (Table 2). The nutrient concentration was kept above 10 $\mathrm{mg} / \mathrm{l}$ for Phosphorous and above $50 \mathrm{mg} / \mathrm{l}$ for Nitrogen.

The PBR was a vertically mounted, transparent plastic tube with the air supplied from the bottom. The air supplied a small amount of $\mathrm{CO}_{2}$ (content in ambient air about $0.03 \%$ ) and accounted for the necessary turbulences (water mixture) in the bioreactor. Additional $\mathrm{CO}_{2}$ was supplied by an external $\mathrm{CO}_{2}$ bottle, controlled by a $\mathrm{pH}$ monitoring computer. An optimal pH of 7.2 was maintained by regulating the $\mathrm{CO}_{2}$ supply. Since $\mathrm{CO}_{2}$ forms carbonic acid in the water, the $\mathrm{CO}_{2}$ dosing reduced the $\mathrm{pH}$. An electrode placed in the bioreactor sensed the $\mathrm{pH}$ in the algae water and transmitted it to the $\mathrm{pH}$ computer, 
which regulated the valve of the $\mathrm{CO}_{2}$ bottle. Figure 16 shows a schematic view of the PBR set-up.

The algal growth was monitored by optical density measurements using a spectrophotometer. A low density condition (transmittance larger than 10\%) was maintained by adding distilled water to the bioreactor as soon as the density increased to a transmittance smaller than $10 \%$. Another optical density reading was taken after adding water in order to monitor the change and keep continuous data analysis. A new batch was started accordingly. This has to be considered later on when selecting the data.

Artificial lighting was also supplied by a fluorescent light bulb $(6,700 \mathrm{~K}, 8 \mathrm{~W}$, $1300 \mathrm{~lm}$ ) hung up parallel to the PBR. The lighting was controlled by a timer providing 16 hours of light and 8 hours of dark periods, respectively. The location of the PBR

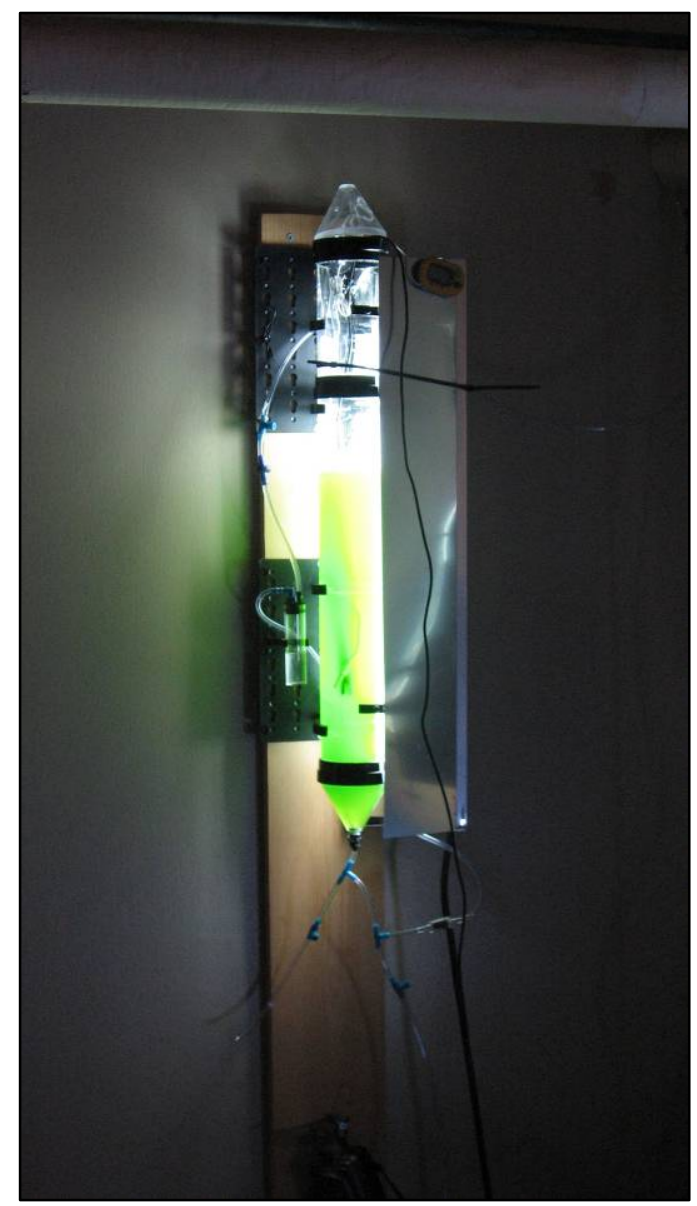

Figure 15. A lab-scale PBR in use. 
offered almost no natural daylight. All bulbs that are above $5600 \mathrm{~K}$ are considered

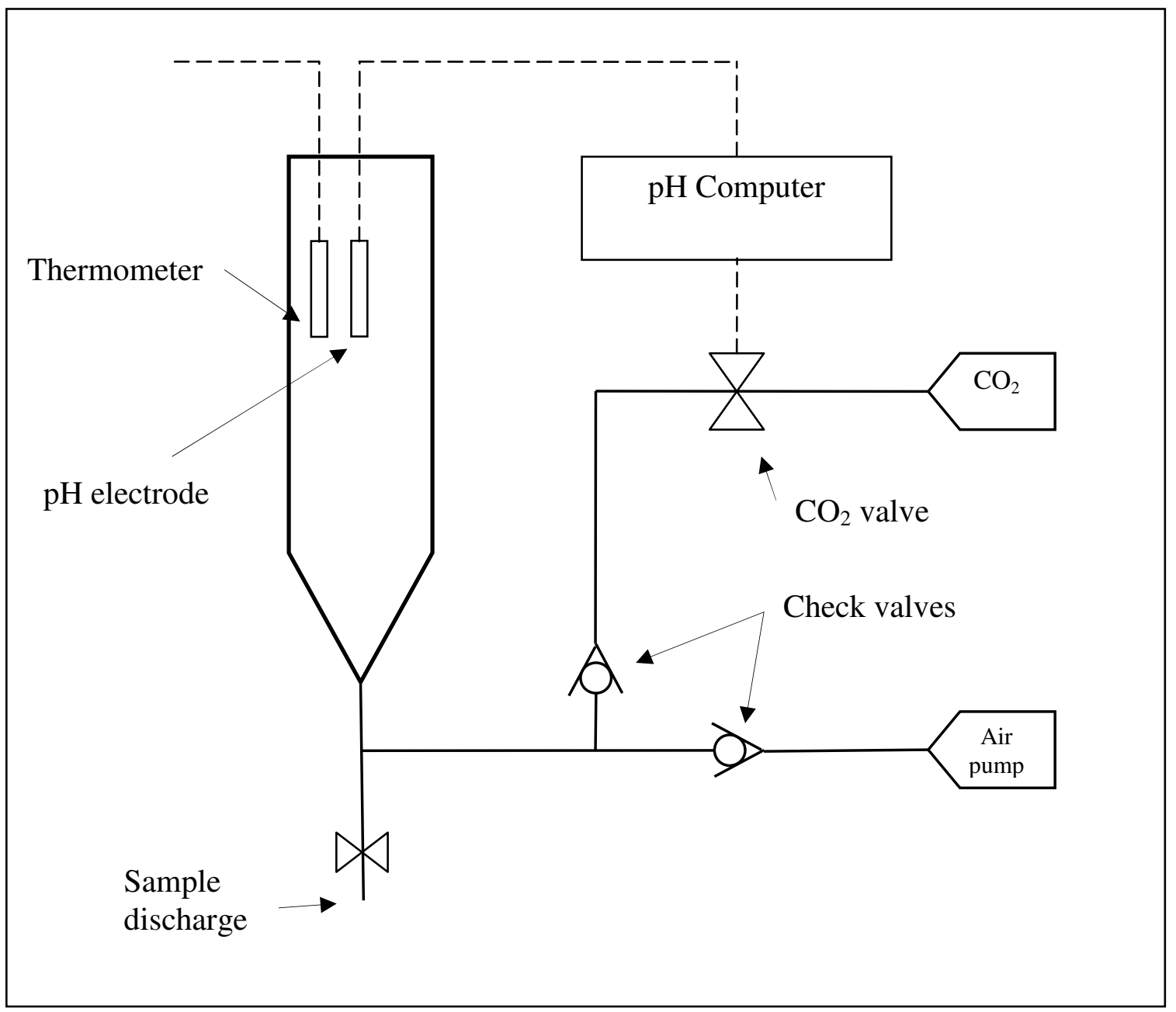

Figure 16. Schematic view of the photobioreactor set-up.

daylight bulbs, offering a clean, bright light condition. These bulbs are used to simulate outdoor conditions conditions providing $65 \mathrm{~W} / \mathrm{m}^{2}$.

As soon as stable conditions and a continuous growth rate were obtained at room temperature, a chiller connected to one of the PBR systems was activated, decreasing the temperature slowly. In order to get the temperature function as described in Chapter II, the temperature with a growth rate of $10 \%$ of the maximum growth rate had to be 
determined. The experiments with colder water, therefore, focused on a region between 9 ${ }^{\circ} \mathrm{C}$ and $14{ }^{\circ} \mathrm{C}$ to determine the $10 \%$ growth rate temperature. The PBR was operated over several weeks within this temperature range, increasing and decreasing the temperature frequently (approximately every forth day).

The same procedure was performed on another PBR by heating the water until a temperature with a growth rate close to $10 \%$ of the maximum growth rate $\left(32^{\circ} \mathrm{C}-39^{\circ} \mathrm{C}\right)$ was determined. The optimal temperature (usually between $23{ }^{\circ} \mathrm{C}$ and $30^{\circ} \mathrm{C}$ ), however, was determined by heating the third PBR at smaller temperature increments.

Table 2. Basic fertilizer composition.

\begin{tabular}{|l|l|}
\hline \multicolumn{2}{|c|}{ Analysis } \\
\hline \hline Total Nitrogen & $10 \%$ \\
& $\begin{array}{l}\text { 1.6\% Ammoniacal Nitrogen } \\
0.2 \% \text { Nitrate Nitrogen } \\
8.2 \% \text { Urea Nitrogen }\end{array}$ \\
\hline Available Phosphate $\left(\mathrm{P}_{2} \mathrm{O}_{5}\right)$ & \\
\hline Soluble Potash $\left(\mathrm{K}_{2} \mathrm{O}\right)$ & $15 \%$ \\
\hline Iron $(\mathrm{Fe})$ & $10 \%$ \\
\hline Manganese $(\mathrm{Mn})$ & $0.1 \%$ \\
\hline Zinc $(\mathrm{Zn})$ & $0.05 \%$ \\
\hline
\end{tabular}

\subsubsection{Applications}

\section{Optical Microscope}

A type of microscope which uses visible light and a system of lenses to magnify images of small samples is optimal. Optical microscopes are the oldest and simplest of 
microscopes. A stereomicroscope was used to examine the algae samples. Figure 17 shows the basic components of a typical research stereomicroscope. The total magnification equals the product of the ocular (eye) and objective lense. A "Köhler illumination" was used in these types of microscopes which means that the incident light shines on the specimen from below. The total magnification was "1000x".

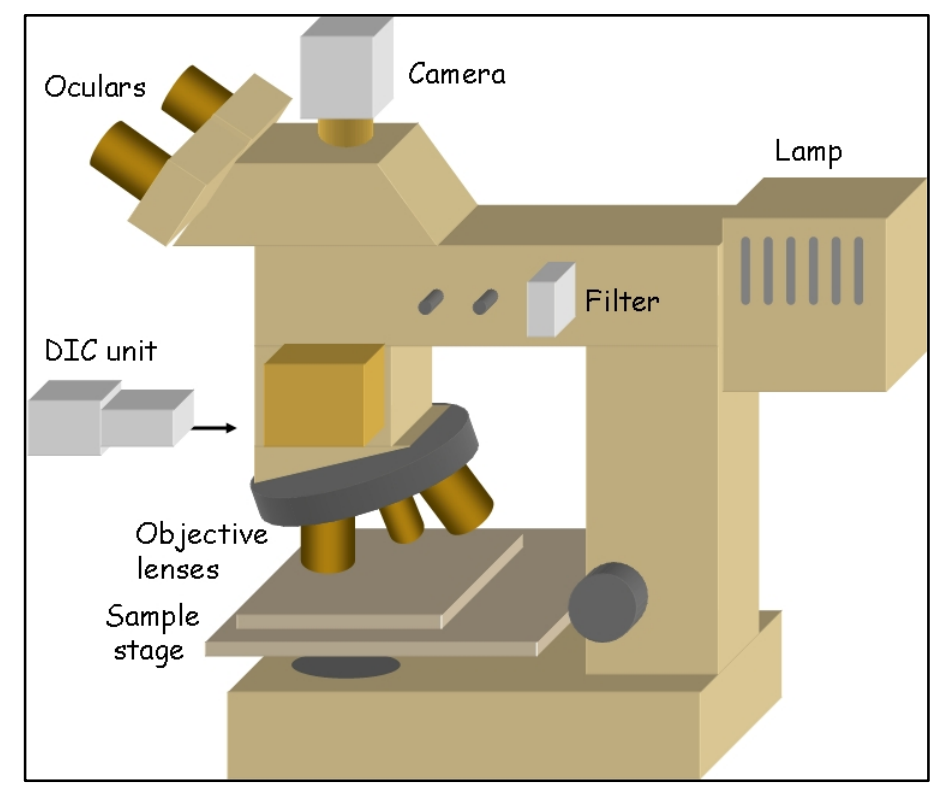

Figure 17. Optical microscope. Source:After Molhave, 2006.

\section{pH-Computer and Valve}

The $\mathrm{pH}$ value indicates the measure of the free carbonic acid in the photobioreactors. The carbonic acid fertilization is the basis for a well thriving algae growth. A pH-Computer (Figure 18) maintained the pre-set $\mathrm{pH}$ value automatically by supplying $\mathrm{CO}_{2}$ through a controlled valve. In this study, the $\mathrm{pH}$-Computer was used to regulate the level of carbonic acid in the photobioreactor. 


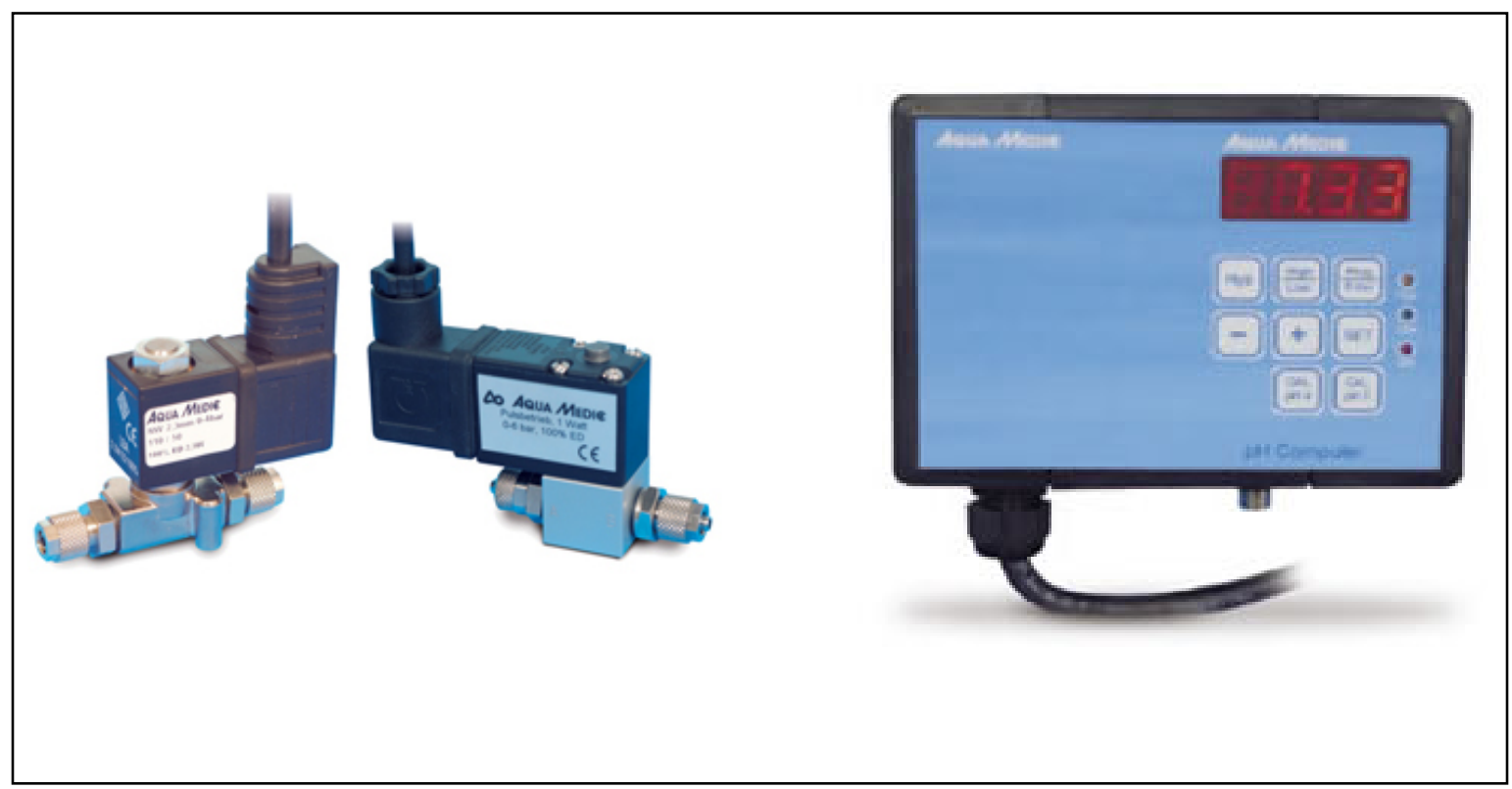

Figure 18. $\mathrm{CO}_{2}$ control valves (left) and $\mathrm{pH}$ computer (right).

Source: After Aqua Medic GmbH, 2007.

\section{Spectrophotometer}

An ultraviolet-visible spectrophotometry (UV/VIS) uses light in the visible and adjacent near ultraviolet (UV) and near infrared (NIR) ranges. In this region of energy space molecules undergo electronic transitions. The device measures the intensity of light passing through a sample, and compares it to the intensity of light before it passes through the sample. The ratio is called the transmittance, and is usually expressed as a percentage. The basic parts of a spectrophotometer (Figure 20 and Figure 19) are a light source, a holder for the sample, a diffraction grating or monochromator to separate the different wavelengths of light, and a detector. The detector is typically a photodiode. Photodiodes are used with monochromators, which filter the light so that only the light of a single wavelength reaches the detector. Samples are typically placed in a transparent cell, known as a cuvette. Cuvettes are typically rectangular or cylindrical in shape, 
commonly with an internal width of one $\mathrm{cm}$ or one inch. This width becomes the path length, PL, in the Beer-Lambert law. The use will be discussed later in the Thesis.

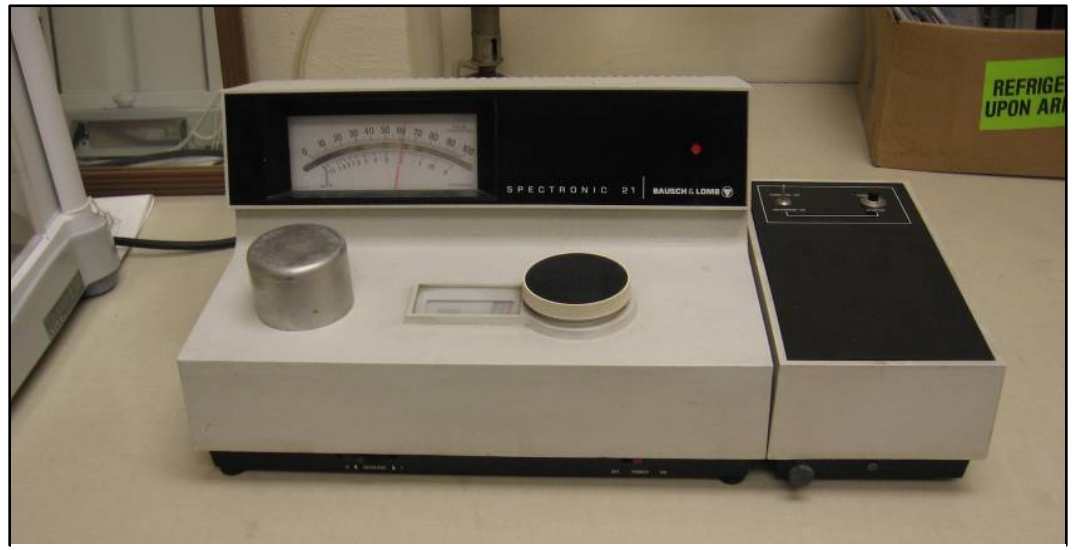

Figure 19. An older spectrophotometer with analog reading. Source: After Mehlitz, 2008.

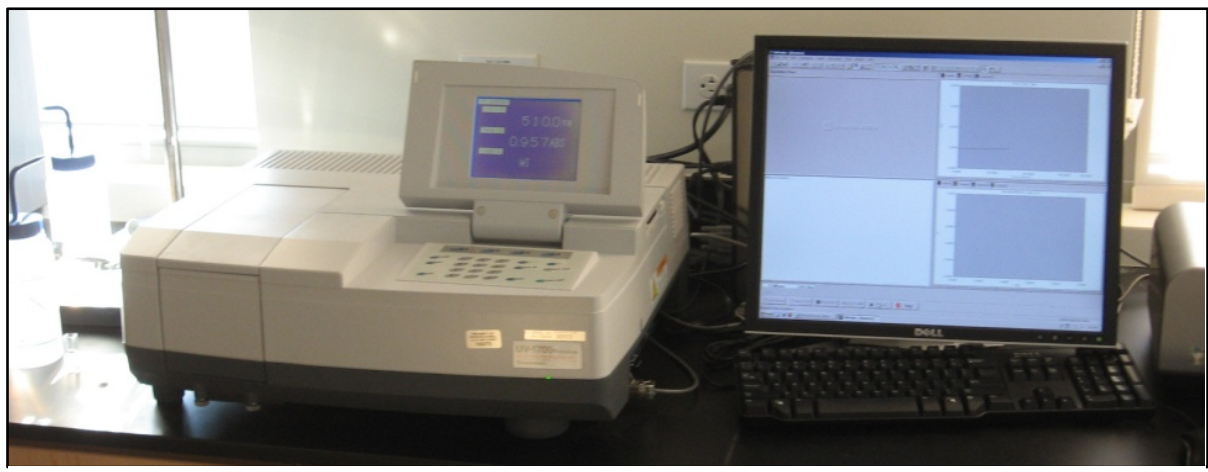

Figure 20. A modern spectrophotometer with PC control. Source: After Mehlitz, 2008.

\section{Multimeter}

A Hanna Instruments ${ }^{\circledR}$ Multimeter (Figure 21) was used in the experiments to measure the amount of different nutrients in the growth media. Essentially, the instrument is a multiparameter bench photometer dedicated for aquacultural analysis. It can measure 13 different methods (nutrients) using specific liquid or powder reagents. The amount of reagent is precisely dosed to ensure maximum reproducibility. 
Absorption of light is a typical phenomenon of interaction between electromagnetic radiation and matter. When a light beam crosses a substance, some of the radiation may be absorbed by atoms, molecules or crystal lattices. If pure absorption occurs, the fraction of light absorbed depends both on the optical path length through the matter and on the physical-chemical characteristics of substance according to the Lambert-Beer law.

The concentration can be calculated from the absorbance of the substance once other factors are known. Photometric chemical analysis is based on the possibility to develop an absorbing compound from a specific chemical reaction between sample and reagents. Given that the absorption of a compound strictly depends on the wavelength of the incident light beam, a narrow spectral bandwidth should be selected as well as a proper central wavelength to optimize measurements.

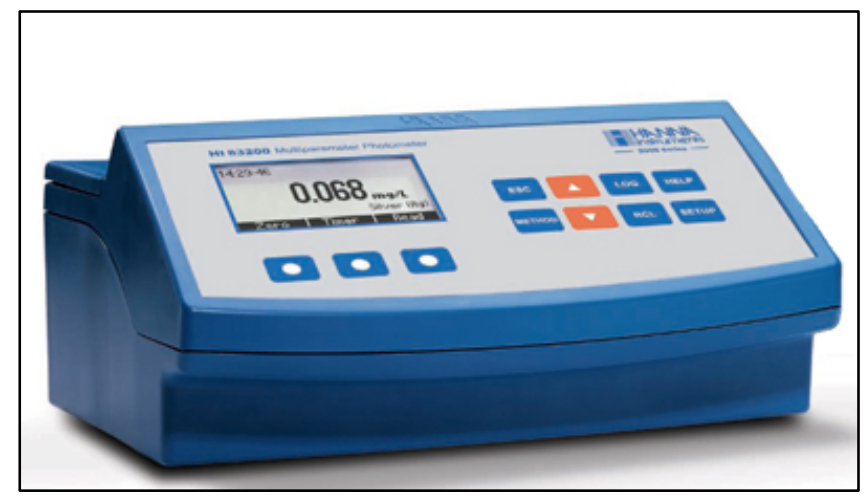

Figure 21. Hanna Instruments Multimeter.

Source: After Hanna Instruments®, 2008.

A microprocessor controlled special tungsten lamp emits radiation which is first optically conditioned and beamed to the sample contained in the cuvette. The optical path is fixed by the diameter of the cuvette. Then the light is spectrally filtered to a narrow spectral bandwidth, in order to obtain a light beam intensity. The photoelectric cell 
collects the radiation that is not absorbed by the sample and converts it into an electric current, producing an electrical potential in milivolts.

The microprocessor uses this potential to convert the incoming value into the desired measuring unit and then displays it on the liquid crystal display (LCD). The measurement process is carried out in two phases: first the meter is zeroed; and then the actual measurement is performed. The cuvette has a very important role, because it is an optical element; and thus requires particular attention. It is important that both the measurement and the calibration (zeroing) cuvette are optically identical to provide the same measurement conditions. Most techniques use the same cuvette for both, so that the measurements take place in the same optical point. The instrument and the cuvette cap have special marks that must be aligned in order to obtain better reproducibility. The surface of the cuvette must be clean and not scratched. This is to avoid measurement interference due to unwanted reflection and absorption of light. Therefore, it is recommended not to touch the cuvette walls with hands. Furthermore, in order to maintain the same conditions during the zeroing and the measurement phases, it is necessary to close the cuvette to prevent the possibility of contamination. Due to the turbid algal water in this study, the measurements had to be taken at the very beginning of each batch cultivation, when the water was still clear (Hanna Instruments, 2008). This instrument could not be used when the transmittance was under $50 \%$. 


\subsubsection{Data Collection and Analyses}

All data were collected and reported by a research team in a limited online database, which was updated daily (Figure 22). Even slight changes or outlying data points could be monitored and evaluated very quickly. The online access enabled the team members to update or download data at all times. Microsoft Excel software was used to perform a number of data analyses.

Three PBRs were operated over a period of 50 days. With two readings per day, the sample size summed up to 300 entries. The data evaluated were manually chosen from the entire set. Recorded data from lag phases with no or hardly growth were deleted. Every single data set was examined and checked for plausibility. Over 150 samples were deleted from the database in order to examine only pure culture findings. Main criteria for this purpose were:

- $\quad$ pH lower than 5.5 or higher than 8.0

- $\quad 3$ data sets after changing an environmental factor (delete lag phase)

- Transmittance below 7\% (density too high)

The measured temperatures were rounded to full degrees Celsius (e.g. $15.3{ }^{\circ} \mathrm{C}$ to $15{ }^{\circ} \mathrm{C}$ ). In accordance with Eqn. 2.5 and 2.6 (Chapter II), only the temperature for the maximum growth (anticipated to be between $23{ }^{\circ} \mathrm{C}$ and $31{ }^{\circ} \mathrm{C}$ ), the temperature at $10 \%$ of the maximum growth rate at the lower end (anticipated to be between $9{ }^{\circ} \mathrm{C}$ and $14{ }^{\circ} \mathrm{C}$ ), and the temperature at $10 \%$ of the maximum growth rate at the upper end (anticipated to 
be between $34{ }^{\circ} \mathrm{C}$ and $40{ }^{\circ} \mathrm{C}$ ) were to be determined. The research therefore mainly focused on these regions.

For the evaluation, the time interval ( $\Delta \mathrm{t}$ in hours) from the previous reading to the current and the corresponding change in transmittance $(\Delta \tau)$ were calculated. The growth rate per day (24 hours) was interpolated from these two parameters and reported with the corresponding temperature. Then, a mean growth rate for each temperature experiment was determined.

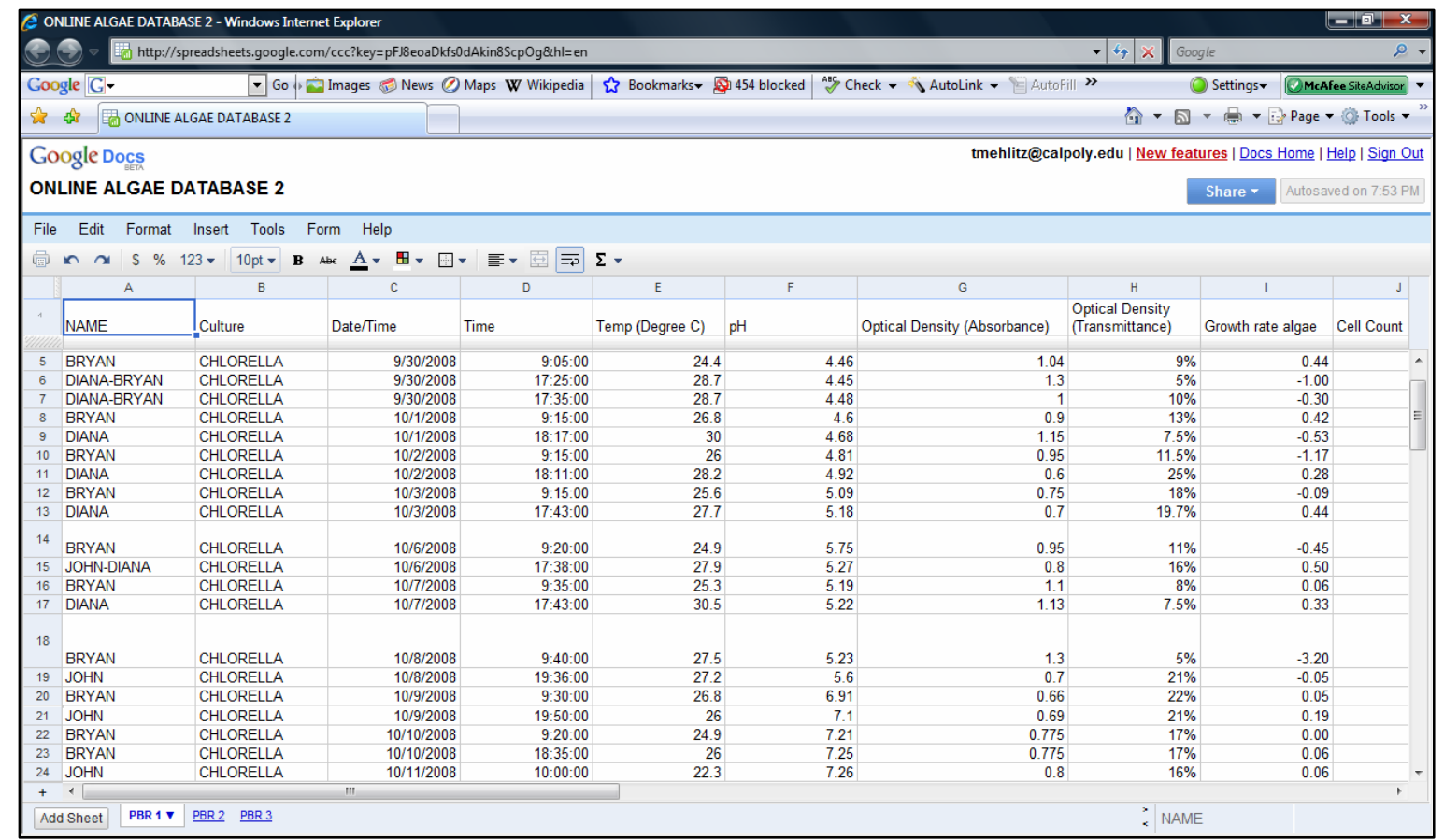

Figure 22. Screen view of the online database where all available data were collected. 


\subsection{Heat Management Simulation Model}

\subsubsection{Introduction}

A dynamic simulation model was developed to provide an accurate prediction of a horizontal tubular photobioreactor as a function of dynamic environmental factors such as solar energy, outside temperature, and wind speed. This dynamic prediction model was developed in Microsoft Excel using VBA (Visual Basic for Application), from basic energy conservation and heat transfer principles for a single glass glazing greenhouse. The model incorporated a dynamic simulation of algae growth. The photobioreactor and greenhouse characteristics used in the simulation model for this study are presented in Table 3. The model was used to predict heating and cooling loads and the benefits associated with heating and cooling. A flow chart of the simulation model is presented in Figure 23. This chapter discusses the techniques employed as well as the assumptions made throughout the system analysis.

Hourly weather data (temperature, solar radiation, wind speed, relative humidity) were downloaded from the California Irrigation Management Information System (CIMIS) weather station for San Luis Obispo $\left(35^{\circ} 17^{\prime} \mathrm{N} ; 120^{\circ} 39^{\prime} \mathrm{W}\right)$, California, U.S.A. for the month of April 2007 (http://wwwcimis.water.ca.gov). However, the simulation model is flexible enough to simulate any other location, any other month, or even any year. Simulations were performed starting at the beginning of the fifth day and ended at the end of 30th day of the month providing 26-day simulations. 


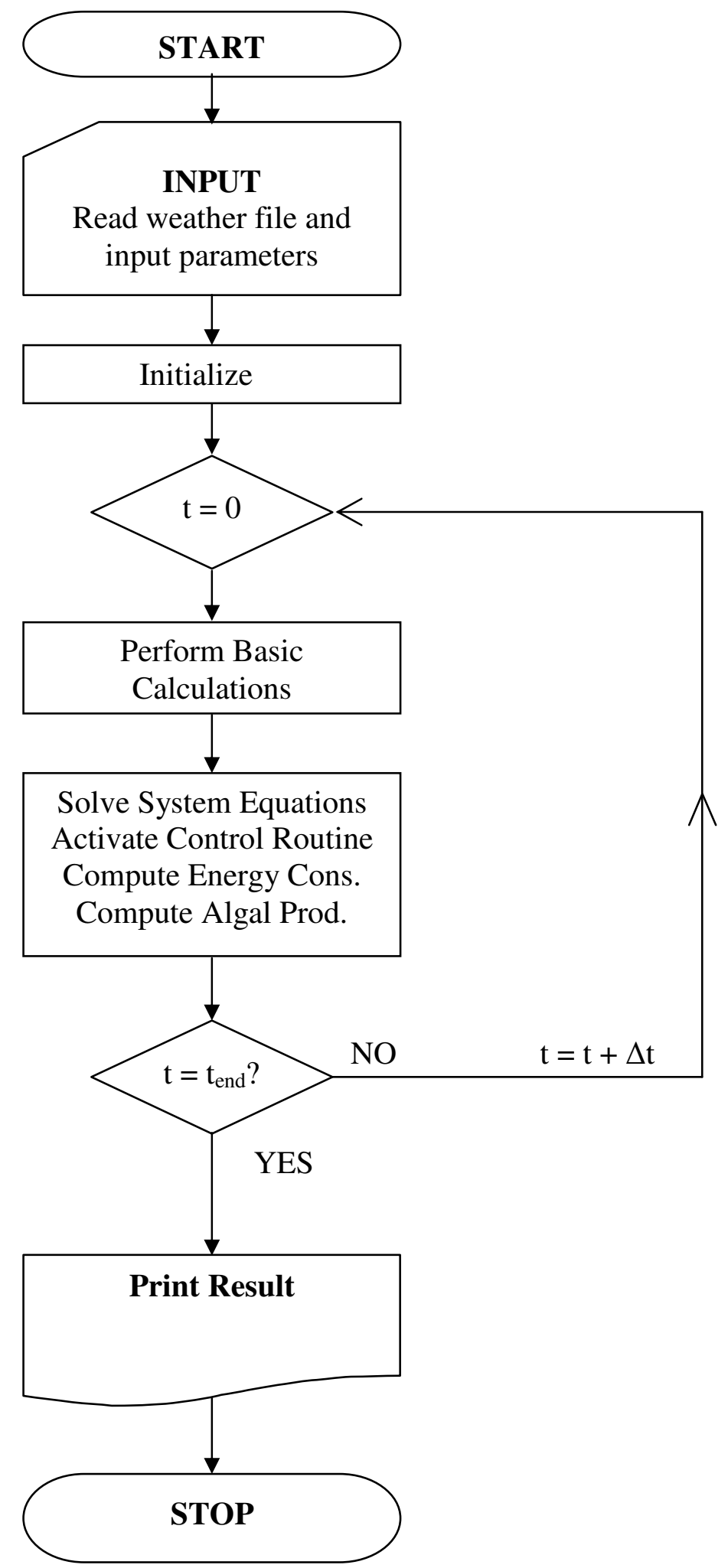

Figure 23. Flow chart of the simulation model. 
Table 3. Photobioreactor and greenhouse characteristics.

\begin{tabular}{|c|c|c|}
\hline Parameter & Description & Value \\
\hline $\mathrm{IR}_{\mathrm{AIR}}$ & Index of refraction $\mathrm{n}$ for the air & $1^{1}$ \\
\hline $\mathrm{IR}_{\mathrm{TUBE}}$ & Index of refraction $\mathrm{n}$ for the glass tube & $1.526^{1}$ \\
\hline$\Phi$ & Latitude for location (San Luis Obispo) & $35.23^{\circ}$ \\
\hline$\gamma$ & Surface azimuth angle & $0^{\circ 3}$ \\
\hline$\beta$ & Slope of virtual surface for beam incidence & $45^{\circ}$ (assumed) \\
\hline $\mathrm{R}_{\mathrm{GROUND}}$ & Reflectivity of the ground & $20 \%$ (assumed) \\
\hline $\mathrm{R}_{\mathrm{ALGAE}}$ & Reflectivity of the algae algae & $5 \%$ (assumed) \\
\hline$\tau_{\mathrm{GH}}$ & Transmissivity of the greenhouse cover & $60 \%{ }^{2}$ \\
\hline $\mathrm{Cp}_{\mathrm{WAT}}$ & Specific heat of water & $1.16278 \mathrm{Wh} / \mathrm{kg} . \mathrm{K}^{4}$ \\
\hline $\mathrm{Cp}$ AIR & Specific heat of air & $0.2811 \mathrm{Wh} / \mathrm{kg} . \mathrm{K}^{4}$ \\
\hline$\rho_{\mathrm{WAT}}$ & Density of water & $996 \mathrm{~kg} / \mathrm{m}^{34}$ \\
\hline$\rho_{\mathrm{AIR}}$ & Density of air & $1.2 \mathrm{~kg} / \mathrm{m}^{34}$ \\
\hline$\varepsilon$ & Emissivity of the glass/Plexiglass tubes & $94 \% \%^{3,4}$ \\
\hline $\mathrm{AEH}$ & Infiltration rate & $1.5{\text { ( air exchanges per hr })^{2}}^{2}$ \\
\hline $\mathrm{U}_{\mathrm{G}}$ & Heat transfer coefficient - single layer glass & $0.00628 \mathrm{~kW} / \mathrm{m}^{2} . \mathrm{K}^{2}$ \\
\hline $\mathrm{U}_{\mathrm{FL}}$ & $\begin{array}{l}\text { Heat transfer coefficient - poured concrete } \\
152 \mathrm{~mm}\end{array}$ & $0.000872 \mathrm{~kW} / \mathrm{m}^{2} \cdot \mathrm{K}^{2}$ \\
\hline $\mathrm{T}_{\mathrm{OPT}}$ & Temperature at max growth rate & $29{ }^{\circ} \mathrm{C}$ \\
\hline$\mu_{\max }$ & Maximum growth rate & 1.44 /day \\
\hline $\mathrm{T}_{\text {SUP }}$ & Temp. at $10 \%$ of max growth rate - upper & $35^{\circ} \mathrm{C}$ \\
\hline $\mathrm{T}_{\mathrm{INF}}$ & Temp. at $10 \%$ of max growth rate - lower & $11{ }^{\circ} \mathrm{C}$ \\
\hline nc & \# of PBR parallel columns & 19 \\
\hline na & \# of PBR columns axial & 10 \\
\hline d & PBR tube diameter & $0.03 \mathrm{~m}$ \\
\hline lt & PBR tube length & $10 \mathrm{~m}$ \\
\hline $\mathrm{dt}$ & Distance between PBR tube centers & $0.18 \mathrm{~m}$ \\
\hline $\mathrm{dtt}$ & Distance between PBR twin tube centers & $0.06 \mathrm{~m}$ \\
\hline $\mathrm{b}$ & Distance between ground \& first PBR tube & $0.3 \mathrm{~m}$ \\
\hline $\mathrm{x}$ & Distance between PBR columns (parallel) & $1.5 \mathrm{~m}$ \\
\hline xa & Distance between PBR columns (axial) & $1.5 \mathrm{~m}$ \\
\hline $\mathrm{t}$ & \# of tubes per PBR column & 32 \\
\hline GHW & Greenhouse width & $7.2 \mathrm{~m}$ \\
\hline GHL & Greenhouse length & $57.6 \mathrm{~m}$ \\
\hline GHWH & Greenhouse wall height & $2.4 \mathrm{~m}$ \\
\hline GHG & Greenhouse gable height & $1.8 \mathrm{~m}$ \\
\hline GHN & \# of greenhouse bays & 12 \\
\hline $\mathrm{tt}$ & $\begin{array}{l}\text { Switch to decide whether twin tubes }(1) \text { or } \\
\text { single tubes }(0) \text { are used in PBR columns }\end{array}$ & 0 or 1 \\
\hline
\end{tabular}

${ }^{1}$ Duffie and Beckman, 2006; ${ }^{2}$ Aldrich and Bartok, 1992; ${ }^{3}$ Iqbal, 1983; ${ }^{4}$ Incropera et al., 2007 


\subsubsection{Physical Model and Photobioreactor Architecture}

A description of the photobioreactor as a series of parallel rows was extended to an overall greenhouse model for indoor operation, whereas the same parallel rows were modeled without a greenhouse for the outside operation, as schematically shown in Figure 25 and Figure 26. In dealing with the energy exchanges, the outside weather conditions and the deep ground temperature served as boundary conditions. The bulk air was analyzed by adopting the assumption of "perfect mixing".

All dimensions of the PBR were variables in the model. This feature allowed optimization and flexibility for different PBR configurations possible. Figure 24 shows the basic dimensions used in the simulation model.

\subsubsection{Energy Balances}

Many factors influence the heat losses and gains of tubular photobioreactors (PBRs). To understand the developed simulation model, general approaches employed in heat transfer calculations and basic principles are explained in this section. The simulation model is able to determine the heating requirements for an outdoor operation as well as for an indoor (greenhouse) operation. Different heat transfer modes occur under the two different conditions. In the case of an outside operation, heat losses due to forced convection (wind) and radiation (ground and sky), and gains due to solar radiation

are present (Figure 25). The photobioreactor and ground have thermal masses; therefore, heat storage has to be considered. 


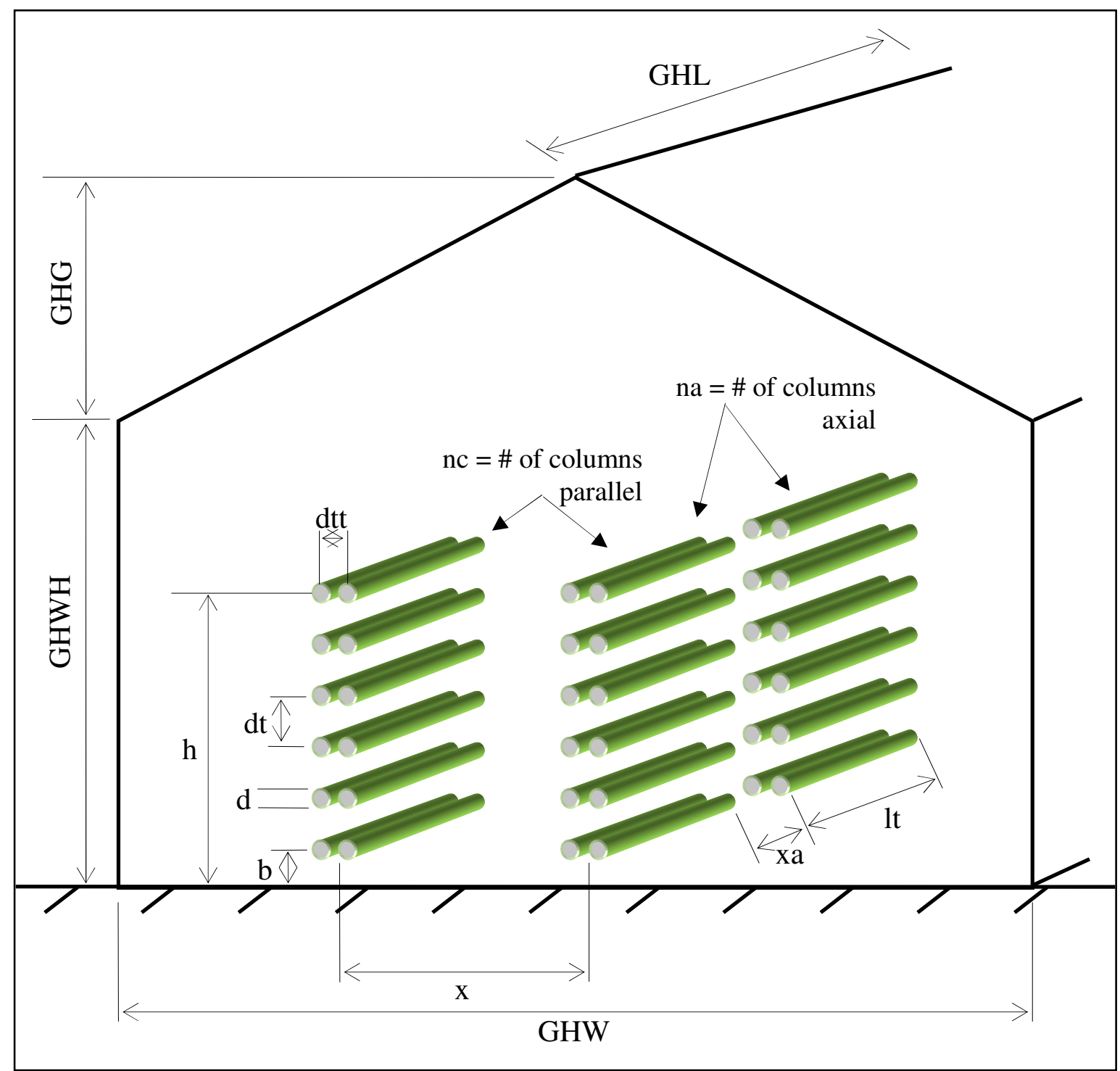

Figure 24. Dimensions of the photobioreactor. 


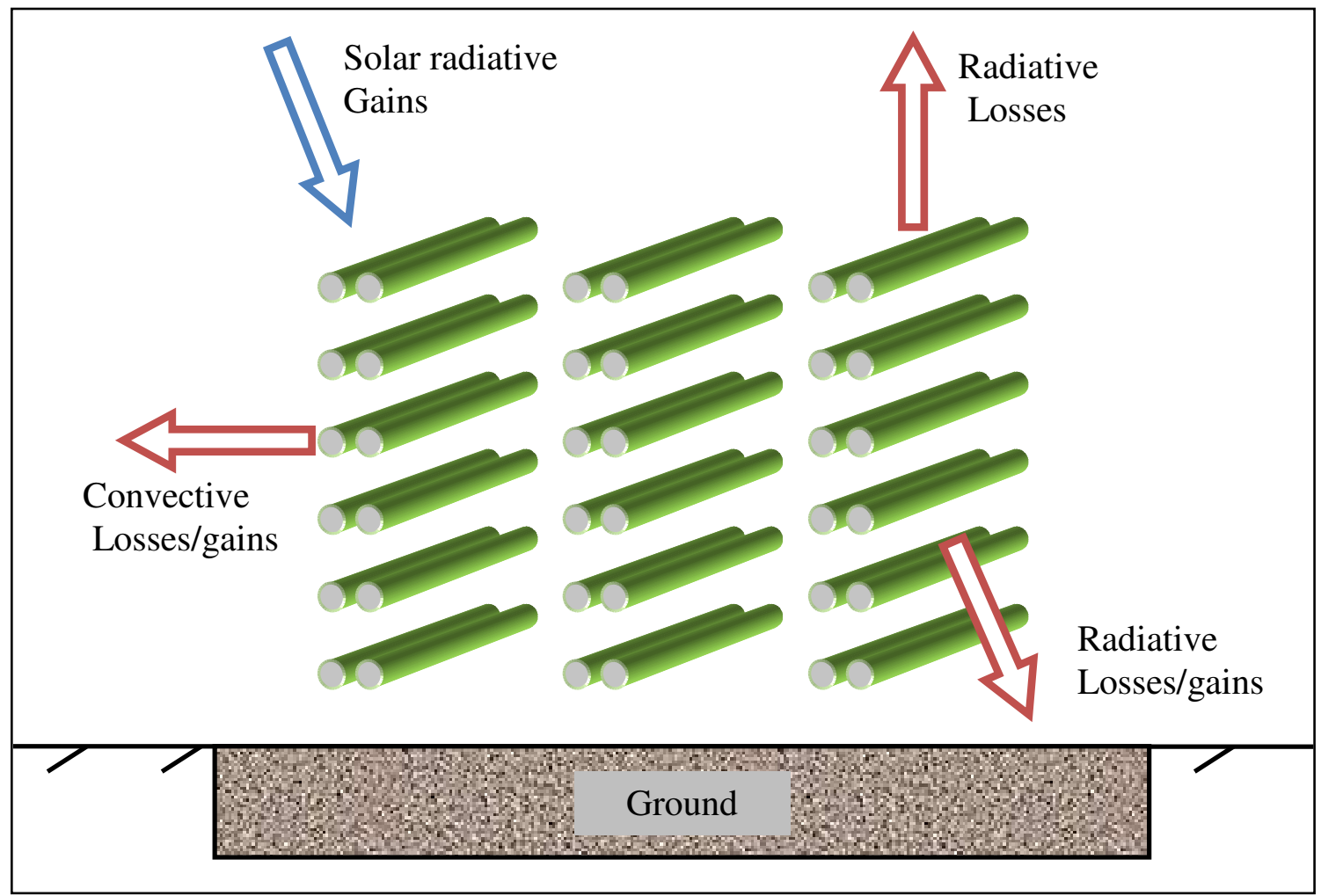

Figure 25. Heat losses and gains from an outdoor PBR.

The energy balance for an outdoor photobioreactor can be symbolically expressed as:

$$
\begin{aligned}
& \text { Energy storage }=\mathrm{E}_{\mathrm{in}}-\mathrm{E}_{\mathrm{out}} \\
& \rho_{\mathrm{WAT}} * \mathrm{~V}_{\mathrm{PBR}} * \mathrm{C}_{\mathrm{WAT}} * \mathrm{dT}_{\mathrm{PBR}} / \mathrm{dt}=\mathrm{Q}_{\mathrm{TSRA}}-\mathrm{Q}_{\mathrm{OS}}-\mathrm{Q}_{\mathrm{OSCL}}
\end{aligned}
$$

where $\rho_{\text {WAT }}$ was the density of water $\left(996 \mathrm{~kg} / \mathrm{m}^{3}\right) ; \mathrm{V}_{\mathrm{PBR}}$ was the total photobioreactor volume $\left(\mathrm{m}^{3}\right)$; C $\mathrm{p}_{\mathrm{WAT}}$ was the specific heat capacity of water $(1.16278 \mathrm{Wh} / \mathrm{kg} . \mathrm{K}) ; \mathrm{dT}_{\mathrm{PBR}}$ was the photobioreactor temperature change $(\mathrm{K})$ over a period of time $\mathrm{dt}$ (one hour); $\mathrm{Q}_{\mathrm{TSR} A}$ was the total solar radiation absorbed by the PBR $(\mathrm{kW})$; Q $\mathrm{OS}$ was the outside longwave radiation exchange with the sky and the ground (kW); QosCL was the outside 
convective heat transfer due to convection (wind), and $\mathrm{HS}_{\mathrm{PBR}}$ was the heat storage component of the PBR. The details of these individual components are explained in the upcoming sections.

For the inside conditions, an interaction between inside and outside air temperatures as well as between inside air and reactor temperatures were considered. Heat storage in the inside air, the ground and the PBR were taken into account. The greenhouse lost heat due to conduction through the walls, roof and ground, and also due to infiltration (air exchange). Heat gains are mainly due to incoming solar radiation. The heat transfer between the PBR and the greenhouse was due to free convection (no air movement around the tubes), and radiation between the PBR and the ground and sky as shown in Figure 26.

The energy balance for the greenhouse air was expressed as the following:

$$
\rho_{\mathrm{AIR}} * \mathrm{~V}_{\mathrm{GH}} * \mathrm{Cp}_{\mathrm{AIR}} * \mathrm{dT}_{\mathrm{GH}} / \mathrm{dt}=\mathrm{Q}_{\mathrm{GHHG}}-\mathrm{Q}_{\mathrm{GHHLI}}-\mathrm{Q}_{\mathrm{GHHLC}}
$$

where $\rho_{\text {AIR }}$ was the density of air $\left(1.2 \mathrm{~kg} / \mathrm{m}^{3}\right) ; \mathrm{V}_{\mathrm{GH}}$ was the total greenhouse volume $\left(\mathrm{m}^{3}\right)$; $\mathrm{Cp}_{\mathrm{AIR}}$ was the specific heat capacity of water $(0.2811 \mathrm{Wh} / \mathrm{kg} . \mathrm{K}) ; \mathrm{dT}_{\mathrm{GH}}$ was the greenhouse air temperature change $(\mathrm{K})$ over a period of time $\mathrm{dt}$ (one hour); $\mathrm{Q}_{\mathrm{GHHG}}$ was the greenhouse heat gains due to solar radiation $(\mathrm{kW})$; $\mathrm{Q}_{\mathrm{GHHLI}}$ was the heat transfer due to infiltration $(\mathrm{kW})$, and $\mathrm{Q}_{\mathrm{GHHLC}}$ was the heat transfer due to conduction $(\mathrm{kW})$. The details of these individual components are explained in the upcoming sections. In this study, it was assumed that the greenhouse air was well mixed and had negligible temperature gradients. 


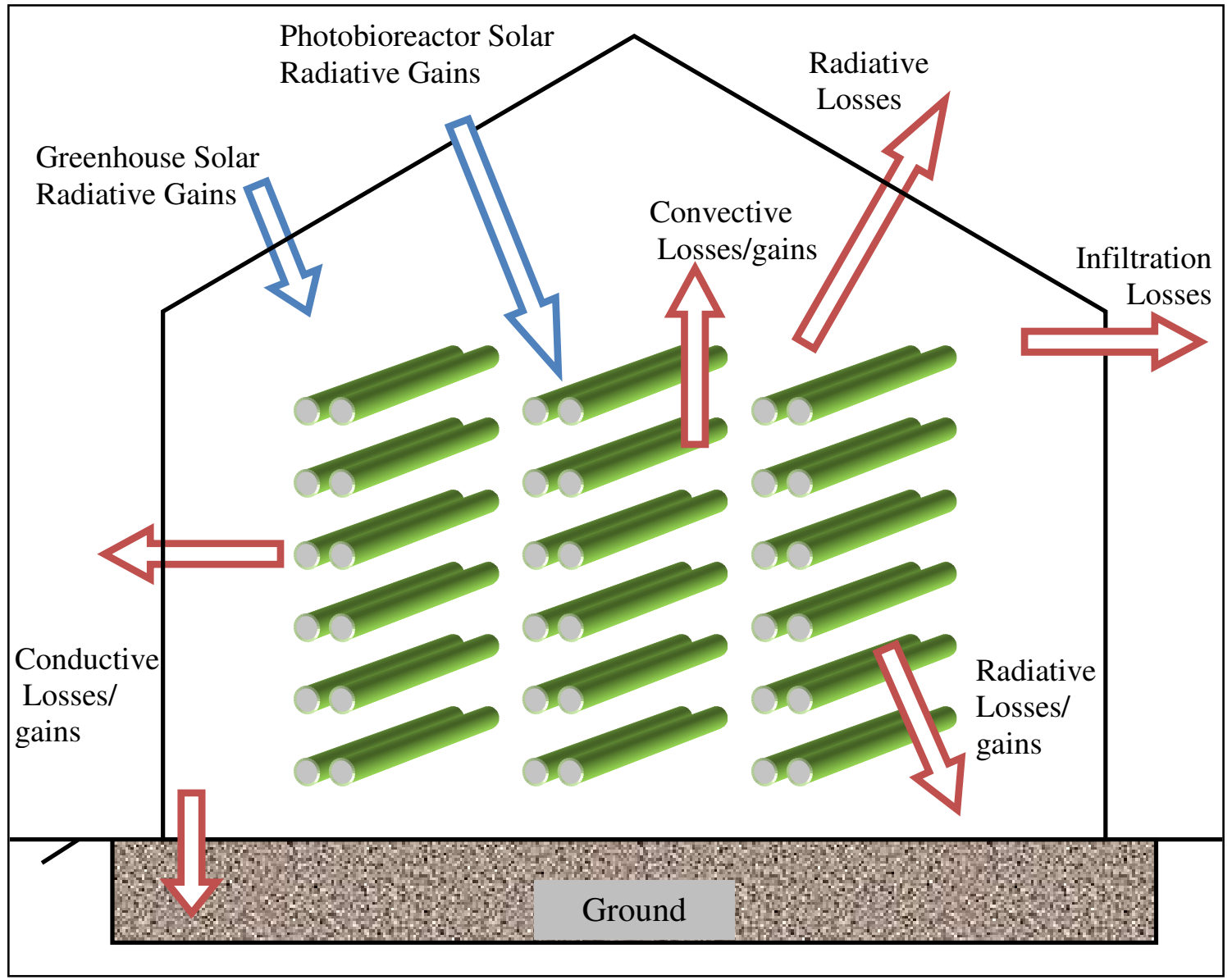

Figure 26. Heat losses/gains from an indoor PBR and a greenhouse.

The energy balance for the PBR in the greenhouse can be written as the following:

$$
\rho_{\mathrm{WAT}} * \mathrm{~V}_{\mathrm{PBR}} * \mathrm{Cp}_{\mathrm{WAT}} * \mathrm{dT}_{\mathrm{PBR}} / \mathrm{dt}=\mathrm{Q}_{\mathrm{GHTSRA}}-\mathrm{Q}_{\mathrm{GHHLR}}+\mathrm{Q}_{\mathrm{GHCL}}
$$

where $\rho_{\text {WAT }}$ was the density of water $\left(996 \mathrm{~kg} / \mathrm{m}^{3}\right) ; \mathrm{V}_{\mathrm{PBR}}$ was the total photobioreactor volume $\left(\mathrm{m}^{3}\right)$; C $\mathrm{p}_{\mathrm{WAT}}$ was the specific heat capacity of water $(1.16278 \mathrm{Wh} / \mathrm{kg} . \mathrm{K}) ; \mathrm{dT}_{\mathrm{PBR}}$ was the photobioreactor temperature change $(\mathrm{K})$ over a period of time dt (one hour); Q $_{\text {GHTSRA }}$ was the total solar radiation absorbed by the PBR in the greenhouse $(\mathrm{kW})$; $\mathrm{Q}_{\mathrm{GHHLR}}$ was the radiation exchange with the ground and sky $(\mathrm{kW})$, and $\mathrm{Q}_{\mathrm{GHCL}}$ was the 
heat transfer due to free convection between the inside air and PBR $(\mathrm{kW})$. The details of these individual components are explained in the upcoming sections.

A one-dimensional heat conduction equation was used in dealing with the energy balance of the floor for inside and outside conditions, by dividing the floor into three layers with the assumption of homogeneous thermal and hydraulic properties within each layer (Kindelan, 1980; Avissar and Mahrer, 1982; Arinze, 1984; Akhter, 1988, Yildiz, 1993). The ground was divided into three layers having thicknesses of $0.05,0.10$ and $0.50 \mathrm{~m}$ for the top, middle and bottom layers, respectively. It was assumed that the deep ground temperature was constant at $15{ }^{\circ} \mathrm{C}$ (Takakura et al., 1971). It was also assumed that the floor layers had identical thermal properties. Considering these assumptions, the energy balance equations for the three floor layers were written as:

Top layer:

$$
\mathrm{V}_{\mathrm{FL} 1} * \mathrm{cV}_{\mathrm{F}} * \mathrm{dT}_{\mathrm{FL} 1} / \mathrm{dt}=\mathrm{Q}_{\mathrm{TSRAF}}-\mathrm{Q}_{\mathrm{RLF}}-\mathrm{Q}_{\mathrm{CLTOPF}}
$$

Middle layer:

$$
\mathrm{V}_{\mathrm{FL} 2} * \mathrm{cV}_{\mathrm{F}} * \mathrm{dT}_{\mathrm{FL} 2} / \mathrm{dt}=\mathrm{Q}_{\mathrm{CLTOPF}}-\mathrm{Q}_{\mathrm{CLMIDF}}
$$

Bottom layer:

$$
\mathrm{V}_{\mathrm{FL} 3} * \mathrm{cv}_{\mathrm{F}} * \mathrm{dT}_{\mathrm{FL} 3} / \mathrm{dt}=\mathrm{Q}_{\mathrm{CLMIDF}}-\mathrm{Q}_{\mathrm{CLBOTF}}
$$

where $\mathrm{V}_{\mathrm{FL} 1}, \mathrm{~V}_{\mathrm{FL} 2}$, and $\mathrm{V}_{\mathrm{FL} 3}$ were the volumes of the three floor layers $\left(\mathrm{m}^{3}\right) ; \mathrm{cV}_{\mathrm{F}}$ was the specific volumetric heat capacity for the floor $\left(0.8139 \mathrm{kWh} / \mathrm{m}^{3} . \mathrm{K}\right) ; \mathrm{dT}_{\mathrm{FL} 1}, \mathrm{dT}_{\mathrm{FL} 2}$, and $\mathrm{dT}_{\mathrm{FL} 3}$ were the ground temperature changes $(\mathrm{K})$ for each layer over the time interval $\mathrm{dt}$ 
(one hour); $\mathrm{Q}_{\mathrm{TSRAF}}$ was the total solar radiation absorbed by the floor $(\mathrm{kW})$; $\mathrm{Q}_{\mathrm{RLF}}$ was the radiation exchange between the sky and floor $(\mathrm{kW})$; Q $\mathrm{CLTOPF}$ was the conductive transfer to the next floor layer $(\mathrm{kW})$; $\mathrm{Q}_{\mathrm{CLMIDF}}$ and $\mathrm{Q}_{\mathrm{CLBOTF}}$ were the conductive heat transfer components of the middle and bottom floor layers, respectively. These individual terms are explained further in the upcoming sections.

\subsubsection{General Equations}

For both inside and outside operations, general equations used in developing the simulation model are presented here.

\section{Julian Day}

For all the following equations, the Julian Day for a specific date of the year had to be determined. The Julian Day is the consecutive number of days in a year. Each year has therefore 365 Julian Days; January $1^{\text {st }}$ being the first day and December $31^{\text {st }}$ being the $365^{\text {th }}$ day. February $1^{\text {st }}$, for example, would be the $32^{\text {nd }}$ Julian Day.

\section{Solar Time}

The solar time is the time based on the apparent angular motion of the sun across the sky, with solar noon being the time the sun crosses the meridian of the observer (Duffie and Beckman, 2006). The solar time was calculated using the following equations (Iqbal, 1983):

$$
\text { STIME }=\text { TIME }+2.4+E
$$


with

$$
\begin{aligned}
\mathrm{E}= & 229.2 *(0.000075+0.001868 * \operatorname{Cos}(\mathrm{b} * \pi / 180) \\
& -0.032077 * \operatorname{Sin}(\mathrm{b} * \pi / 180)-0.014615 * \operatorname{Cos}(2 * \mathrm{~b} * \pi / 180) \\
& -0.04089 * \operatorname{Sin}(2 * \mathrm{~b} * \pi / 180))
\end{aligned}
$$

and

$$
\mathrm{b}=(\mathrm{JD}-1) * 360 / 365
$$

where STIME was the solar time on a specific day of the year; JD was the Julian Day number, TIME the time of that specific day, and $\mathrm{b}$ and $\mathrm{E}$ were calculated parameters.

\section{Solar Radiation / Sun Angle}

One major parameter of the model was the direction of the sunlight, and consequently the sun angle with respect to the PBR. Figure 27 shows main angles of solar radiation that were considered:

$\Phi=$ Latitude, the angular location north or south of the equator, north positive; $-90^{\circ}<=\Phi<=90^{\circ}$, for San Luis Obispo, CA, U.S.A.: $\Phi=35.23^{\circ}$.

$\delta=$ Declination, the angular position of the sun at solar noon (i.e., when the sun is on the local meridian) with respect to the plane of the equator, north positive; $-23.45^{\circ}<=\delta<=23.45^{\circ}$. 
$\beta=$ Slope, the angle between the plane of the surface in question and the horizontal; $0^{\circ}<=\beta<=180^{\circ}$. ( $\beta>90^{\circ}$ means that the surface has a downwardfacing component).

$\gamma=$ Surface azimuth angle, the deviation of the projection on a horizontal plane of the normal to the surface from the local meridian, with zero due south, east negative, and west positive; $-180^{\circ}<=\gamma<=180^{\circ}$.

$\omega=$ Hour angle, the angular displacement of the sun east or west of the local meridian due to rotation of the earth on its axis at $15^{\circ}$ per hour; morning negative, afternoon positive.

$\theta=$ Angle of incidence, the angle between the beam radiation on a surface and the normal to that surface.

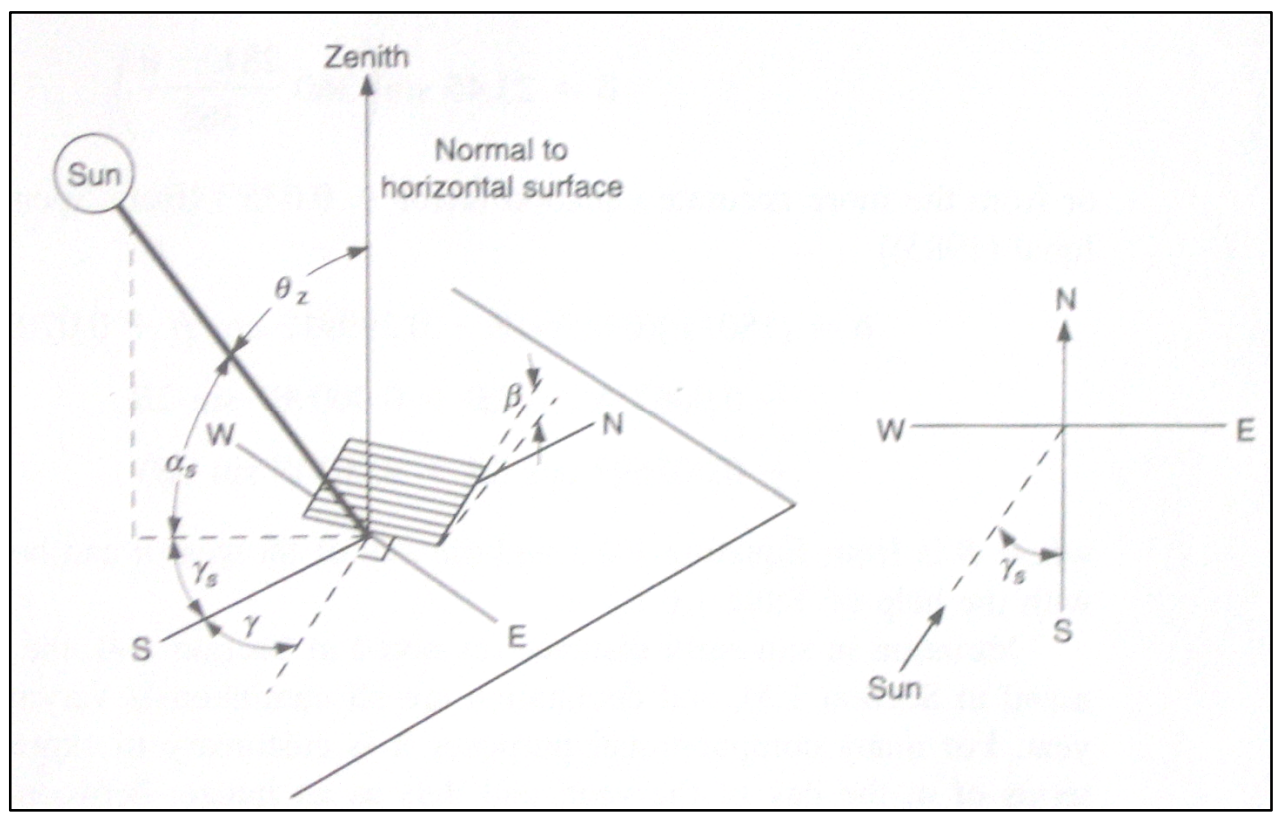

Figure 27. Zenith angle, slope, surface azimuth angle, and solar azimuth angle for a tilted surface. Source: After Duffie and Beckman, 2006. 
In this study, approximate equations developed by Cooper (1969) were used to determine the declination $(\delta)$, hour angle $(\omega)$, and angle of incidence $(\theta)$ :

$$
\begin{aligned}
\delta= & 23.45 * \operatorname{Sin}(360 *((284+\mathrm{JD}) / 365 * \pi / 180)) \\
\omega= & (\operatorname{STIME}-1200) / 100 * 15 \\
\theta= & \operatorname{Acos}(\operatorname{Sin}(\delta * \pi / 180) * \operatorname{Sin}(\Phi * \pi / 180) * \operatorname{Cos}(\beta * \pi / 180) \\
& -\operatorname{Sin}(\delta * \pi / 180) * \operatorname{Cos}(\Phi * \pi / 180) * \operatorname{Sin}(\beta * \pi / 180) \\
& * \operatorname{Cos}(\gamma * \pi / 180)+\operatorname{Cos}(\delta * \pi / 180) * \operatorname{Cos}(\Phi * \pi / 180) \\
& * \operatorname{Cos}(\beta * \pi / 180) * \operatorname{Cos}(\omega * \pi / 180)+\operatorname{Cos}(\delta * \pi / 180) \\
& * \operatorname{Sin}(\Phi * \pi / 180) * \operatorname{Sin}(\beta * \pi / 180) * \operatorname{Cos}(\gamma * \pi / 180) \\
& * \operatorname{Cos}(\omega * \pi / 180)+\operatorname{Cos}(\delta * \pi / 180) * \operatorname{Sin}(\beta * \pi / 180) \\
& * \operatorname{Sin}(\gamma * \pi / 180) * \operatorname{Sin}(\omega * \pi / 180))
\end{aligned}
$$

\section{Shading}

Shading (received solar radiation) of the PBR had a major impact on the performance of the system since the tubes shade each other differently throughout the day. An equation construct was developed, covering all possible shading options within every PBR column, and also through multiple columns standing next to each other. A shade factor (SF) as a function of the Julian Day (JD) and the time of the day (TIME) were derived and later multiplied by the incoming solar radiation. A critical sun angle (TC) existed, where the tubes shade each other (Figure 28). This angle was estimated by the following equation: 


$$
\mathrm{TC}=\operatorname{Atan}(\mathrm{dt} / \mathrm{d})
$$

where $\mathrm{d}$ was the tube diameter $(\mathrm{m})$; and $\mathrm{dt}$ was the distance between the tubes within one column (m).

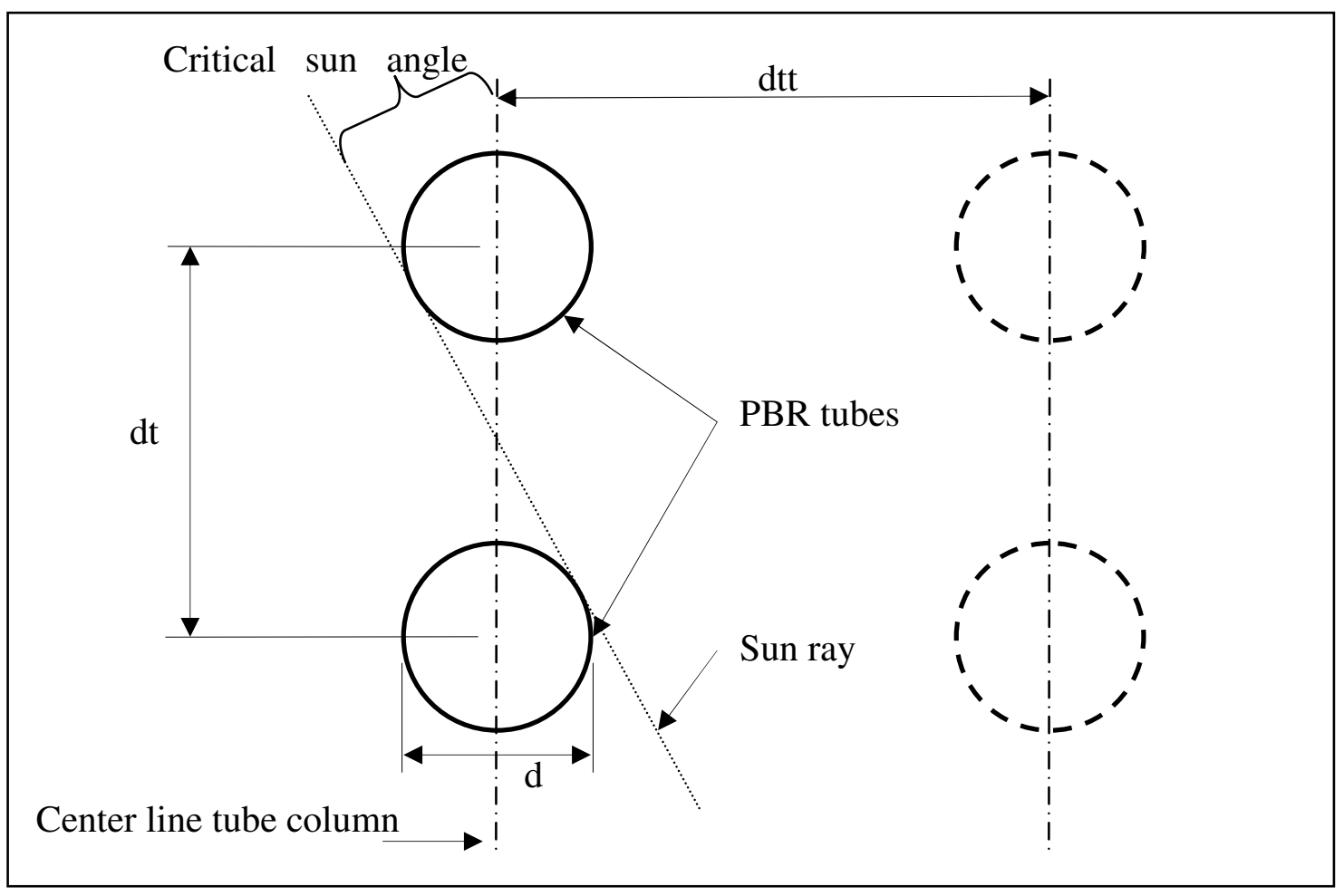

Figure 28. Photobioreactor tube configuration used in determining the critical sun angle, TC. The upper tube shades the lower tube. Source: After Mehlitz, 2008. 
For the angle of incidence $(\theta)$ greater than the critical angle (TC), no shading occurs. For an angle of incidence less than the critical angle, however, the following equation was used to determine the percentage of shading $\left(\mathrm{S}_{\mathrm{FR}}\right)$ :

$$
\mathrm{S}_{\mathrm{FR}}=(\mathrm{TC}-\theta) * 100 / \mathrm{TC}
$$

where $\mathrm{S}_{\mathrm{FR}}$ was the percentage of shading the first column received.

For the second to the $\mathrm{n}^{\text {th }}$ column, the illuminated height was calculated based on the following equation:

$$
\mathrm{H}_{\mathrm{ILL} 1}=\mathrm{x} / \mathrm{Tan}(\theta * \pi / 180)
$$

where $\mathrm{H}_{\mathrm{ILL} 1}$ was the illuminated height ( $\mathrm{m}$ from the top) of a column $\mathrm{n}$ within a field of multiple columns set-up parallel, and $\mathrm{x}$ was the distance between columns (m). The illuminated height should not be greater than the total height of tubes stacked over each other (i.e. total height (h) minus the distance of the tube next to the ground (b)). Turning this height into a percentage value of illuminated tubes, delivered the following equation:

$$
\mathrm{P}_{\mathrm{ERCNILL}}=\mathrm{H}_{\mathrm{ILL} 1} * 100 /(\mathrm{h}-\mathrm{b})
$$

where $P_{\text {ERCNILL }}$ was the percentage of tubes illuminated in the $\mathrm{n}^{\text {th }}$ column.

The remainder of tubes in column $\mathrm{n}$ was not illuminated fully, however, received solar rays through the gaps of tubes of the previous column:

$$
\mathrm{P}_{\text {ERCNSHAdE } 1}=\mathrm{ddr} *\left(100-\mathrm{P}_{\mathrm{ERCNILL}}\right)
$$


where $\mathrm{P}_{\text {ERCNSHADE1 }}$ was the shading percentage of tubes in a column $\mathrm{n}$ receiving solar rays through the gaps of the previous columns, expressed by the diameter to distance ratio, $\mathrm{ddr}=\mathrm{d} / \mathrm{dt}$.

Related to the critical sun angle, the total percentage of shading was expressed as:

$$
\mathrm{P}_{\text {ERCNShade }}=\mathrm{P}_{\mathrm{ERCNILL}} * \mathrm{P}_{\mathrm{ERCNILL}} / 100+\mathrm{P}_{\text {ERCNShade1 }}
$$

where $P_{\text {ERCNSHADE }}$ was the total percentage of shading received in column $n$.

Putting all columns together, and considering that the top tube of each column receives solar radiation without shading all day long, the final equation for total shading was developed:

$$
\mathrm{SF}=\left(\left(\left(\left(\mathrm{S}_{\mathrm{FR}}+(\mathrm{nc}-1) * \mathrm{P}_{\mathrm{ERCNSHADE}}\right) / \mathrm{nc}\right) *(\mathrm{t}-1)+1 / \mathrm{t}\right) / \mathrm{t}\right) / 100
$$

where SF was the total shading factor for the PBR; nc was the number of columns standing parallel to each other, and $t$ was the number of tubes per column.

Shading for the second half of the day (i.e. after solar noon) was treated the same as the first half of the day.

Since the simulation model had an option to handle twin tubes within one column (i.e. two tube rows were hold by one frame), the shading factor had to be adjusted to this case. Eqns. 3.14 through 3.20 were used to calculate the shading factor for one twin tube column $\left(\mathrm{SF}_{\mathrm{tt1}}\right)$. Therefore, the distance between two different columns (x) were substituted by the distance between the twin tubes (dtt). Then, the usual shading factor (SF) for the entire PBR setting was determined as described above. The shading factor 
for one twin tube column was then multiplied by the remaining illumination height $(1-\mathrm{SF})$. Adding this percentage to the usual shading factor resulted in an overall shading factor for twin tubes $\left(\mathrm{SF}_{\mathrm{tt}}\right)$. In general, the twin tubes will increase the total shading factor.

\section{Air / PBR Interface}

Further steps had to be considered to handle the air and PBR interface: The total incoming solar radiation were partly reflected or transmitted through the PBR tubes. Absorption of the glass or plexiglass tubes was neglected. The transmitted portion was partly absorbed by the growth media (algae water). The reflected portion was exposed to the other tubes consequently. Figure 29 shows the relationships between total incoming beams and refraction at a surface of a different media. The refraction angle $\left(\theta_{2}\right)$ was calculated by using Snell's Law (Dietz, 1963):

$$
\theta_{2}=\operatorname{Asin}\left(\left(\mathrm{IR}_{\mathrm{AIR}} / \mathrm{IR}_{\mathrm{TUBE}}\right) * \operatorname{Sin}(\theta * \pi / 180)\right) / \pi * 180
$$

where $\theta_{2}$ was the refraction angle, $I_{\mathrm{AIR}}$ the refraction index of air, $\mathrm{IR}_{\mathrm{TUBE}}$ was the refraction index of the tube; and $\theta$ was the angle of the total incoming solar radiation. 


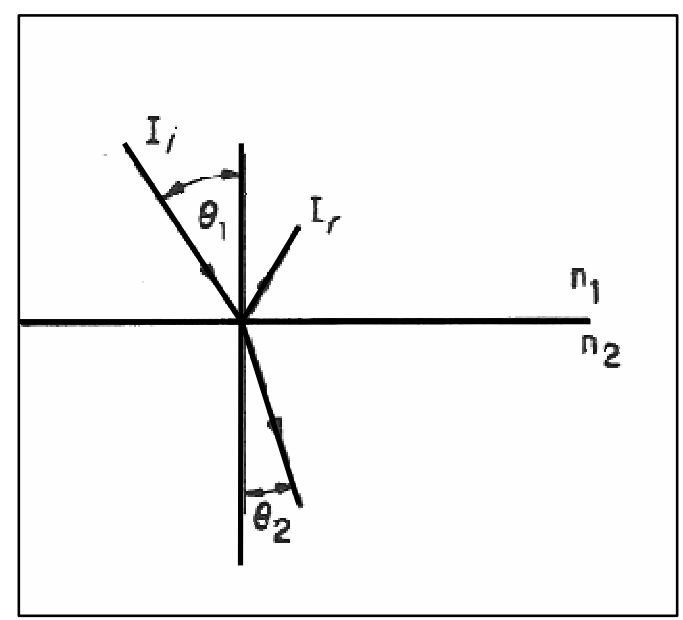

Figure 29. Angles of incidence and refraction in media with refractive indices n1 and n2. Source: After Duffie and Beckman, 2006.

In order to determine how much radiation was transmitted through the tube and algae water, the transmittance of the tube and water was multiplied:

$$
\tau=\tau_{\mathrm{T}} * \tau_{\mathrm{A}}
$$

where $\tau$ was the total transmittance $(\%) ; \tau_{\mathrm{T}}$ was the transmittance of the tube (\%); and $\tau_{\mathrm{A}}$ was the transmittance of the algae water $(\%)$.

The transmittance of the tube was a function of the parallel and perpendicular reflection of the tube in accordance with Fresnel's equation (Duffie and Beckman, 2006):

$$
\tau_{\mathrm{T}}=0.5 *\left(\left(1-\mathrm{R}_{\mathrm{PARA}}\right) /\left(1+\mathrm{R}_{\mathrm{PARA}}\right)+\left(1-\mathrm{R}_{\mathrm{PERP}}\right) /\left(1+\mathrm{R}_{\mathrm{PERP}}\right)\right)
$$

where $R_{\text {PARA }}$ was the parallel reflection of the tube $(\%)$; and $R_{\text {PERP }}$ was the perpendicular reflection of the tube (\%). 
Consequently, the parallel and perpendicular reflections were calculated as follows:

$$
\begin{aligned}
& \left.\mathrm{R}_{\text {PARA }}=\left(\operatorname{Tan}\left(\theta_{2}-\theta\right) * \pi / 180\right)^{2}\right) /\left(\left(\operatorname{Tan}\left(\theta+\theta_{2}\right) * \pi / 180\right)^{2}\right) \\
& \operatorname{R}_{\text {PERP }}=\left((\operatorname{Sin}((\theta 2-\theta) * \pi / 180))^{2}\right) /\left((\operatorname{Sin}((\theta+\theta 2) * \pi / 180))^{2}\right)
\end{aligned}
$$

where $\theta$ and $\theta_{2}$ were the incoming and refracted angles at the surface, respectively.

The total reflection $\left(\mathrm{R}_{\mathrm{EFT}}\right)$ of the tube was calculated using the following equation with the assumption that the mean angle the beams hit the tubes was $45^{\circ}$ :

$$
\mathrm{R}_{\mathrm{EFT}}=0.5 *\left(\mathrm{R}_{\mathrm{PERP}}+\mathrm{R}_{\mathrm{PARA}}\right)
$$

The transmittance of the algae water was calculated using Bouguer's law (Duffie and Beckman, 2006), which is based on the assumption that the absorbed radiation was proportional to the local intensity in the medium and the distance the radiation has traveled in the medium:

$$
\mathrm{dI}=-\mathrm{I} * \mathrm{Kdx}
$$

where $\mathrm{K}$ was the proportionality constant, the extinction factor (EF), which is assumed to be a constant in the solar spectrum (Duffie and Beckman, 2006). Integrating along the actual pathlength (PL) in the medium (i.e. from zero to PL/cos $\theta_{2}$ ) yielded:

$$
\tau_{\mathrm{A}}=\operatorname{Exp}\left(-\mathrm{EF} * \mathrm{PL} / \operatorname{Cos}\left(\theta_{2} * \pi / 180\right)\right)
$$

The pathlength was assumed to be approximately $60 \%$ of the tube diameter ( $\mathrm{d}$ in $\mathrm{m}$ ). 
In Eqn. 3.28, the extinction factor (EF) needed to be calculated from experimental data:

$$
\mathrm{EF}=-\operatorname{Ln}\left(\tau_{\mathrm{AP}}\right) / \mathrm{D}_{\mathrm{AP}}
$$

where $\tau_{\mathrm{AP}}$ was the transmittance $(\%)$ of an algae probe examined in a spectrophotometer using a specific testing vial with a specific diameter $\mathrm{D}_{\mathrm{AP}}(\mathrm{m})$. For this study, a mean transmittance (optimal density for algae) of 0.3 as well as a vial with a diameter of $0.00127 \mathrm{~m}$ was used.

\subsubsection{Outdoor Photobioreactor}

As previously described, three major heat transfer modes occur in outdoor conditions: Heat gain due to absorbed solar radiation ( $\left.\mathrm{Q}_{\mathrm{TSRA}}\right)$, heat loss due to convection $\left(\mathrm{Q}_{\mathrm{OSCL}}\right)$, and heat loss due to radiation with the sky and ground $\left(\mathrm{Q}_{\mathrm{OS}}\right)$. The total solar radiation absorbed was calculated using the following equations:

$$
\begin{aligned}
& \mathrm{I}_{\mathrm{T}}=(1-\mathrm{SF}) * \mathrm{I}_{\mathrm{S}}+\mathrm{I}_{\mathrm{S}} * \mathrm{R}_{\mathrm{GROUND}}+\mathrm{I}_{\mathrm{S}} * \mathrm{R}_{\mathrm{EFT}}+\mathrm{I}_{\mathrm{S}} * \tau \\
& \mathrm{Q}_{\mathrm{TSRA}}=\mathrm{I}_{\mathrm{T}} * \mathrm{~A}_{\mathrm{TSURPRO}} *\left(1-\tau-\mathrm{R}_{\mathrm{ALGAE}}\right) / 1000
\end{aligned}
$$

where $I_{T}$ was the total solar radiation reaching the tubes $\left(\mathrm{W} / \mathrm{m}^{2}\right)$, consisting of four components: The first component was the solar radiation, $\mathrm{I}_{\mathrm{S}}\left(\mathrm{W} / \mathrm{m}^{2}\right)$, at a specific time. The second was the reflected solar radiation from the ground $\left(\mathrm{W} / \mathrm{m}^{2}\right)$, and the reflectivity of the ground, $\mathrm{R}_{\mathrm{GROUND}}$, was assumed to be 0.2 . The third one was the reflected solar radiation from the tubes $\left(\mathrm{W} / \mathrm{m}^{2}\right)$, and the forth component was the transmitted radiation from the tubes $\left(\mathrm{W} / \mathrm{m}^{2}\right)$. 
Then, the amount of absorbed solar radiation, $\mathrm{Q}_{\text {TSRA, }}$ was determined as the product of the total solar radiation $\left(\mathrm{W} / \mathrm{m}^{2}\right)$, the total projected surface area of the PBR, $\mathrm{A}_{\text {TSURPRO }}\left(\mathrm{m}^{2}\right)$, and the absorptivity of the algae water which was assumed to be 1 minus the total transmittance $(\tau)$ minus the reflection of single algae cells $\left(\mathrm{R}_{\mathrm{ALGAE}}\right.$ assumed to be 0.05 ). Finally, the product was divided by 1000 to convert the dimension to $\mathrm{kW}$.

Heat losses due to convection were calculated for the forced convection conditions since the wind was the main driver for the heat losses. According to Newton's law of cooling, the heat transfer q can be expressed as:

$$
\mathrm{Q}_{\text {conv }}=\mathrm{h} * \mathrm{~A} * \Delta \mathrm{T}
$$

where $\mathrm{h}$ was the heat transfer coefficient $\left(\mathrm{W} / \mathrm{m}^{2} . \mathrm{K}\right)$; A was the area $\left(\mathrm{m}^{2}\right)$; and $\Delta \mathrm{T}$ was the temperature difference between the tube and ambient air (K). For the PBR convective heat transfer, the equation was modified to:

$$
\operatorname{QOSCL}_{\mathrm{HTC}}=\mathrm{h}_{\mathrm{HSUR}} *\left(\mathrm{~T}_{\mathrm{ALG}}-\mathrm{T}_{\mathrm{OS}}\right) / 1000
$$

where QoscL was the total convective heat transfer $(\mathrm{kW})$; $\mathrm{h}_{\mathrm{HTC}}$ was the heat transfer coefficient $\left(\mathrm{W} / \mathrm{m}^{2} . \mathrm{K}\right) ; \mathrm{A}_{\mathrm{TSUR}}$ was the total outside surface of the PBR tubes $\left(\mathrm{m}^{2}\right) ; \mathrm{T}_{\mathrm{ALG}}$ was the PBR or algae temperature $(\mathrm{K})$; and $\mathrm{T}_{\mathrm{OS}}$ was the outside temperature $(\mathrm{K})$. To convert QoscL from W to $\mathrm{kW}$, the product was divided by 1000. In Eqn. 3.33, the heat transfer coefficient, $\mathrm{h}_{\mathrm{HTC}}$, was calculated using the following equation (Incropera et al., 2007):

$$
\mathrm{h}_{\mathrm{HTC}}=\mathrm{Nu} * \mathrm{k} / \mathrm{d}
$$


where $\mathrm{Nu}$ was the Nusselt number; $\mathrm{d}$ was the tube diameter (m); and $\mathrm{k}$ was an air constant (0.0263 W/m.K) (Vargaftik, 1975).

The value of the Reynolds number ( $\mathrm{Re})$ provided the information about the flow conditions (i.e. laminar or tubulent flow over a tubular surface), and it was calculated as follows (Incropera et al., 2007):

$$
\mathrm{Re}=\mathrm{WS} * \mathrm{~d} / \mathrm{v}
$$

where WS was the wind speed $(\mathrm{m} / \mathrm{s})$; and $\mathrm{v}$ was an air property. With a maximum wind speed of $5.2 \mathrm{~m} / \mathrm{s}$ obtained from the weather file, a tube diameter of $0.003 \mathrm{~m}$, and $\mathrm{v}$ being $0.00001589 \mathrm{~m}^{2} / \mathrm{s}$ at room temperature (Vargaftik, 1975), the Reynolds number resulted in 9820, which was smaller than $10^{7}$, hence a laminar flow condition was assumed (Incropera et al., 2007).

For laminar flow, the following Nusselt equation was used (Incropera et al., 2007):

$$
\mathrm{Nu}=\mathrm{c} * \operatorname{Re}^{\mathrm{m}} * \operatorname{Pr}^{(1 / 3)}
$$

where $\mathrm{c}$ and $\mathrm{m}$ were constants; for the range of Reynolds numbers for the given conditions, their numerical values were 0.193 and 0.618 , respectively (Incropera et al., 2007). The Prandtl number (Pr) for air at $300 \mathrm{~K}$ was 0.707 (Vargaftik, 1975). The Reynolds number was calculated each time as a function of the wind speed. 
The radiative heat transfer with the sky and ground were determined using the simplified radiation equations for an object in a large enclosure (in this study, small diameter tubes under the sky and exposed to the ground) (Incropera et al., 2007):

$$
\mathrm{Q}_{\mathrm{rad}}=\varepsilon * \mathrm{~A} * \sigma *\left(\mathrm{~T}_{1}^{4}-\mathrm{T}_{2}^{4}\right)
$$

where $\mathrm{Q}_{\mathrm{rad}}$ was the radiative heat transfer $(\mathrm{W}) ; \varepsilon$ was the emissivity of the small surface; $\sigma$ was the Stefan-Boltzman constant $\left(5.67 * 10^{-8} \mathrm{~W} / \mathrm{m}^{2} \cdot \mathrm{K}^{4}\right)$; and $\mathrm{T}_{1}$ and $\mathrm{T}_{2}$ were the temperatures of the relevant surfaces $(\mathrm{K})$. For the outside PBR, Eqn. 3.37 was modified to:

$$
\begin{aligned}
& \mathrm{Q}_{\mathrm{SKY}}=\varepsilon * \mathrm{~A}_{\mathrm{GH}} * \sigma *\left(\mathrm{~T}_{\mathrm{ALG}}{ }^{4}-\mathrm{T}_{\mathrm{SKY}}{ }^{4}\right) / 1000 \\
& \mathrm{Q}_{\mathrm{FLOOR}}=\varepsilon * \mathrm{~A}_{\mathrm{GH}} * \sigma *\left(\mathrm{~T}_{\mathrm{ALG}}{ }^{4}-\mathrm{T}_{\mathrm{FLOOR}}{ }^{4}\right) / 1000 \\
& \mathrm{Q}_{\mathrm{OS}}=0.5 * \mathrm{Q}_{\mathrm{SKY}}+0.5 * \mathrm{Q}_{\mathrm{FLOOR}}
\end{aligned}
$$

where it was assumed that the total outside radiative heat exchange (Qos) was $50 \%$ with the sky $\left(\mathrm{Q}_{\mathrm{SKY}}\right)$ and $50 \%$ with the ground $\left(\mathrm{Q}_{\mathrm{FLOOR}}\right)$. $\varepsilon$ was the emissivity of the glass (or plexiglass) tubes, which was 0.9 (Vargaftik, 1975); $\mathrm{A}_{\mathrm{GH}}$ was the total surface area of the greenhouse $\left(\mathrm{m}^{2}\right) ; \mathrm{T}_{\mathrm{ALG}}$ was the temperature of the PBR tubes $(\mathrm{K}) ; \mathrm{T}_{\mathrm{FLOOR}}$ was the floor temperature $(\mathrm{K})$; and $\mathrm{T}_{\mathrm{SKY}}$ was the sky temperature $(\mathrm{K})$.

The sky temperature was determined as a function of the ambient air temperature as defined by Swinbank (1963):

$$
\mathrm{T}_{\mathrm{SKY}}=0.0552 * \mathrm{~T}_{\mathrm{OS}}^{1.5}
$$

where $\mathrm{T}_{\mathrm{OS}}$ was the outside air temperature $(\mathrm{K})$. 
The heat exchange done by the floor layers were calculated using the following equations:

$$
\mathrm{Q}_{\mathrm{TSRAF}}=\mathrm{A}_{\mathrm{GHSUR}} * \mathrm{I}_{\mathrm{S}} * \alpha_{\mathrm{FLOOR}} / 1000
$$

where $\mathrm{Q}_{\mathrm{TSRAF}}$ was the total solar radiation absorbed by the floor $(\mathrm{kW})$; $\mathrm{A}_{\mathrm{GHSUR}}$ was the total surface area of the floor equal to the area needed for a greenhouse (indoor) operation $\left(\mathrm{m}^{2}\right)$; IS was the incoming solar radiation $\left(\mathrm{W} / \mathrm{m}^{2}\right)$; and $\alpha_{\mathrm{FLOOR}}$ was the absorptivity of the floor layer.

The conductive heat transfers between floor layers were calculated using the following equations:

$$
\begin{aligned}
& \mathrm{Q}_{\mathrm{CLTOPF}}=\mathrm{K}_{\mathrm{FLOOR}} * \mathrm{~A}_{\mathrm{GHSUR}} *\left(\mathrm{~T}_{\mathrm{FLOOR}}-\mathrm{T}_{\mathrm{FLOORMID}}\right) / \mathrm{D}_{\mathrm{FLOOR} 1} \\
& \mathrm{Q}_{\mathrm{CLMIDF}}=\mathrm{K}_{\mathrm{FLOOR}} * \mathrm{~A}_{\mathrm{GHSUR}} *\left(\mathrm{~T}_{\mathrm{FLOORMID}}-\mathrm{T}_{\mathrm{FLOORBOT}}\right) / \mathrm{D}_{\mathrm{FLOOR} 2} \\
& \mathrm{Q}_{\mathrm{CLBOTF}}=\mathrm{K}_{\mathrm{FLOOR}} * \mathrm{~A}_{\mathrm{GHSUR}} *\left(\mathrm{~T}_{\mathrm{FLOORBOT}}-\mathrm{T}_{\mathrm{G}}\right) / \mathrm{D}_{\mathrm{FLOOR} 3}
\end{aligned}
$$

where $\mathrm{Q}_{\mathrm{CLTOPF}}, \mathrm{Q}_{\mathrm{CLMIDF}}$ and $\mathrm{Q}_{\mathrm{CLBOTF}}$ were the heat fluxes of the top, middle and bottom layers, respectively $(\mathrm{kW}) ; \mathrm{K}_{\mathrm{FLOOR}}$ was the thermal conductivity of floor layers $(1.75$ $\mathrm{W} / \mathrm{m} . \mathrm{K}$ ) (Arinze et al., 1984); $\mathrm{T}_{\mathrm{FLOOR}}$ was the floor temperature (K), $\mathrm{T}_{\mathrm{FLOORMID}}$ was the middle layer temperature $(\mathrm{K}), \mathrm{T}_{\mathrm{FLOORBOT}}$ was the bottom layer temperature $(\mathrm{K})$, and $\mathrm{T}_{\mathrm{G}}$ was the ground temperature $(\mathrm{K})$; $\mathrm{D}_{\text {FLOOR1, }} \mathrm{D}_{\mathrm{FLOOR} 2}$ and $\mathrm{D}_{\mathrm{FLOOR} 3}$ were the layer thicknesses for the top, middle and bottom layers, respectively (m). 


\section{Solving differential equations}

The ordinary differential equations, represented in a general form in Eqn. 3.46 with an initial value, were solved using Euler's method (Eqn. 3.47).

$$
\begin{aligned}
& \mathrm{dX} / \mathrm{dt}=f(\mathrm{X}, \mathrm{t}) \\
& \mathrm{X}(0)=\mathrm{X}_{0} \\
& \mathrm{X}_{\mathrm{j}+1}=\mathrm{X}_{\mathrm{j}}+f\left(\mathrm{X}_{\mathrm{j}}, \mathrm{t}_{\mathrm{j}}\right) * \Delta \mathrm{t}
\end{aligned}
$$

Eqn. 3.47 was used to advance in time and to obtain a new solution at the next time step. In this study, a time interval of one hour was used. Because of the fairly large time constants of the heat storage elements, no stability problems were observed using Euler's method.

With the knowledge of heat fluxes through all modes, the temperature of the system was calculated as follows, taking the heat storage term into account:

$$
\mathrm{Q}=\rho * \mathrm{~V} * \mathrm{Cp} * \mathrm{dT} / \mathrm{dt}
$$

where $\mathrm{Q}$ was the total net energy input $(\mathrm{kW}) ; \rho$ was the density $\left(\mathrm{kg} / \mathrm{m}^{3}\right) ; \mathrm{V}$ was the system's volume $\left(\mathrm{m}^{3}\right)$; Cp was the specific heat capacity $(\mathrm{kW} / \mathrm{kg} . \mathrm{K})$; dT the temperature change $(\mathrm{K})$; and dt was the time interval in which the temperature change dT occurred.

The floor temperature was calculated taking the heat storage term into account:

$$
\mathrm{HS}_{\mathrm{TOPF}}=\mathrm{A}_{\mathrm{GHSUR}} * \mathrm{D}_{\mathrm{FLOOR} 1} * \mathrm{Cpv}_{\mathrm{FLOOR}} *\left(\mathrm{~T}_{\mathrm{FLOORNEW}}-\mathrm{T}_{\mathrm{FLOOR}}\right)
$$


where $\mathrm{HS}_{\mathrm{TOPF}}$ was the heat storage term of the top layer (equal to total net heat flux) in $\mathrm{kW}$; $\mathrm{A}_{\mathrm{GHSUR}}$ was the total floor surface area $\left(\mathrm{m}^{2}\right)$; $\mathrm{D}_{\text {FLOOR1 }}$ was the thickness of the top layer (m); $\mathrm{Cpv}_{\mathrm{FLOOR}}$ was the volumetric heat capacity of the floor $\left(2.93 * 10^{6} \mathrm{~J} / \mathrm{m}^{3} . \mathrm{C}\right)$ (Takakura et al., 1971); $\mathrm{T}_{\text {FLOORNEW }}$ was the new floor temperature; and $\mathrm{T}_{\text {FLOOR }}$ was the floor temperature at the previous integration step as discussed above. A time interval (dt) of one hour was used.

Reorganizing Eqn. 3.49 resulted in the equation used to calculate the new floor temperature, $\mathrm{T}_{\mathrm{FLOORNEW}}$ :

$$
\mathrm{T}_{\mathrm{FLOORNEW}}=\mathrm{HS}_{\mathrm{TOPF}} /\left(\mathrm{A}_{\mathrm{GHSUR}} * \mathrm{D}_{\mathrm{FLOOR} 1} * \mathrm{Cpv}_{\mathrm{FLOOR}}\right)+\mathrm{T}_{\mathrm{FLOOR}}
$$

For the photobioreactor, the equation was modified to:

$$
\mathrm{Q}_{\mathrm{TOSHR}}=\rho_{\mathrm{WAT}} * \mathrm{~V}_{\mathrm{PBR}} * \mathrm{Cp}_{\mathrm{WAT}} *\left(\mathrm{~T}_{\mathrm{ALGNEW}}-\mathrm{T}_{\mathrm{ALG}}\right)
$$

where $\mathrm{Q}_{\mathrm{TOSHR}}$ was the total energy balance of the photobioreactor system in one hour time interval $(\mathrm{kW})$; $\rho_{\text {WAT }}$ was the density of water $\left(\mathrm{kg} / \mathrm{m}^{3}\right) ; \mathrm{V}_{\mathrm{PBR}}$ was the total PBR volume $\left(\mathrm{m}^{3}\right)$; C p $_{\text {WAT }}$ was the specific heat of water (4186 J/kg.C); $\mathrm{T}_{\mathrm{ALGNEW}}$ was the new PBR temperature $(\mathrm{K})$, whereas $\mathrm{T}_{\mathrm{ALG}}$ was the PBR temperature at the previous step. The time interval (dt) was one hour. Reorganizing Eqn. 3.51 resulted in the following equation used to calculate the new PBR temperature, $\mathrm{T}_{\text {ALGNEW: }}$

$$
\mathrm{T}_{\mathrm{ALGNEW}}=\mathrm{Q}_{\mathrm{TOSHR}}\left(\rho_{\mathrm{WAT}} * \mathrm{~V}_{\mathrm{PBR}} * \mathrm{cp}_{\mathrm{WAT}}\right)+\mathrm{T}_{\mathrm{ALG}}
$$




\subsubsection{Indoor Photobioreactor}

The inside air of the greenhouse had a major influence on the PBR temperature itself. Hence, the inside air temperature was calculated first and then used to calculate the PBR temperature. At the greenhouse interfaces, three heat fluxes occurred: The heat gain due to solar radiation $\left(\mathrm{Q}_{\mathrm{GHHG}}\right)$, the heat loss due to infiltration (air exchange) $\left(\mathrm{Q}_{\mathrm{GHHL}}\right)$, and the heat transfer due to conduction through the walls and roof ( $\left.\mathrm{Q}_{\mathrm{GHHLC}}\right)$.

The gained heat due to solar radiation was estimated by using the following equation in accordance with Aldrich and Bartok (1992):

$$
\mathrm{Q}_{\mathrm{GHHG}}=\tau_{\mathrm{GH}} * \mathrm{I}_{\mathrm{S}} *\left(\mathrm{~A}_{\mathrm{GH}}+\mathrm{A}_{\mathrm{TSURPRO}} *(1-\mathrm{SF})\right) / 1000
$$

where $\mathrm{Q}_{\mathrm{GHHG}}$ was the greenhouse heat gain $(\mathrm{kW})$; $\tau_{\mathrm{GH}}$ was the transmissivity of the greenhouse walls of 94\% (Aldrich and Bartok, 1992); Is was the hourly solar radiation $\left(\mathrm{W} / \mathrm{m}^{2}\right) ; \mathrm{A}_{\mathrm{GH}}$ was the total greenhouse floor surface area $\left(\mathrm{m}^{2}\right) ; \mathrm{A}_{\text {TSURPRO }}$ was the projected PBR surface area $\left(\mathrm{m}^{2}\right)$; and SF was the shading factor of the PBR at each specific time of the day $(\%)$.

The largest heat transfer component was by conduction through the greenhouse cover. Conductive heat transfer was estimated by the following equation (Aldrich and Bartok, 1992):

$$
\mathrm{Q}_{\mathrm{GHHLC}}=\mathrm{A}_{\mathrm{GHGSUR}} * \mathrm{U}_{\mathrm{G}} *\left(\mathrm{~T}_{\mathrm{GH}}-\mathrm{T}_{\mathrm{OS}}\right)+\mathrm{A}_{\mathrm{GH}} * \mathrm{U}_{\mathrm{FL}} *\left(\mathrm{~T}_{\mathrm{GH}}-\mathrm{T}_{\mathrm{OS}}\right)
$$

where $\mathrm{Q}_{\mathrm{GHHLC}}$ was the greenhouse conductive heat transfer $(\mathrm{kW})$; $\mathrm{A}_{\mathrm{GHGSUR}}$ was the total

greenhouse cover surface area $\left(\mathrm{m}^{2}\right)$; $\mathrm{U}_{\mathrm{G}}$ was the heat transfer coefficient for the 
greenhouse cover $\left(0.00628 \mathrm{KW} / \mathrm{m}^{2} . \mathrm{K}\right)$; and $\mathrm{U}_{\mathrm{FL}}$ for the floor $\left(0.000872 \mathrm{KW} / \mathrm{m}^{2} . \mathrm{K}\right)$ (Aldrich and Bartok, 1992). $\mathrm{T}_{\mathrm{GH}}$ was the greenhouse temperature $(\mathrm{K})$; and $\mathrm{T}_{\mathrm{OS}}$ was the outside temperature at each specific time $(\mathrm{K})$.

The greenhouse infiltration losses were estimated as followed (Aldrich and Bartok, 1992):

$$
\mathrm{Q}_{\mathrm{GHHLI}}=0.02 * \mathrm{AEH} * \mathrm{~V}_{\mathrm{GH}} *\left(\mathrm{~T}_{\mathrm{GH}}-\mathrm{T}_{\mathrm{OS}}\right) * 0.0002928
$$

where $\mathrm{Q}_{\mathrm{GHHLI}}$ was the greenhouse heat loss due to infiltration $(\mathrm{kW})$; AEH was the air exchanges per hour (assumed to be $1.5 \mathrm{per} \mathrm{hr}$ ); $\mathrm{V}_{\mathrm{GH}}$ was the greenhouse volume $\left(\mathrm{m}^{3}\right)$; and 0.0002928 was a conversion factor used to convert Btu/h into $\mathrm{kW}$.

With the knowledge of all the heat fluxes, the temperature response of the greenhouse air was calculated taking the heat storage term into account and following the approach described in Eqns. 3.46 through 3.48:

$$
\mathrm{T}_{\mathrm{GHNEW}}=\mathrm{Q}_{\mathrm{GHHLG}} /\left(\rho_{\mathrm{AIR}} * \mathrm{~V}_{\mathrm{GH}} * \mathrm{Cp}_{\mathrm{AIR}}\right)+\mathrm{T}_{\mathrm{GH}}
$$

where $\mathrm{T}_{\mathrm{GHNEW}}$ was the new greenhouse temperature $(\mathrm{K})$; $\mathrm{Q}_{\mathrm{GHHLG}}$ was the total net energy input $(\mathrm{kW}) ; \rho_{\mathrm{AIR}}$ was the density of air $\left(1.2 \mathrm{~kg} / \mathrm{m}^{3}\right) ; \mathrm{V}_{\mathrm{GH}}$ was the total greenhouse volume $\left(\mathrm{m}^{3}\right) ; \mathrm{Cp}_{\mathrm{AIR}}$ was the specific heat capacity of air $(1.012 \mathrm{~J} / \mathrm{g} . \mathrm{C})$; and $\mathrm{T}_{\mathrm{GH}}$ was the greenhouse temperature of the previous integration step. The time interval (dt) was one hour. 
As previously described, three heat transfer modes were considered for the inside photobioreactor. Heat gain due to absorbed solar radiation $\left(\mathrm{Q}_{\mathrm{GHTSRA}}\right)$; convective heat exchange $\left(\mathrm{Q}_{\mathrm{GHCL}}\right)$; and radiative heat exchange with the sky and the ground $\left(\mathrm{Q}_{\mathrm{GHHLR}}\right)$.

The total solar radiation absorbed, $\mathrm{I}_{\mathrm{T}}$, was calculated using the following equations:

$$
\begin{aligned}
& \mathrm{Q}_{\mathrm{GHTSRA}}=\tau_{\mathrm{GH}} * \mathrm{Q}_{\mathrm{TSRA}} \\
& \mathrm{Q}_{\mathrm{TSRA}}=\mathrm{I}_{\mathrm{T}} * \mathrm{~A}_{\mathrm{TSURPRO}} *\left(1-\tau-\mathrm{R}_{\mathrm{ALGAE}}\right) / 1000 \\
& \mathrm{I}_{\mathrm{T}}=(1-\mathrm{SF}) * \mathrm{I}_{\mathrm{S}}+\mathrm{I}_{\mathrm{S}} * \mathrm{R}_{\mathrm{GROUND}}+\mathrm{I}_{\mathrm{S}} * \mathrm{R}_{\mathrm{EFT}}+\mathrm{I}_{\mathrm{S}} * \tau
\end{aligned}
$$

where $\mathrm{Q}_{\mathrm{GHTSR}}$ was the total solar radiation absorbed by the PBR in the greenhouse $(\mathrm{kW}) ; \tau_{\mathrm{GH}}$ was the transmissivity of the greenhouse cover of $94 \%$ (Aldrich and Bartok, 1992); $Q_{\text {TSRA }}$ and $I_{T}$ were the same as previously calculated for outdoor conditions in Eqn. 3.30 and 3.31.

Heat fluxes due to convection were calculated using equations for free (buoyancy) convection, since no wind and hardly any air movement occurred around the tubes. Newton's law of cooling (Eqn. 3.32) was modified to calculate the convective heat transfer for the indoor photobioreactor:

$$
\mathrm{Q}_{\mathrm{GHCL}}=\mathrm{h}_{\mathrm{HTC}} * \mathrm{~A}_{\mathrm{TSUR}} *\left(\mathrm{~T}_{\mathrm{ALG}}-\mathrm{T}_{\mathrm{GH}}\right) / 1000
$$

Where $\mathrm{Q}_{\mathrm{GHCL}}$ was the total convective heat transfer $(\mathrm{kW}) ; \mathrm{h}_{\mathrm{HTC}}$ the heat transfer coefficient $\left(\mathrm{W} / \mathrm{m}^{2} . \mathrm{K}\right)$; $\mathrm{A}_{\mathrm{TSUR}}$ was the total outside surface area of the PBR tubes $\left(\mathrm{m}^{2}\right)$; $\mathrm{T}_{\mathrm{ALG}}$ was the $\mathrm{PBR}$ or algae temperature $(\mathrm{K})$; and $\mathrm{T}_{\mathrm{GH}}$ was the greenhouse air temperature 
previously calculated $(\mathrm{K})$. To convert $\mathrm{Q}_{\mathrm{GHCL}}$ from $\mathrm{W}$ to $\mathrm{kW}$, the product was divided by 1000.

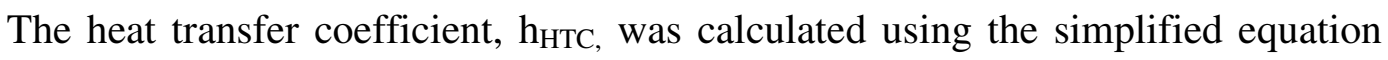
for buoyancy-induced convection to air at atmospheric pressure and moderate temperatures for horizontal cylinders (Incropera et al., 2007):

$$
\mathrm{h}_{\mathrm{HTC}}=1.32 *\left(\left(\mathrm{~T}_{\mathrm{ALG}}-\mathrm{T}_{\mathrm{GH}}\right) / \mathrm{d}\right)^{0.25}
$$

where $\mathrm{d}$ was the tube diameter $(\mathrm{m})$.

The radiative heat exchange with the sky and ground were calculated using the simplified radiation equations as discussed before (Eqn. 3.37). For the indoor photobioreactor, the equations were modified to:

$$
\begin{aligned}
& \mathrm{Q}_{\mathrm{SKY}}=\tau_{\mathrm{GH}} * \varepsilon * \mathrm{~A}_{\mathrm{TSUR}} * \sigma *\left(\mathrm{~T}_{\mathrm{ALG}}{ }^{4}-\mathrm{T}_{\mathrm{SKY}}{ }^{4}\right) / 1000 \\
& \mathrm{Q}_{\mathrm{FLOOR}}=\varepsilon * \mathrm{~A}_{\mathrm{TSUR}} * \sigma *\left(\mathrm{~T}_{\mathrm{ALG}}{ }^{4}-\mathrm{T}_{\mathrm{FLOOR}}{ }^{4}\right) / 1000 \\
& \mathrm{Q}_{\mathrm{GHHLR}}=0.5 * \mathrm{Q}_{\mathrm{SKY}}+0.5 * \mathrm{Q}_{\mathrm{FLOOR}}
\end{aligned}
$$

where it was assumed that the total radiative heat exchange $\left(\mathrm{Q}_{\mathrm{GHHLR}}\right)$ was $50 \%$ with the

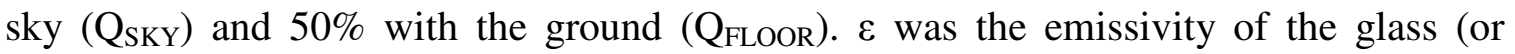
plexiglass) tubes, which was 0.9 (Aldrich and Bartok, 1992); $\mathrm{A}_{\text {TSUR }}$ was the total surface area of the PBR tubes $\left(\mathrm{m}^{2}\right)$; $\sigma$ was the Stefan-Boltzman constant $\left(5.67 * 10^{-8} \mathrm{~W} / \mathrm{m}^{2} . \mathrm{K}^{4}\right)$; $\mathrm{T}_{\mathrm{ALG}}$ was the temperature of the PBR tubes $(\mathrm{K}) ; \mathrm{T}_{\mathrm{FLOOR}}$ was the floor temperature $(\mathrm{K})$; and $\mathrm{T}_{\mathrm{SKY}}$ the sky temperature (K), which was calculated in Eqn. 3.41. 
The floor temperatures were calculated using the same approach as in outdoor conditions, however, now the long and shortwave transmittance of the greenhouse roof was considered, too.

With the knowledge of all the heat fluxes, the temperature response of the photobioreactor was calculated, taking the heat storage term into account and following the approach described in Eqns. 3.46 through 3.48:

$$
\mathrm{Q}_{\mathrm{TGHHR}}=\rho_{\mathrm{WAT}} * \mathrm{~V}_{\mathrm{PBR}} * \mathrm{Cp}_{\mathrm{WAT}} *\left(\mathrm{~T}_{\mathrm{ALGNEW}}-\mathrm{T}_{\mathrm{ALG}}\right)
$$

where $\mathrm{Q}_{\mathrm{TGHHR}}$ was the total energy balance of the photobioreactor system in one hour time interval $(\mathrm{kW})$; $\rho_{\mathrm{WAT}}$ was the density of water $\left(\mathrm{kg} / \mathrm{m}^{3}\right) ; \mathrm{V}_{\mathrm{PBR}}$ was the total PBR volume $\left(\mathrm{m}^{3}\right)$; C p $_{\text {WAT }}$ was the specific heat of water $(4186 \mathrm{~J} / \mathrm{kg} . \mathrm{C}) ; \mathrm{T}_{\mathrm{ALGNEW}}$ was the new PBR temperature $(\mathrm{K})$, whereas $\mathrm{T}_{\mathrm{ALG}}$ was the $\mathrm{PBR}$ temperature at the previous step. The time interval (dt) was one hour. Reorganizing Eqn. 3.65 resulted in the following equation used to calculate the new PBR temperature, $\mathrm{T}_{\text {ALGNEW: }}$

$$
\mathrm{T}_{\mathrm{ALGNEW}}=\mathrm{Q}_{\mathrm{TGHHR}} /\left(\rho_{\mathrm{WAT}} * \mathrm{~V}_{\mathrm{PBR}} * \mathrm{Cp}_{\mathrm{WAT}}\right)+\mathrm{T}_{\mathrm{ALG}}
$$




\subsubsection{Sensitivity Analyses and Evaluations}

After developing the simulation model, sensitivity analyses were performed on the indoor photobioreactor system, which had a glass greenhouse glazing. The shading system was not operational. The default values are shown in Table 4.

Table 4. Key model parameters and their values used in the sensitivity analyses.

\begin{tabular}{l|c|c|c|c|c|c}
\hline \multicolumn{1}{c|}{ Parameter } & \multicolumn{7}{c}{ Values } \\
\hline \hline Outside Air Temp. $\left({ }^{\circ} \mathrm{C}\right)$ & -20 & -5 & 10 & 25 & 40 & 55 \\
\hline Outside Solar Radiation $\left(\mathrm{W} / \mathrm{m}^{2}\right)$ & 0 & 300 & $600^{*}$ & 900 & 1200 & \\
\hline Ground Reflectivity $(\%)$ & 20 & $40^{*}$ & 60 & 80 & & \\
\hline PBR column distance (m) & 0.25 & 0.5 & 0.75 & 1.0 & $1.5^{*}$ & 2.0 \\
\hline Transmissivity Shading Mat. $(\%)$ & 20 & 40 & 60 & 80 & $100^{*}$ & \\
\hline Infiltration Rate $\left(\mathrm{m}^{3} / \mathrm{s.m}^{2}\right)$ & $0.001^{*}$ & 0.01 & 0.02 & 0.03 & 0.04 & \\
\hline \hline
\end{tabular}

*Default values, the default value for outside temperature was $18{ }^{\circ} \mathrm{C}$

Table 4 shows some of the key model parameters and their deviations from the standard value used in the sensitivity analyses. Each parameter was varied individually while all other parameters were held at their standard values.

In addition to the sensitivity analyses, responses of some key parameters to step inputs in outside air temperature and outside solar radiation were also determined and the findings were presented in Chapter IV. 


\section{CHAPTER IV}

\section{RESULTS AND DISCUSSION}

This section presents the results for the temperature experiment first, and is followed by the results and analysis of the developed heat management model.

\subsection{Temperature Experiments}

The overall goal of the temperature experiments was to develop a procedure to find out the temperature influence on algal growth. Later on, this procedure was used to determine out the temperature properties of the algae strain Chlorella. The data were needed to supply the heat management model with information about the algae growth as a function of temperature.

\section{Observations}

The visible color of the algae water changed as the density changed due to increased chlorophyll content in the water. Also, the color of each alga changed over time, especially when they were exposed to stress conditions (i.e. high or low temperature, high or low nutrient level). After almost 8 months of algae research in this project, the research team was able to guess what happened to the algae just by visual examination. Generally, a "healthy" Chlorella alga would look fresh to dark green, whereas stressed algae would turn to bright green first, and later on to yellow. Especially in the accelerated death phase (Figure 6) the algae looked bright green and soon turned to yellow before turning to white dead biomass, eventually. 
A lag (adaption) phase was observed after almost all environmental changes (temperature, density, $\mathrm{pH}$, nutrients), which was indicated by hardly any or no growth for several hours up to two days.

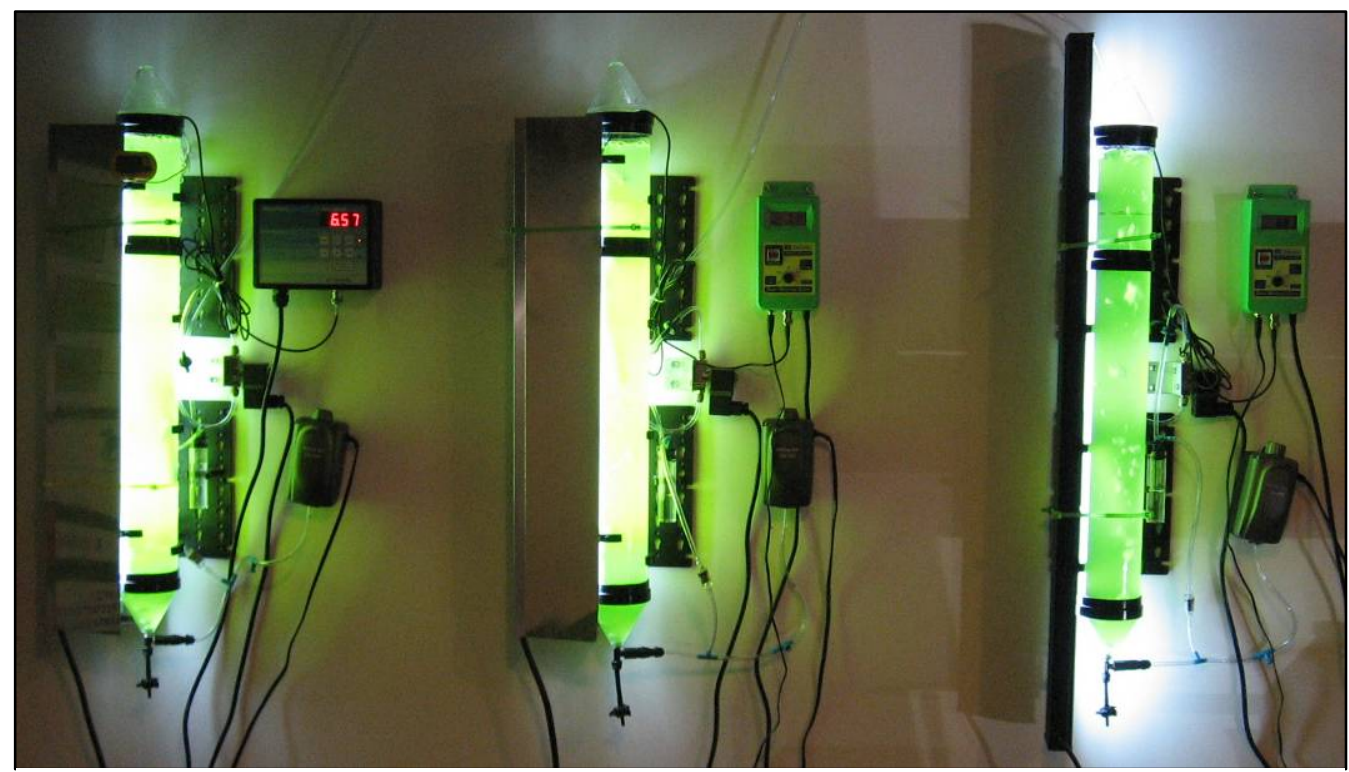

Figure 30. Photobioreactors during operation

\section{Results}

Optical density (OD) measurements were made twice a day, and reported in an online database (Figure 31) together with the temperature, date, time, and $\mathrm{pH}$. The nutrient content was controlled about every fifth day and adjusted (nutrients added) as needed.

Three PBRs were operated over a period of 50 days. With two readings per day, the sample size summed up to 300 entries. The data evaluated were manually chosen from the entire set. Recorded data from lag phases with no or hardly growth were deleted. Every single data set was examined and checked for plausibility. Over 150 samples were 


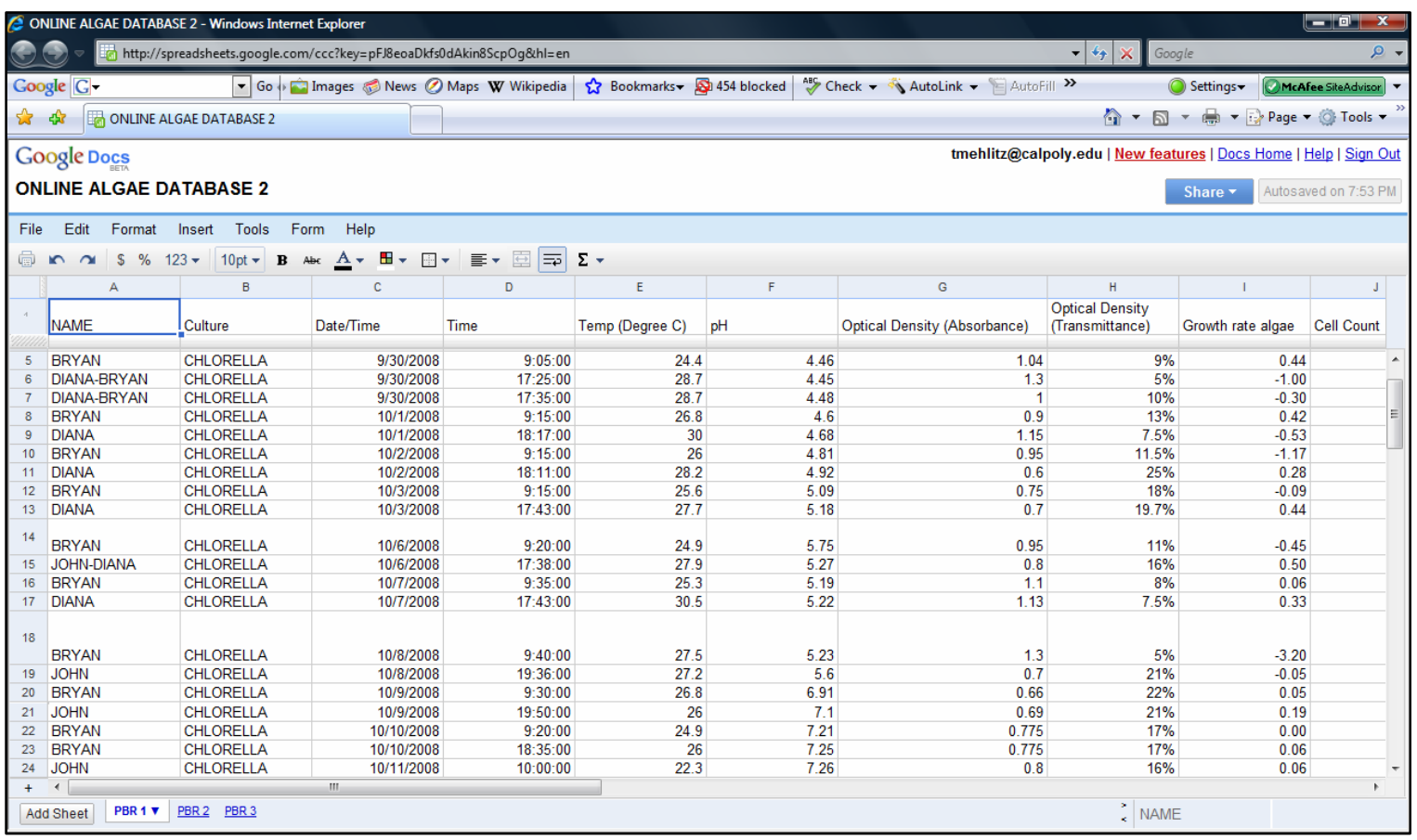

Figure 31. Online database where all observed data were collected.

deleted from the database in order to examine only pure culture findings. Main criteria for this purpose were:

- $\quad \mathrm{pH}$ lower than 5.5 or higher than 8.0

- 3 data sets after changing an environmental factor (delete lag phase)

- $\quad$ Transmittance below 7\% (density too high)

The distribution of sample sizes for each temperature experiment was shown in Figure 32. The temperatures were rounded to full degrees Celsius (e.g. $15.3{ }^{\circ} \mathrm{C}$ to $15{ }^{\circ} \mathrm{C}$ ). In accordance with Eqns. 2.5 and 2.6 (Chapter II), only the temperature for the maximum growth (anticipated to be between $23{ }^{\circ} \mathrm{C}$ and $31{ }^{\circ} \mathrm{C}$ ), the temperature at $10 \%$ of the maximum growth rate at the lower end (anticipated to be between $9{ }^{\circ} \mathrm{C}$ and $14{ }^{\circ} \mathrm{C}$ ), and the temperature at $10 \%$ of the maximum growth rate at the upper end (anticipated to be 
between $34{ }^{\circ} \mathrm{C}$ and $40{ }^{\circ} \mathrm{C}$ ) were to be determined. The research therefore mainly focused on these regions.

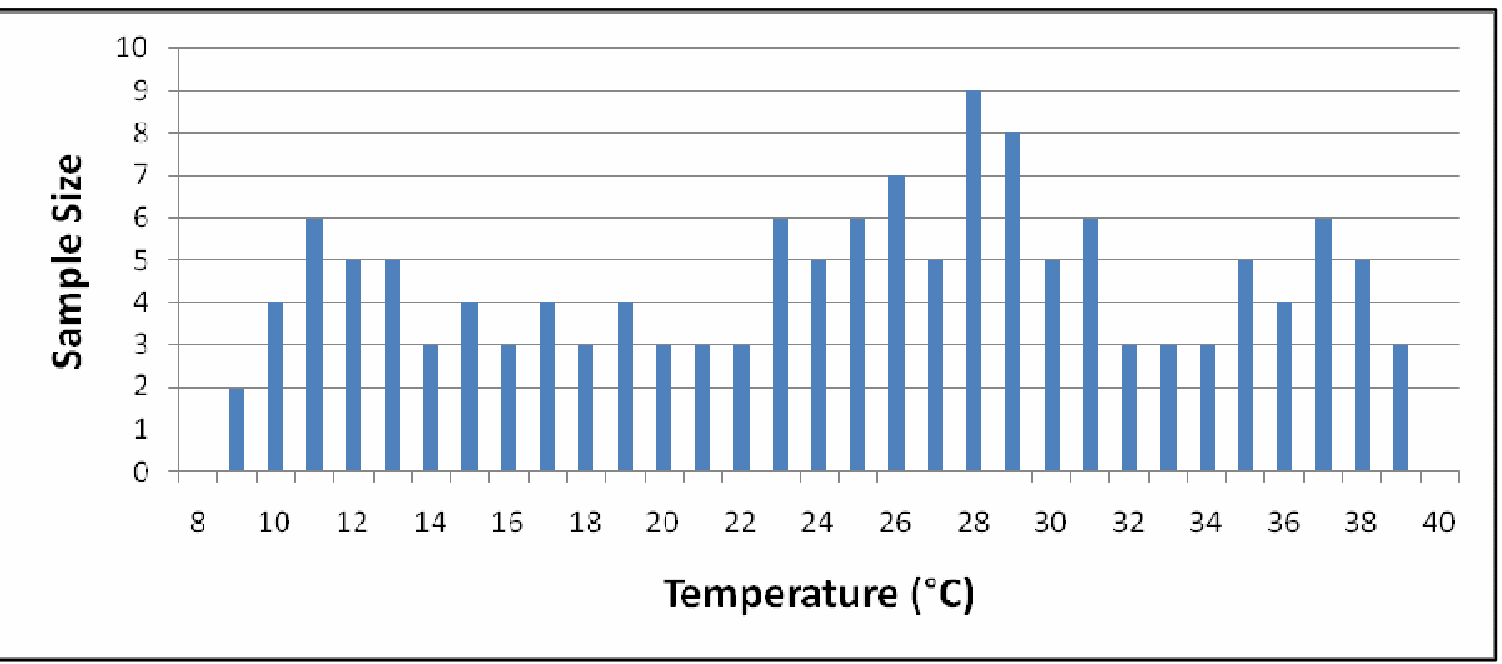

Figure 32. Sample size for each temperature experiment.

For the evaluation, the time interval ( $\Delta \mathrm{t}$ in hours) from the previous reading to the current and the corresponding change in transmittance $(\Delta \tau)$ were calculated. The growth rate per day (24 hours) was interpolated from these two parameters and reported with the corresponding temperature. Then, a mean growth rate for each temperature experiment was determined (Figure 33 and Table 5). The total growth rate distribution with respect to temperature was as expected in the form of a skewed normal distribution (Figure 33). The maximum growth rate (1.44/day) was observed at a medium temperature of $29^{\circ} \mathrm{C}$ (Figure 33 and Table 5). The observed maximum growth rate was in agreement with the previous studies; i.e. 1.44 doublings per day versus 1.0 to 2.0 doublings per day in the literature (Reynolds, 1984; Raven and Geider, 1988; Dauta et al., 1990). For our study, the goal was not to reach the maximum growth rate, rather to monitor the growth distribution and develop a growth function as a function of 
temperature. The important outcome was the percent losses and gains with respect to the maximum growth rate. Beside the maximum growth rate, the upper and lower $10 \%$ maximum growth rates had to be determined. Ten percent of 1.44 doublings per day was 0.144 doublings per day. For the lower value, a growth medium temperature of $11{ }^{\circ} \mathrm{C}$ was determined from Table 5. The upper value was determined at the temperature of 35 ${ }^{\circ} \mathrm{C}$. Finally, all parameters needed for the heat management model were determined and incorporated into the model (Table 6).

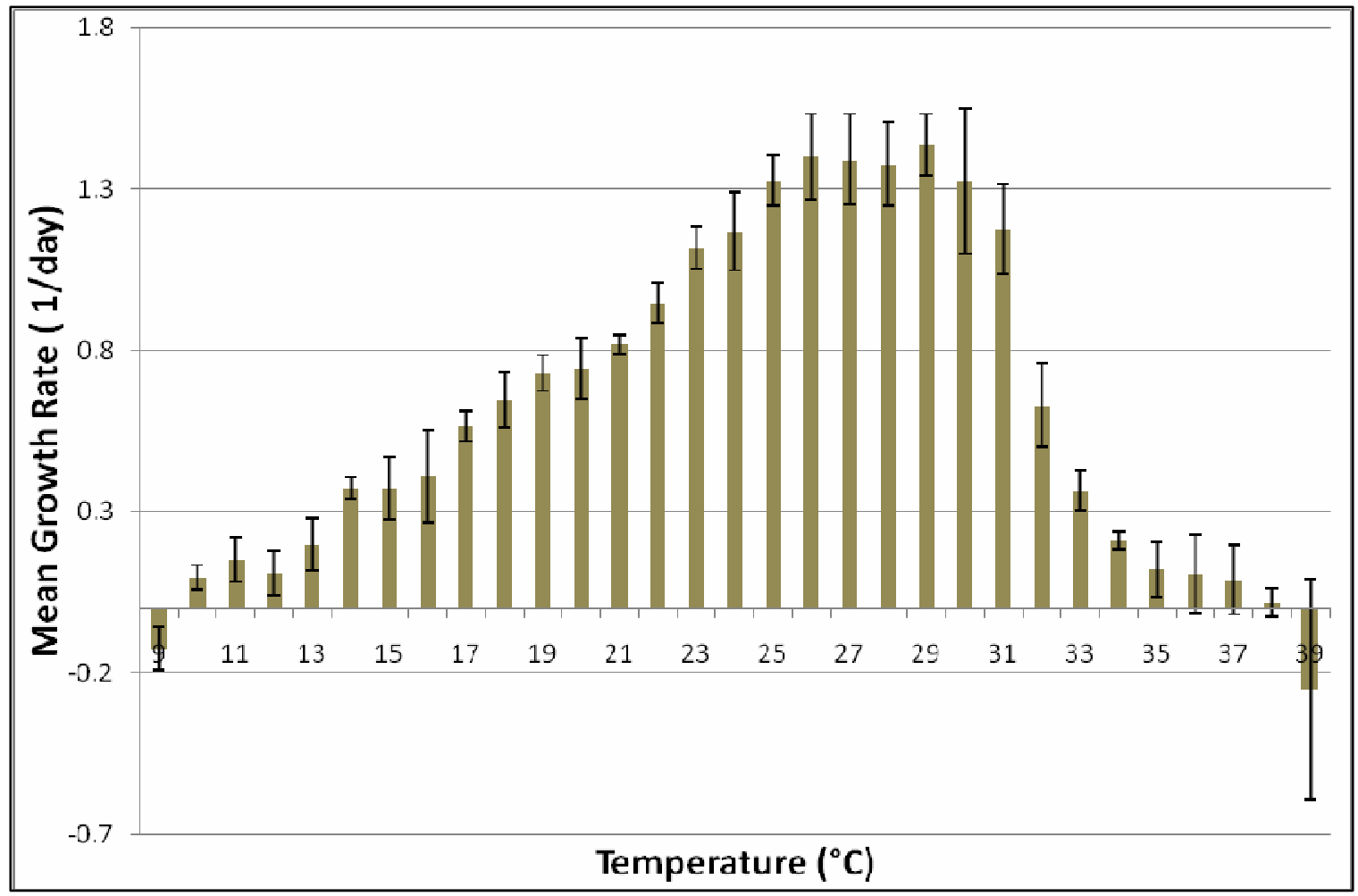

Figure 33. Mean growth rates and standard deviations at different temperatures 
Table 5. Mean growth rates at different growth medium temperatures.

\begin{tabular}{|c|c|c|c|}
\hline $\begin{array}{c}\text { TEMPERATURE } \\
\left({ }^{\circ} \mathrm{C}\right)\end{array}$ & $\begin{array}{c}\text { MEAN } \\
\text { GROWTH } \\
\text { RATE (1/day) }\end{array}$ & $\begin{array}{c}\text { TEMPERATURE } \\
\left({ }^{\circ} \mathbf{C}\right)\end{array}$ & $\begin{array}{c}\text { MEAN } \\
\text { GROWTH } \\
\text { RATE (1/day) }\end{array}$ \\
\hline 9 & -0.12 & 25 & 1.33 \\
\hline 10 & 0.10 & 26 & 1.40 \\
\hline 11 & 0.15 & 27 & 1.39 \\
\hline 12 & 0.11 & 28 & 1.38 \\
\hline 13 & 0.20 & 29 & 1.44 \\
\hline 14 & 0.37 & 30 & 1.33 \\
\hline 15 & 0.37 & 31 & 1.17 \\
\hline 16 & 0.41 & 32 & 0.63 \\
\hline 17 & 0.57 & 33 & 0.37 \\
\hline 18 & 0.65 & 34 & 0.21 \\
\hline 19 & 0.73 & 35 & 0.12 \\
\hline 20 & 0.74 & 36 & 0.11 \\
\hline 21 & 0.82 & 37 & 0.09 \\
\hline 22 & 0.95 & 38 & 0.02 \\
\hline 23 & 1.12 & 39 & -0.25 \\
\hline 24 & 1.17 & 40 & N/A \\
\hline
\end{tabular}

Table 6. Values incorporated into the heat management model.

\begin{tabular}{|l|c|c|}
\hline Temperature at $\boldsymbol{\mu}_{\max }$ & $\mathbf{T}_{\text {OPT }}$ & $29{ }^{\circ} \mathrm{C}$ \\
\hline Temperature at $10 \% \boldsymbol{\mu}_{\max }$ lower & $\mathbf{T}_{\text {INF }}$ & $11^{\circ} \mathrm{C}$ \\
\hline Temperature at $\mathbf{1 0} \% \boldsymbol{\mu}_{\max }$ upper & $\mathbf{T}_{\text {SUP }}$ & $35{ }^{\circ} \mathrm{C}$ \\
\hline Maximum Growth rate $\boldsymbol{\mu}_{\max }(\mathbf{1} /$ day $)$ & MGR & 1.44 \\
\hline
\end{tabular}

The results also showed some interesting deviations. The growth rates between 26 to $29^{\circ} \mathrm{C}$ had similar values. In fact, the growth rate at $28{ }^{\circ} \mathrm{C}$ was less than those at $26{ }^{\circ} \mathrm{C}$ and $27{ }^{\circ} \mathrm{C}$. This unsteadiness could be due to the measurement techniques used as discussed later. A similar unsteadiness occurred in the lower temperature range $\left(14{ }^{\circ} \mathrm{C}\right.$ to $16{ }^{\circ} \mathrm{C}$ ). The growth rate at $12{ }^{\circ} \mathrm{C}$ was smaller than the one at $11{ }^{\circ} \mathrm{C}$, which was not in 
concurrence with the pattern of the skewed normal distribution. One reason could be again the measurement techniques; another could be the slow growth rate itself. At such critical temperatures, algae are more sensitive to all other environmental parameters, too. Longer periods required for one doubling under these conditions allow more time for other environmental factors (nutrients, $\mathrm{pH}$, light, contamination, etc.) to interfere. At the growth medium temperature of $9{ }^{\circ} \mathrm{C}$ and $39{ }^{\circ} \mathrm{C}$, the growth rates were observed to be negative, which means that the algae died due to environmental stress.

This study shows that Chlorella algae were very sensitive to high temperatures. The range between the optimal temperature $\left(29^{\circ} \mathrm{C}\right)$ and death $\left(38^{\circ} \mathrm{C}\right)$ was very tight. This indicates that special considerations with respect to the heat management of large scale systems have to be taken into account.

Using the data presented in Table 6, a growth function as described in Chapter II was generated and plotted accordingly (Figure 35). The differences in the mean growth rates at specific temperatures could also be expressed as percent losses with respect to the maximum growth rate. This is especially important for the productivity considerations. Considering that the temperature at the maximum growth rate has a $100 \%$ productivity, the temperatures below and above the maximum will be a fraction thereof and can be presented as in Figure 34. 


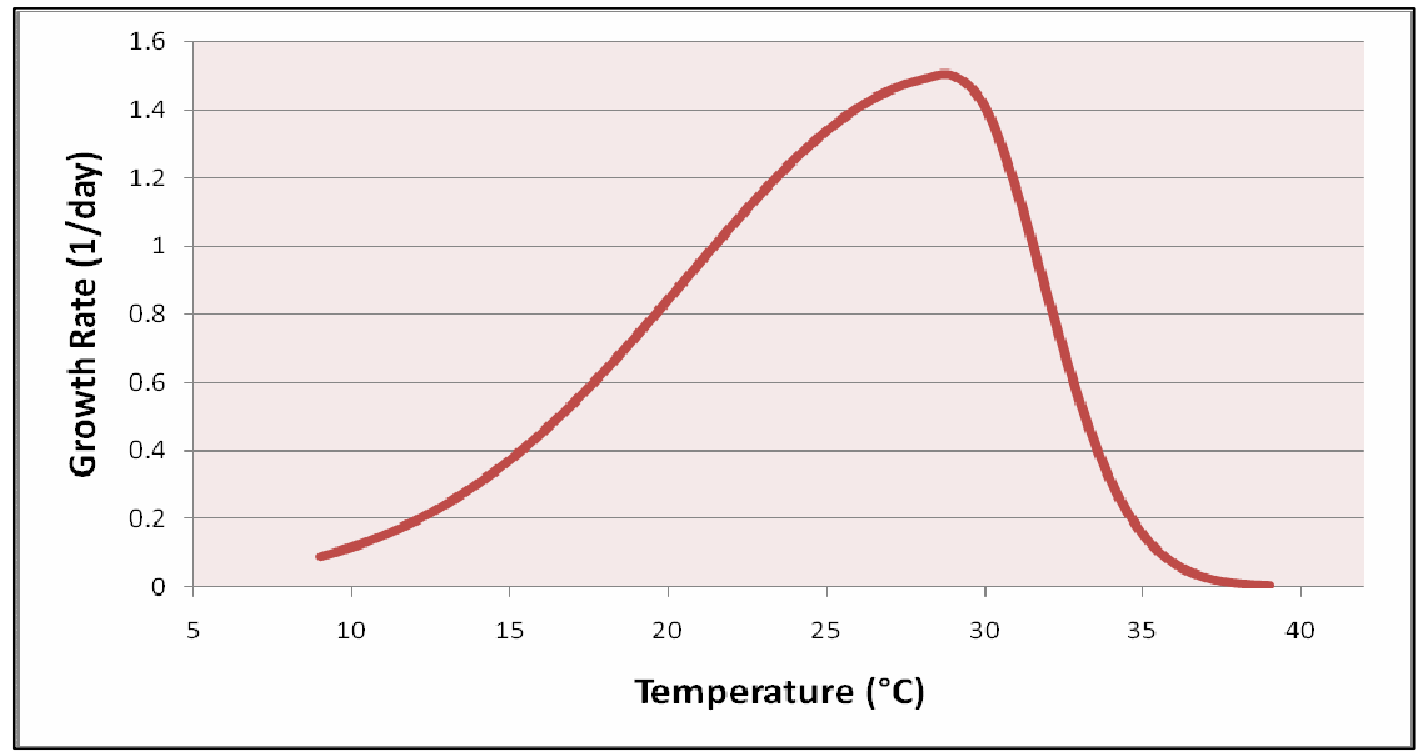

Figure 35. Chlorella growth curve with respect to growth medium temperature.

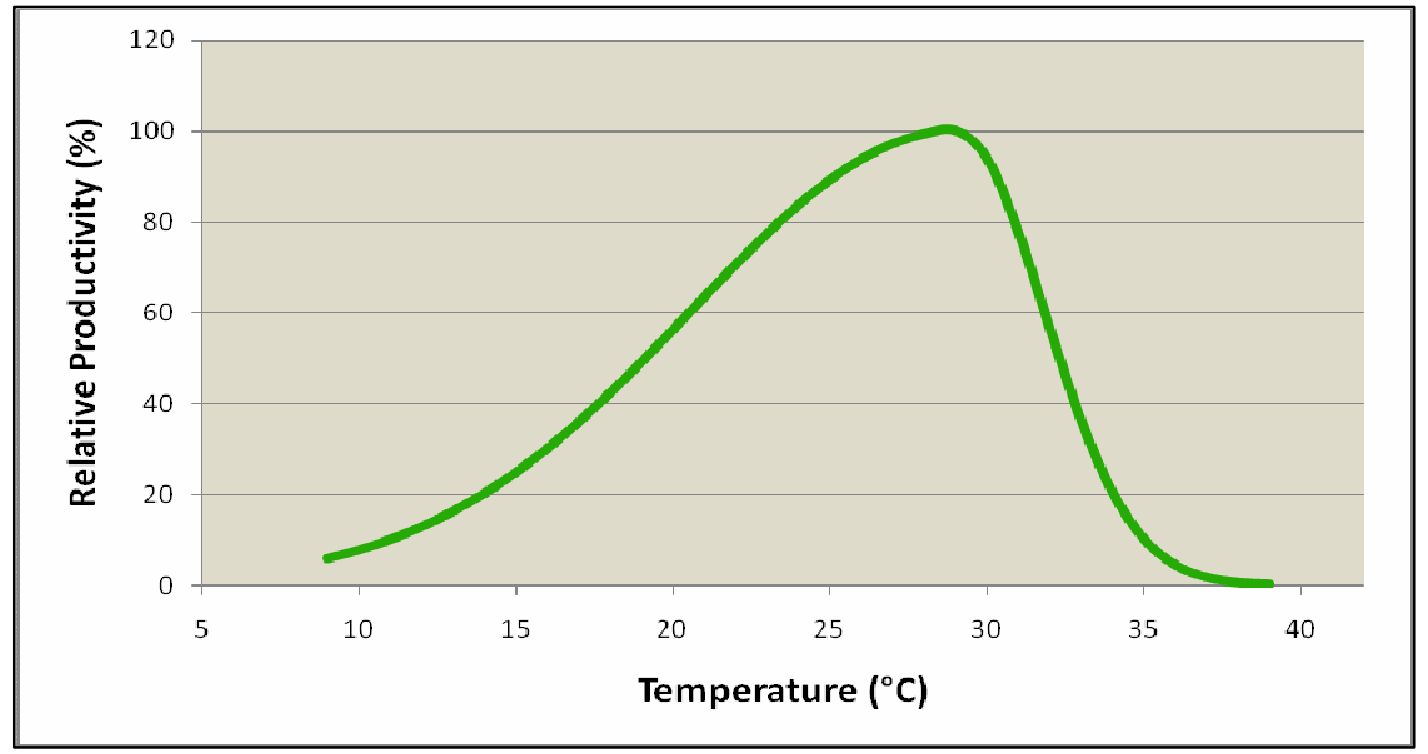

Figure 34 . Relative productivity rates with respect to growth medium temperature. 


\subsection{Heat Management Model}

\section{Sensitivity Analyses}

A sensitivity analysis was performed on the simulation model in order to show the impact of outside temperature changes on the PBR and inside greenhouse air temperatures. A second analysis was performed to determine the impact of outside solar radiation on the PBR temperature and inside greenhouse air temperatures. Finally, the energy consumption was monitored for different ground reflectivities and different distances between the PBR columns.

For the temperature sensitivity analysis (Figure 36), the solar radiation was kept constant at $600 \mathrm{~W} / \mathrm{m}^{2}$ for nine hours each day. The outside temperature was kept the same for five consecutive days at each temperature starting at $-20{ }^{\circ} \mathrm{C}$ and ending at $40{ }^{\circ} \mathrm{C}$. The greenhouse air temperature and the PBR temperature responded accordingly. It took roughly two days for the responding temperatures to adjust to the new climatic condition as seen in Figure 36. Focusing on the critical region, where the outside temperature step change took place (Figure 37), it was obvious to see that the maximum temperatures for the greenhouse and the PBR had a gap of about two to three hours due to the difference in their thermal masses. The distribution of the PBR temperature as well was shown in detail. Due to shading effects within the PBR columns, the temperature rose rapidly until the critical sun angle (TC) and slower afterwards due to less direct sun light reaching the PBR tubes. The temperature differences at the maximums were between $8{ }^{\circ} \mathrm{C}$ and $10{ }^{\circ} \mathrm{C}$. 

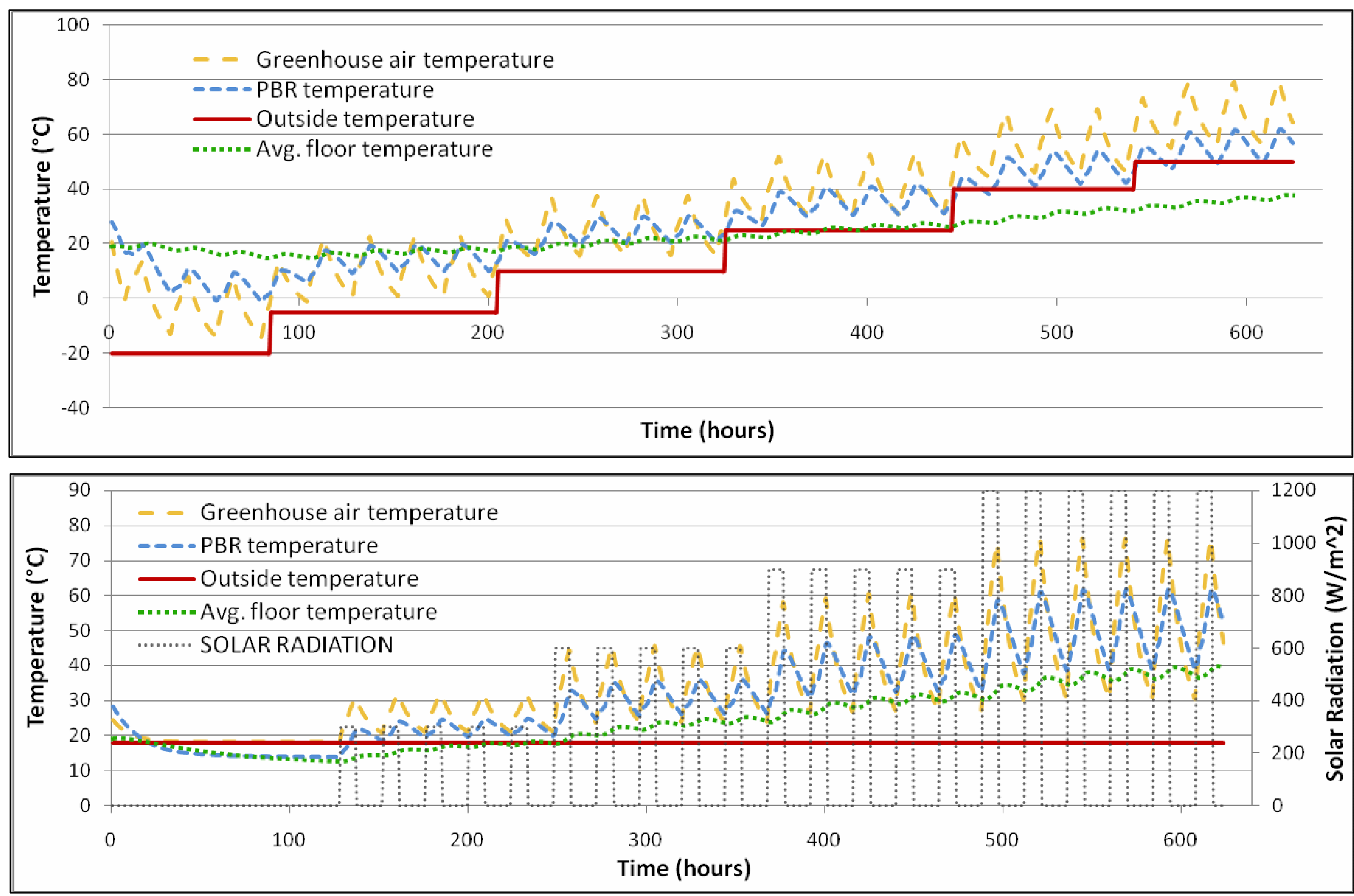

Figure 36. Sensitivity analyses on outside temperature (top) and solar radiation (bottom). 


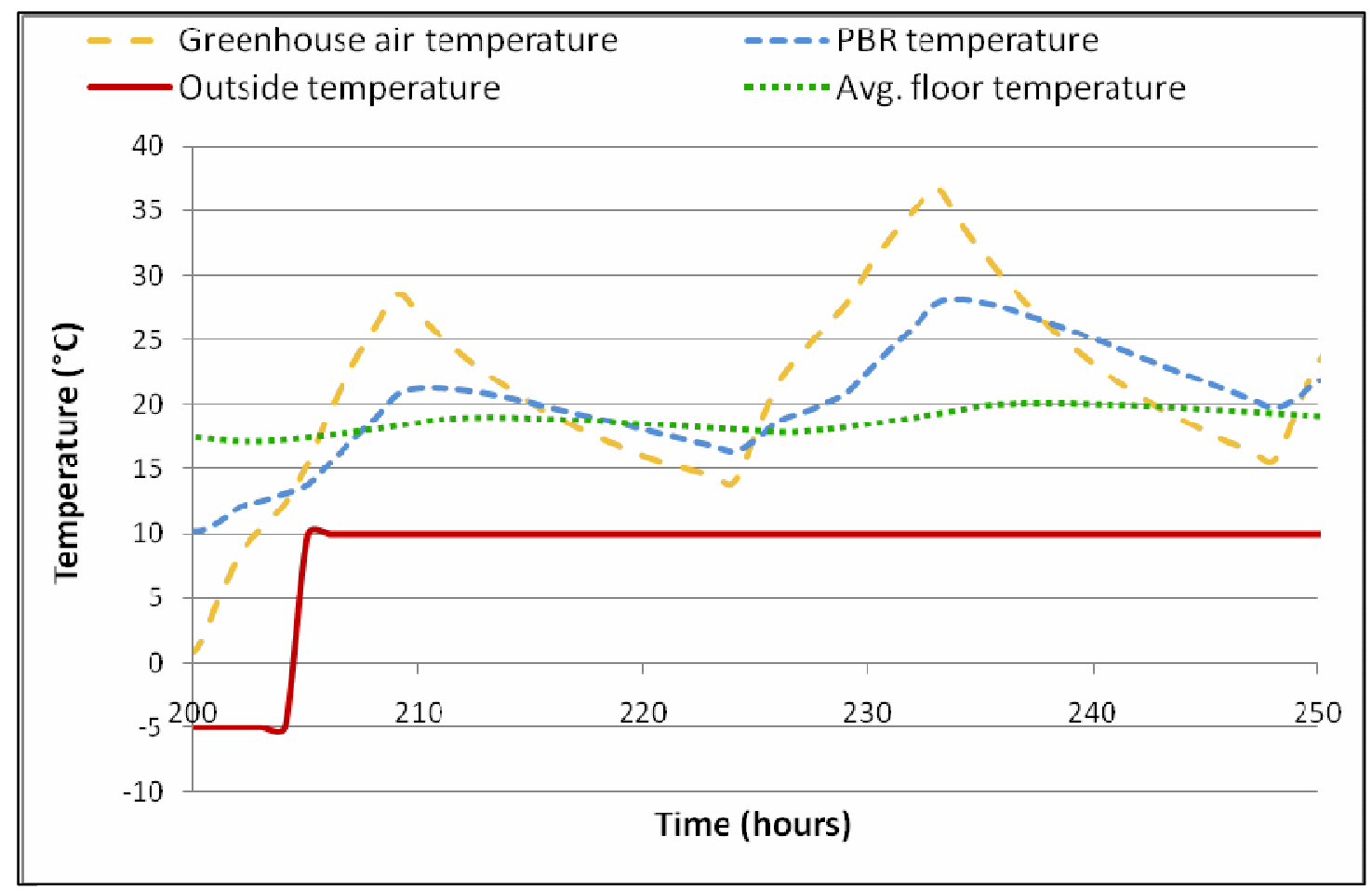

Figure 37. Responses to a step change in outdoor temperature.

For the solar radiation sensitivity analysis, the outside air temperature was kept constant at $18{ }^{\circ} \mathrm{C}$ for day and night (Figure 36). The solar radiation was varied in 300 $\mathrm{W} / \mathrm{m}^{2}$ increments between $0 \mathrm{~W} / \mathrm{m}^{2}$ and $1200 \mathrm{~W} / \mathrm{m}^{2}$ for five days each. It was assumed that the sun was shining at a constant radiation rate for 9 hours every day. The greenhouse air temperature and the PBR temperature responded accordingly, and increased after each step. Due to the difference in thermal masses, the maximum temperature of the PBR was reached about one to two hours after the greenhouse air temperature reached its maximum (Figure 38). Also, the temperature variability of the PBR was due to higher thermal mass less than the one of the greenhouse temperature. The shape of the temperature distribution looked similar to the previous sensitivity analysis, and was again a result of the shading function, and therefore, of the sun angle. 
However, the magnitudes were different. The temperature differences at the maximums were between $5{ }^{\circ} \mathrm{C}$ and $18{ }^{\circ} \mathrm{C}$, depending on the level of incoming solar radiation.

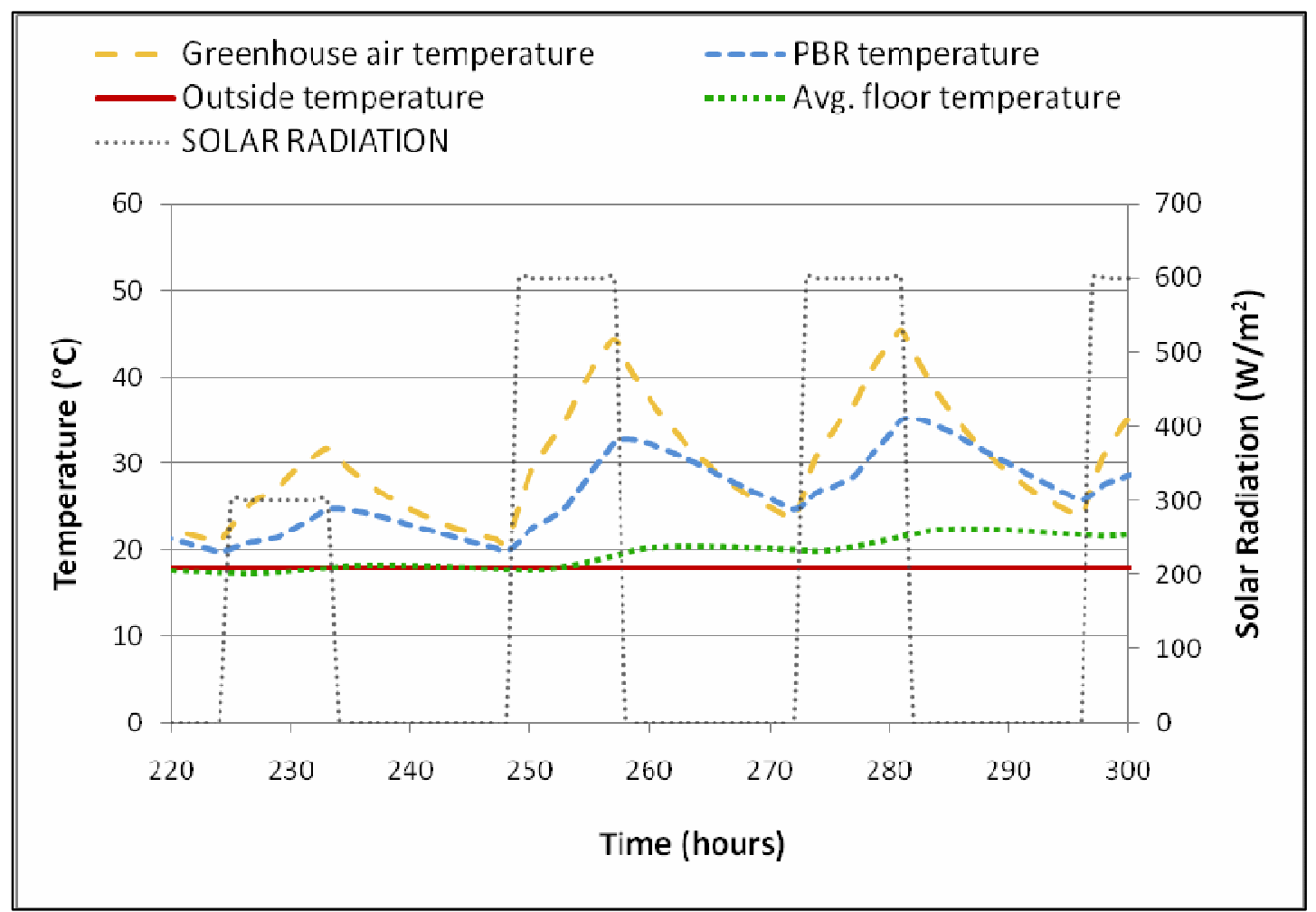

Figure 38. Responses to a step change in solar radiation.

For the ground reflectivity sensitivity analysis, the original weather file for San Luis Obispo, CA, U.S.A. for April 2007 was used. The simulations were performed for ground reflectivities of 20,40,60 and $80 \%$. Associated energy requirements and average productivities were monitored (Figure 39). The results showed that the higher the reflectivity was, the lower the average productivity was (a function of the PBR temperature). The higher the reflectivity, the less heating and the more cooling were required. The total energy needs for heating and cooling rose with rising ground reflectivity. 


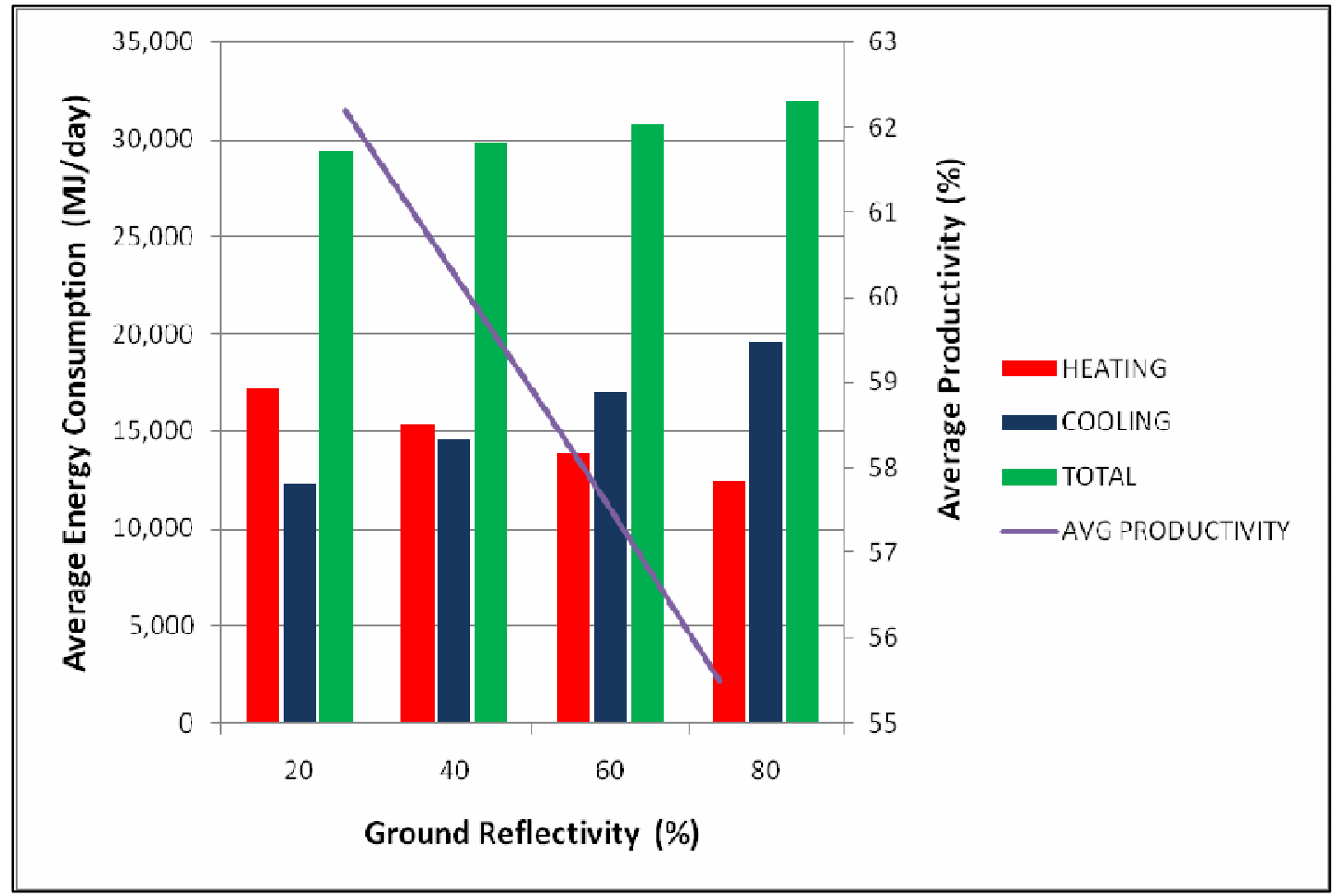

Figure 39. Energy requirements and average productivity for different ground reflectivities.

For the PBR column distance sensitivity analysis, the original weather file for San Luis Obispo, CA, U.S.A. for April 2007 was used. The simulations were performed for PBR column distances of $0.25,0.5,0.75,1.0,1.5$, and $2.0 \mathrm{~m}$. In each simulation, the greenhouse size was kept the same, which means that there was the same number of PBRs in the greenhouse, but they were closer or wider apart.

The distance between the PBR columns had a major impact on the energy requirements and the average productivity (Figure 40). The most heating (18,331 MJ per day) was required at a distance of $0.75 \mathrm{~m}$, the least (16,474 MJ per day) at $2 \mathrm{~m}$. The most cooling (12,974 MJ per day) was required for a distance of $2 \mathrm{~m}$, the least $(10,531 \mathrm{MJ}$ per day) at $0.75 \mathrm{~m}$. The total energy needs rose with larger distances and peaked at the $2 \mathrm{~m}$ 
distance with 29,448 MJ per day. However, the algal productivity was a function of the PBR temperature and its distribution during the day. Too high and too low temperatures had direct impact on the productivity. Shading had a major impact on the temperature regime of the PBR. The distance between the PBRs influenced the shading factor as previously described. Apparently, an optimal distance between columns existed, where heat gains due to solar radiation and the shading at midday (avoid overheating) were in a most advantageous ratio. For the examined PBR, the best distance seemed to be about $0.75 \mathrm{~m}$. However, the total productivity (biomass output and price per area) is also a measure of the price of greenhouse space. A smaller distance will eventually save space. Whether space savings outweigh the higher productivity rate or not can now be investigated.

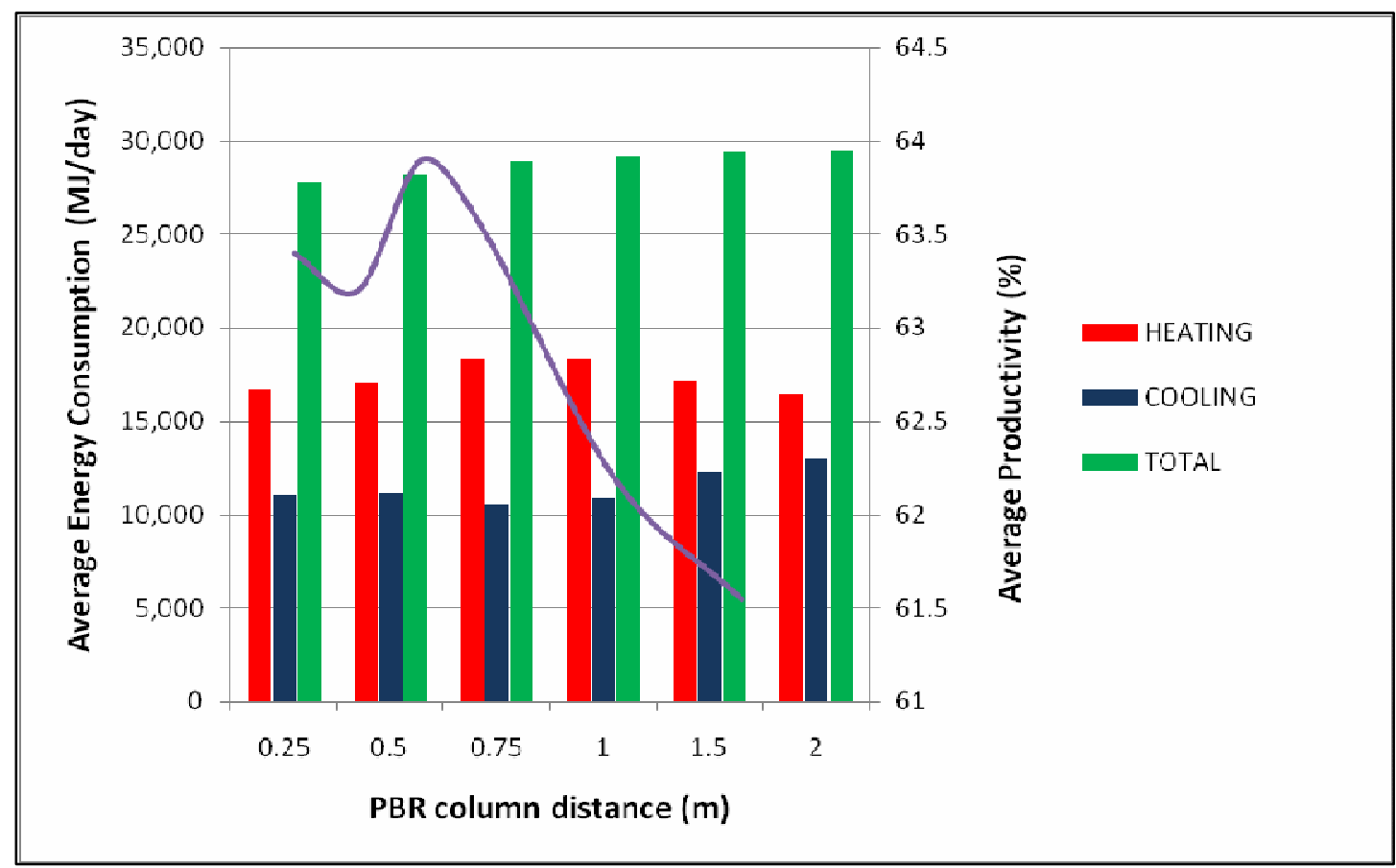

Figure 40. Energy requirements and average productivity for different PBR distances. 
For the transmissivity of greenhouse shading material sensitivity analysis, the original weather file for San Luis Obispo, CA, U.S.A. for April 2007 was used. The simulations were performed for greenhouse shading material transmissivities of 20,40 , 60 and $80 \%$ as well as for a greenhouse without shading (100\% transmissivity). Associated energy requirements and average productivities were monitored (Figure 42).

The transmissivity of the shading material had a major impact on the energy requirements and the average productivity. The most heating (59,678 $\mathrm{MJ}$ per day) was required for a transmissivity of $20 \%$, the least (15,830 MJ per day) for $100 \%$ (without shading material). The most cooling (10,243 MJ per day) was required for no shading material (100\% transmissivity), the least ( $0 \mathrm{MJ}$ per day) for a transmissivity of $20 \%$. The total energy needs rose with lesser transmissivity and was the least for $100 \%$ transmissivity with $26,073 \mathrm{MJ}$ per day. However, the algal productivity as a function of the PBR temperature and its distribution during the day could not be correlated to the energy consumption. The highest productivity (73.9\%) was determined at $60 \%$ transmissivity, whereas the lowest productivity (47.1\%) was determined for a transmissivity of $20 \%$. Important for further considerations was the productivity rate of $66.9 \%$ for a transmissivity of $100 \%$ (no shading). Apparently, an optimal shading transmissivity existed, where heat gains due to solar radiation and the shading at midday (avoid overheating) were in a most advantageous ratio. The productivity can be increased by $7 \%$ by using a shading material with $60 \%$ transmissivity. Whether more energy input (using a shading material with less transmissivity) will outweigh the higher algal productivity can now be determined by the photobioreactor operator. Further discussion about the shading will follow later in this work. 


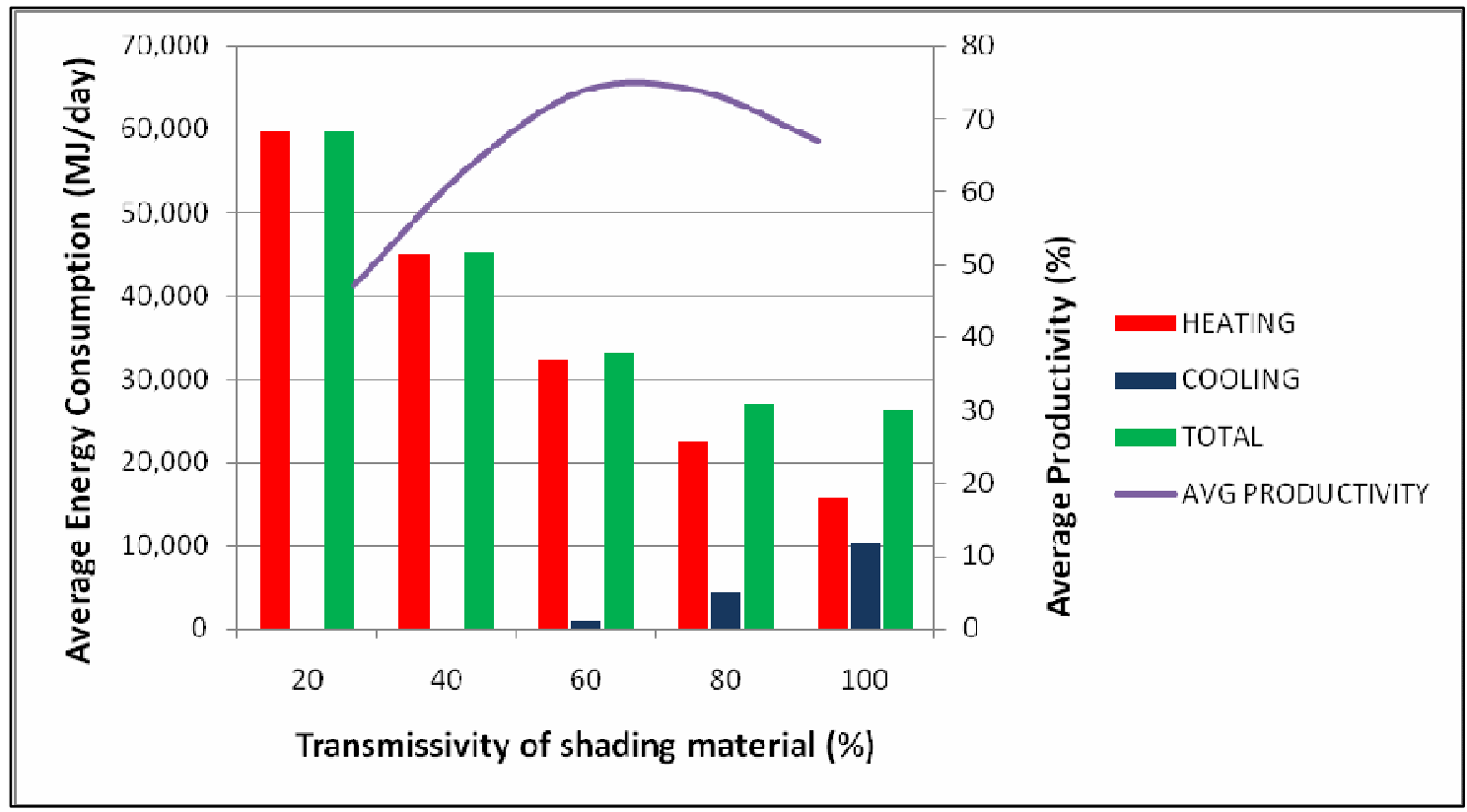

Figure 42. Energy requirements and average productivity for different shading material transmissivities.

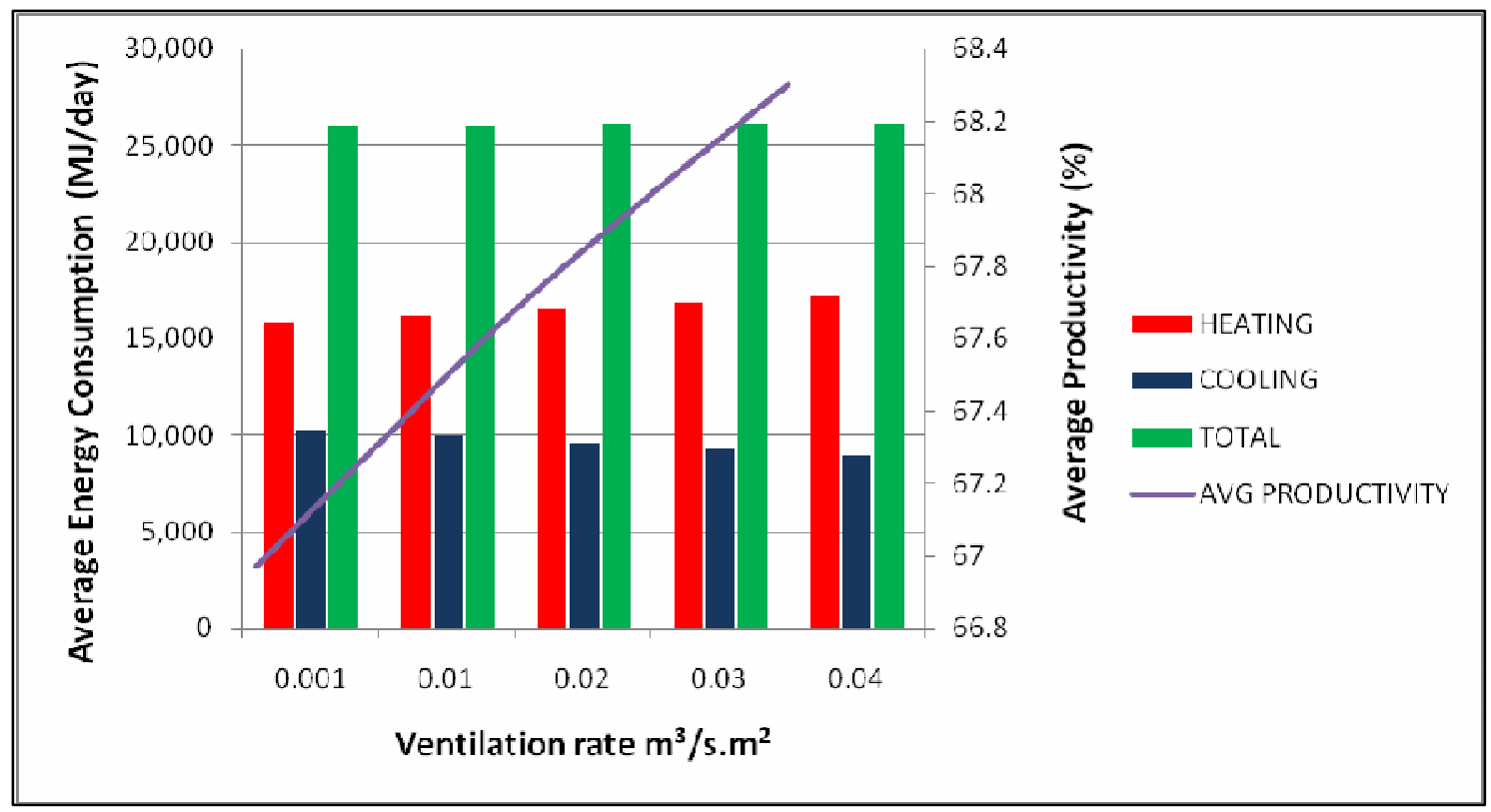

Figure 41. Energy requirements and average productivity for ventilation rates. 
For the ventilation rate sensitivity analysis, the original weather file for San Luis Obispo, CA, U.S.A. for April 2007 was used. The simulations were performed for ventilation rates of $0.01,0.02,0.03$ and $0.04 \mathrm{~m}^{3} / \mathrm{s} . \mathrm{m}^{2}$ as well as for the default value $\left(0.001 \mathrm{~m}^{3} / \mathrm{s} . \mathrm{m}^{2}\right)$ that reflected the natural ventilation only (no mechanical ventilation). Ventilation was only supplied when the PBR (algae) temperature was over its optimum of $29{ }^{\circ} \mathrm{C}$. Associated energy requirements and average productivities were monitored (Figure 41).

The ventilation rate had an impact on the energy requirements and the average productivity. The most heating (17,207 MJ per day) was required for the highest ventilation rate $\left(0.04 \mathrm{~m}^{3} / \mathrm{s} . \mathrm{m}^{2}\right)$, the least $(15,830 \mathrm{MJ}$ per day) for no ventilation. The most cooling (10,243 MJ per day) was required for no ventilation, the least (8,942 MJ per day) for the highest ventilation rate, as expected. The total energy needs rose with higher ventilation rates and was the most at the highest ventilation rate with $26,149 \mathrm{MJ}$ per day. The algal productivity as a function of the PBR temperature and its distribution during the day was directly correlated to the energy consumption. The higher the ventilation rate was, the higher the average productivity. However, the magnitudes were very small. The highest productivity $(68.3 \%)$ was determined for a ventilation rate of $0.04 \mathrm{~m}^{3} / \mathrm{s} . \mathrm{m}^{2}$, whereas the lowest productivity $(66.97 \%)$ was determined for no ventilation. The productivity can be increased by approximately $1 \%$ by utilizing high ventilation. Whether the savings in cooling and the small increase in productivity rectifies the costs of ventilation can now be determined by the photobioreactor operators. 


\section{Results}

The model was run using the weather data for San Luis Obispo, CA, U.S.A. to exemplify the process and possibilities of analysis. The weather file contained hourly weather data for outside temperature, solar radiation, wind speed, and relative humidity for April $5^{\text {th }}$ to $30^{\text {th }}, 2007$. The month of April was chosen to represent an average month of the year. A specific photobioreactor and greenhouse were chosen for this analysis as described in Chapter III.

The first scenario studied was the DO-NOTHING scenario: how the PBR system performed in local San Luis Obispo weather without heating or cooling. An outdoor PBR operation was compared to a PBR operation in a greenhouse to be able to draw a conclusion about feasibility in a future study. Since the time interval used in the simulation was one hour, the calculated output temperature was based on the heat exchange, which took place during the previous hour. The PBR system performance was studied in the outdoor conditions first. The hourly temperature distributions were presented for the entire evaluation period as shown in the upcoming figures presented in this chapter.

Figure 43 shows the temperature variations for outdoor and indoor PBR operations. For outdoor operation, the PBR temperature followed the outside temperature closely. However, as expected, the PBR itself functioned as a thermal storage device due to its thermal mass, and responded to the outside temperature change with a time lag. The temperature of the PBR was higher during the day due to solar radiation heat gains. As a result, the PBR temperature did not fall below the outside temperature. The same was 
true for the floor temperature. A longer time lag was observed due to a bigger thermal mass. The bigger the thermal mass was, the slower the reaction of the component was to the changes in outside weather conditions. The temperature peaks were skewed by about 1 to 3 hours. The maximum PBR temperature occurred about 2 hours after the greenhouse air temperature reached its maximum. The floor temperature peaked about 1 to 2 hours after the PBR temperature peaked; and this was because of the bigger thermal storage of the ground compared to that of the PBR. For outdoor operation, four graphs were plotted (Figure 43 bottom) to compare the outside temperature, the greenhouse air temperature, the floor temperature and the PBR temperature over the entire period. In this case, the greenhouse air functioned as a buffer, and therefore; the PBR temperature was approximately 10 to $15{ }^{\circ} \mathrm{C}$ higher than the outside temperature. As for the outdoor condition, the peak temperatures for the indoor conditions were a function of the thermal masses, too. The floor temperature responded to the PBR temperature with a time lag of approximately 2 to 3 hours. The PBR temperature responded to the greenhouse air temperature with a time lag of approximately 1 to 3 hours. The greenhouse air temperature responded to the outside air temperature with a time lag of 1 to 4 hours.

Due to a long time interval between simulation steps (one hour) in the model, it took about 2 to 4 days to adjust the PBR and floor temperature to the outside conditions. The temperatures of the first 5 days should not be considered reliable, and were not considered in the evaluations. Some unsteadiness' at the peaks of the outside temperature during noon time were recorded. These jags were due to the typical California Central Coast weather with a harsh wind (up to $7 \mathrm{~m} / \mathrm{s}$ ) during the midday hours. The temperatures dropped accordingly and the temperature response of the PBR followed subsequently. 

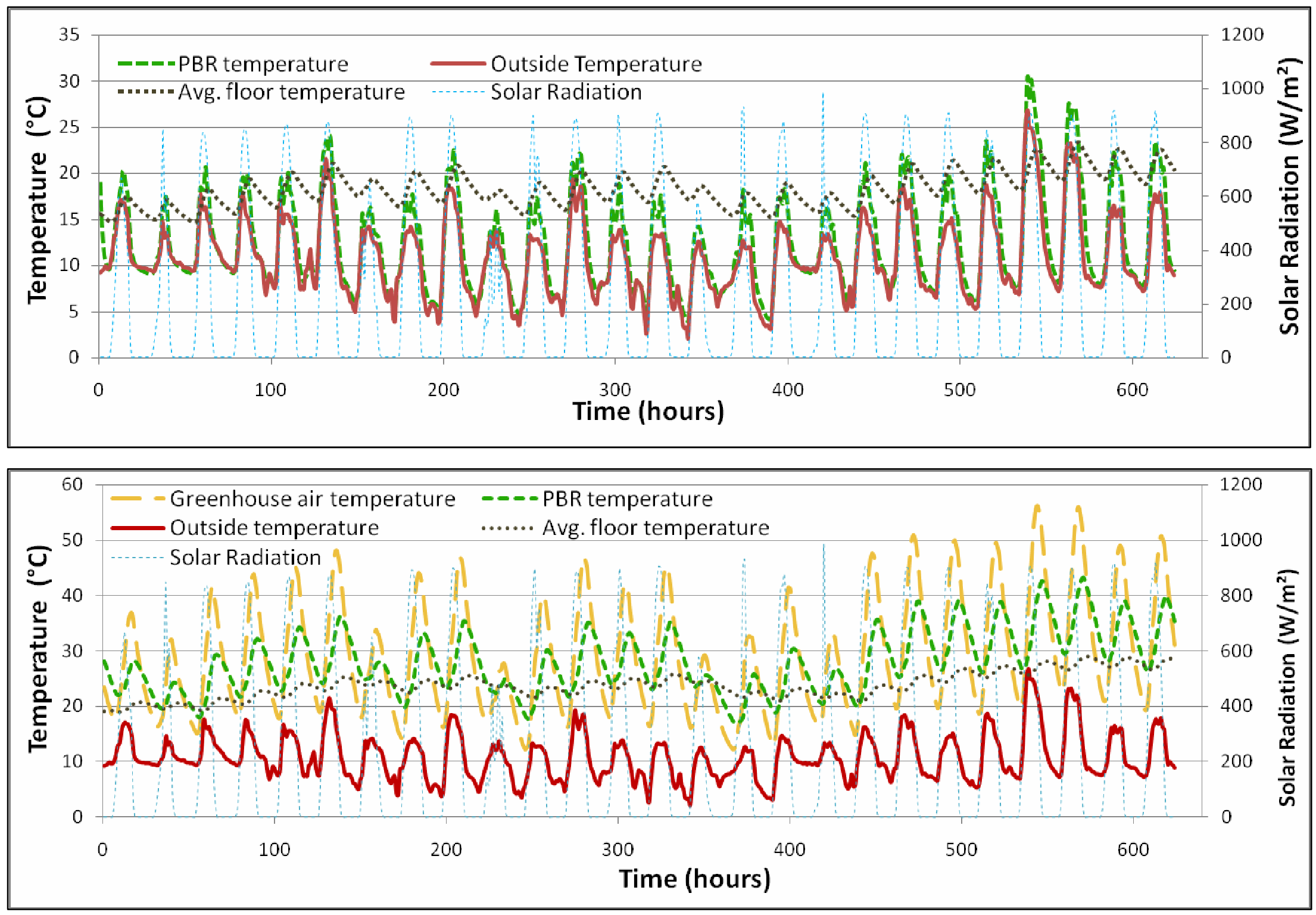

Figure 43. Temperature variations for outdoor (top) and indoor (bottom) PBR operations. 


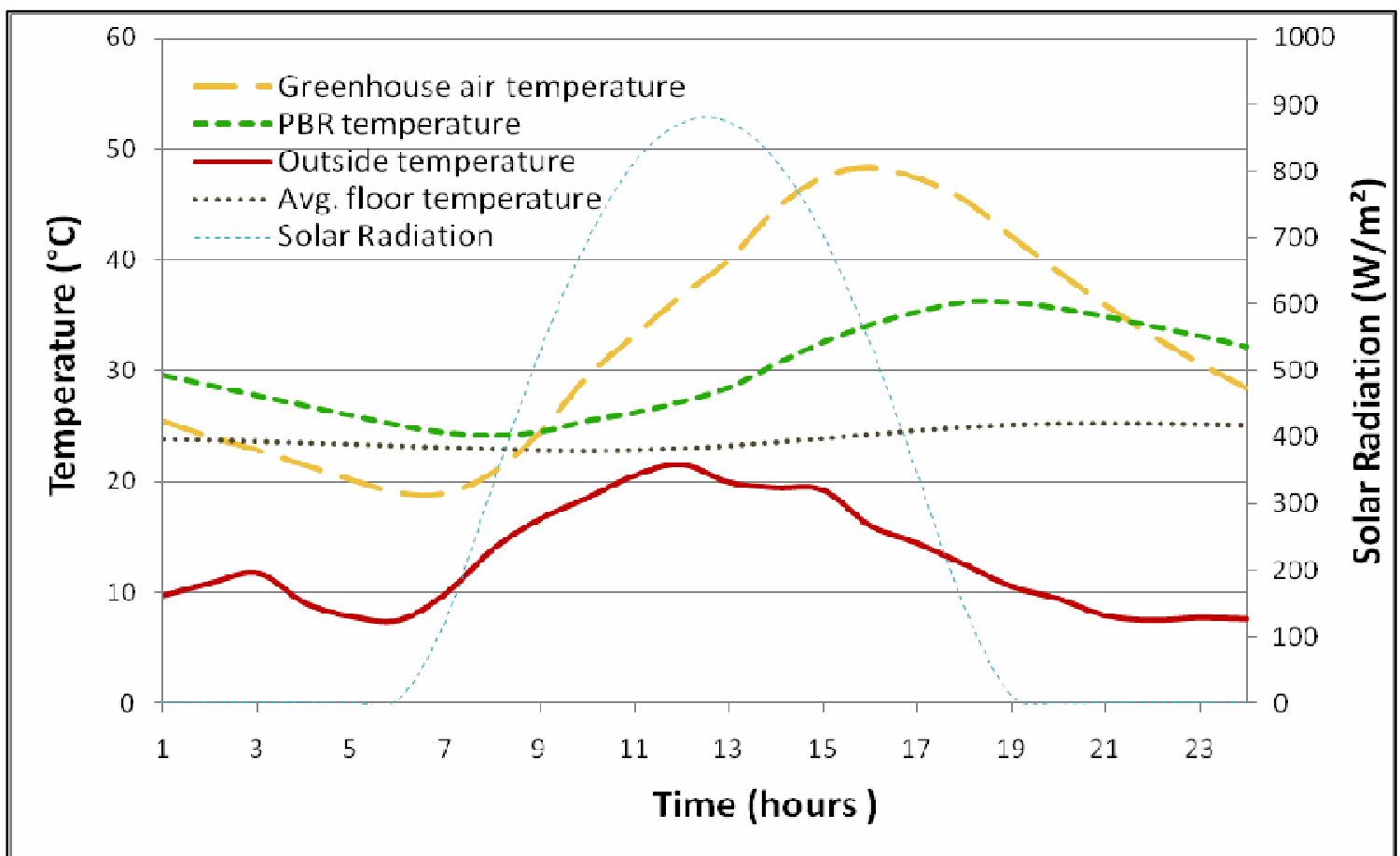

Figure 44. Temperature distribution on a clear day (April 10 $\left.{ }^{\text {th }}, 2007\right)$.

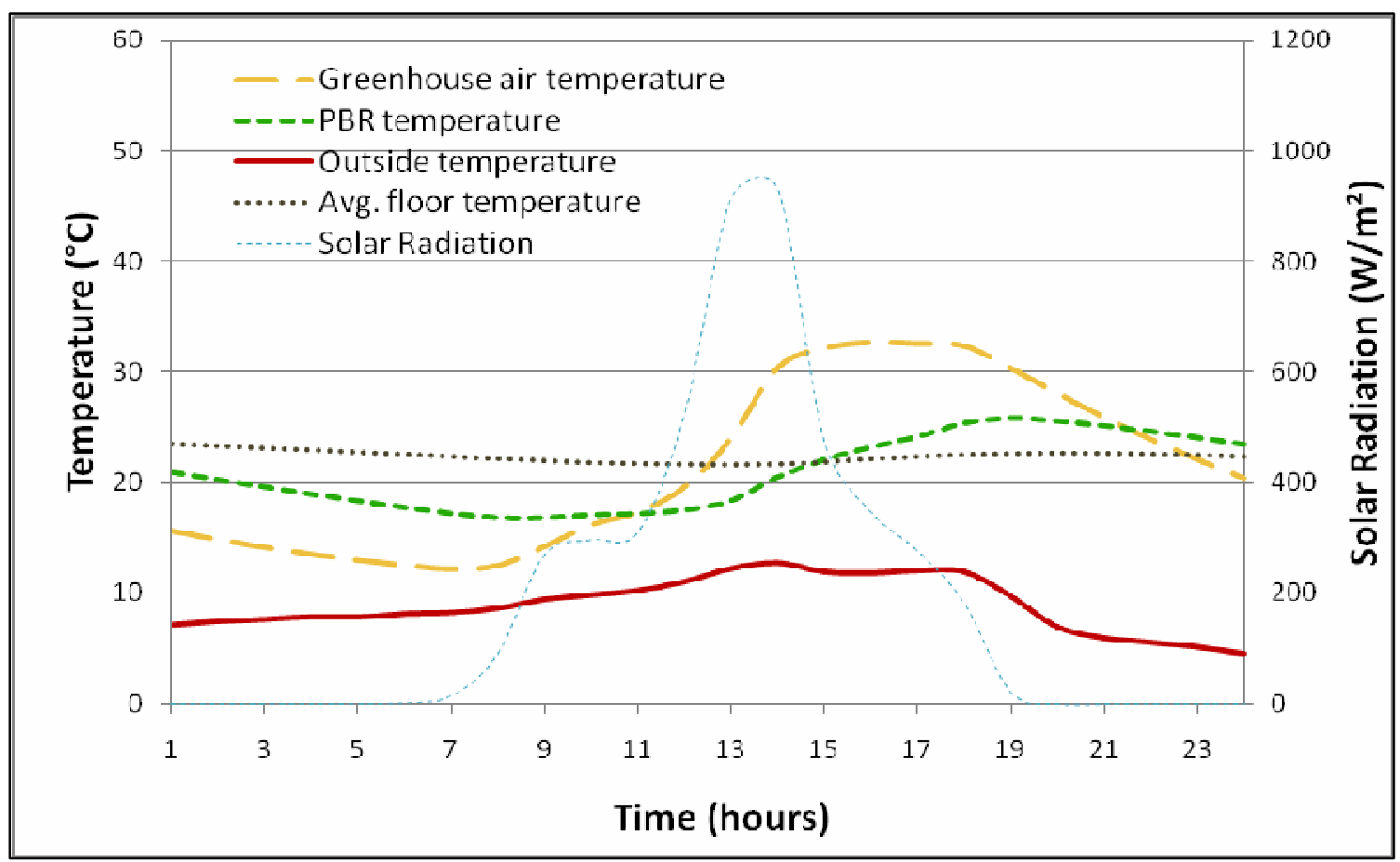

Figure 45. Temperature distribution on an overcast day (April $20^{\text {th }}, 2007$ ). 
Figure 44 and Figure 45 show the temperature distribution for an indoor PBR operation on a clear day and an overcast day, respectively, in a scaled-up view in order to have a deeper insight and better understanding. Obviously, there was a much higher greenhouse, floor and PBR temperature, compared to the outdoor PBR condition, where the temperature followed the outside temperature air closely. Here, the greenhouse air was used as a heat buffer and kept the surrounding air of the PBR at relatively higher temperatures (what also can turn into a disadvantage on hot days if proper ventilation is not provided, because the PBR temperature will rise accordingly). The floor temperature was maintained at about $5{ }^{\circ} \mathrm{C}$ above the outside conditions. As typical for greenhouses, the inside air temperature was mainly a function of the incoming solar radiation rather than that of the outside air temperature, which also explains the temperature differences between the outdoor and indoor PBR operations. The outdoor PBR was exposed to the outside air and the indoor PBR was exposed to the greenhouse air.

The inside air temperature fluctuated more than the inside PBR temperature, and the inside PBR temperature more than the floor temperature, due to relatively smaller heat storage capacities. The PBR temperature responded to the greenhouse temperature with a lag phase of 1 to 3 hours due to the greater thermal mass. The floor temperature followed the PBR temperature by another 1 to 3 hours. The maximum air temperatures in the greenhouse, especially at the end of the month when the solar radiation was much higher $\left(980 \mathrm{~W} / \mathrm{m}^{2}\right.$ instead of $\left.820 \mathrm{~W} / \mathrm{m}^{2}\right)$, reached up to $50{ }^{\circ} \mathrm{C}$ and above. Even the PBR temperature rose to the upper $40{ }^{\circ} \mathrm{C}$, and the floor temperature to almost $30{ }^{\circ} \mathrm{C}$. This phenomenon was experienced during trial runs of a lab-scale PBR in a greenhouse with no cooling, shading or ventilation on Cal Poly campus in Spring 2008. Greenhouse 
temperatures of up to $50{ }^{\circ} \mathrm{C}$ and PBR temperatures of far more than $40{ }^{\circ} \mathrm{C}$ were recorded then. As a consequence, the algae died (also shown in the temperature experiments in the previous section).

Not only too high temperatures, but also too low temperatures harmed algae growth as shown in the temperature experiments section earlier. The theoretical yield losses due to temperature fluctuations (or not maintaining the temperature at optimal level) can be calculated with the data obtained from the experiments. The yield losses were expressed as percent productivity where the productivity at optimal temperature was 100\%. Temperatures above and below the optimum reduced the productivity.

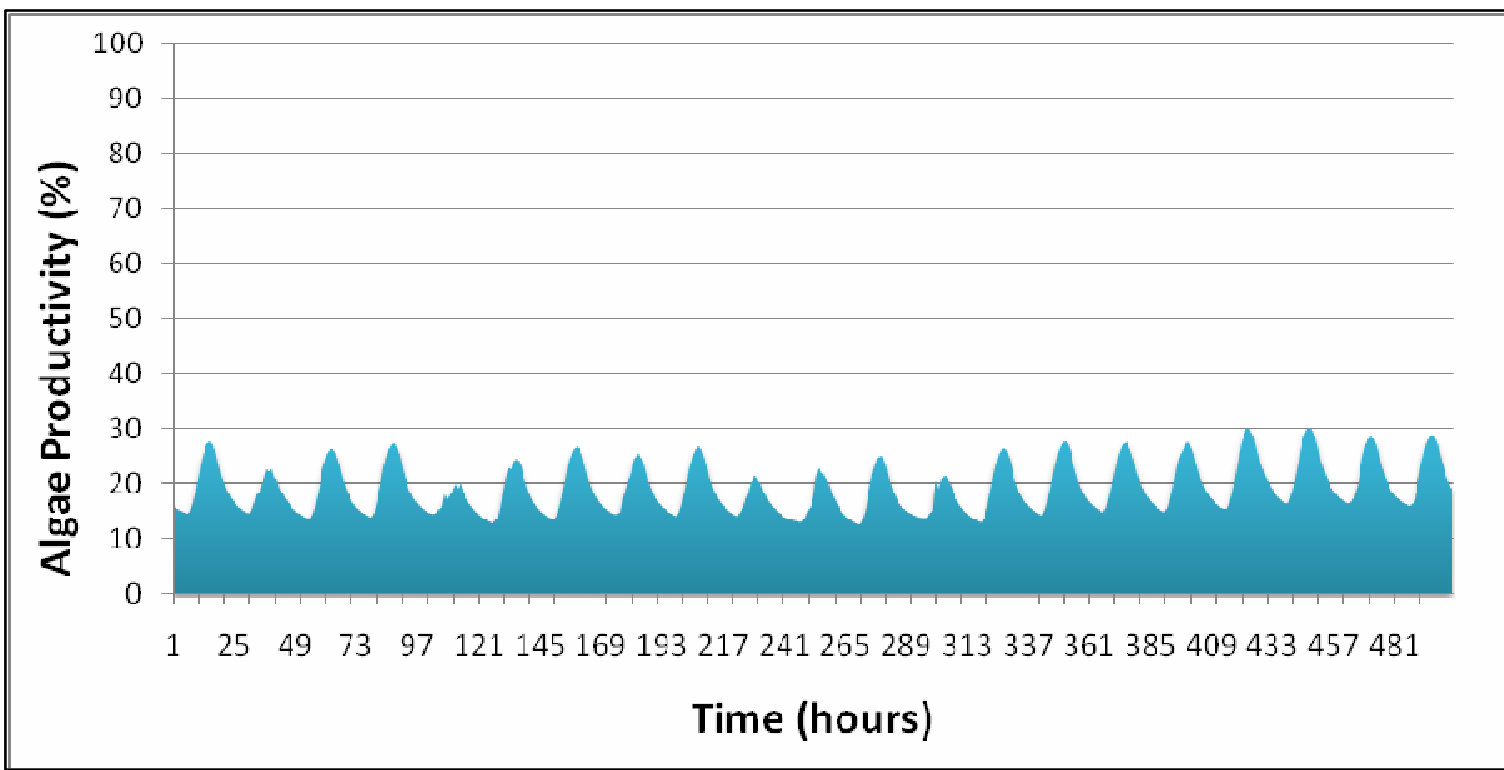

Figure 46. Algae productivity with respect to the temperature in each hour in the outdoor PBR operation. 
Detailed productivity rates per hour were presented in Figure 46 and Figure 47 for outdoor and indoor operations, respectively. The average productivity for outdoor operations was $23.4 \%$ (in Figure 46 it was shown as blue area, whereas the white area under the $100 \%$ line was the productivity losses). The average productivity for the indoor operation was $66.9 \%$ (in Figure 47 it was shown as orange area). The main difference between the outdoor and indoor operations was the way productivity losses occurred. In the outdoor operation, all productivity losses occurred due to low temperatures (the solar radiation was not strong enough to heat up the system to optimal temperature), whereas in the indoor operation, productivity losses occurred mainly due to overheating of the PBR.

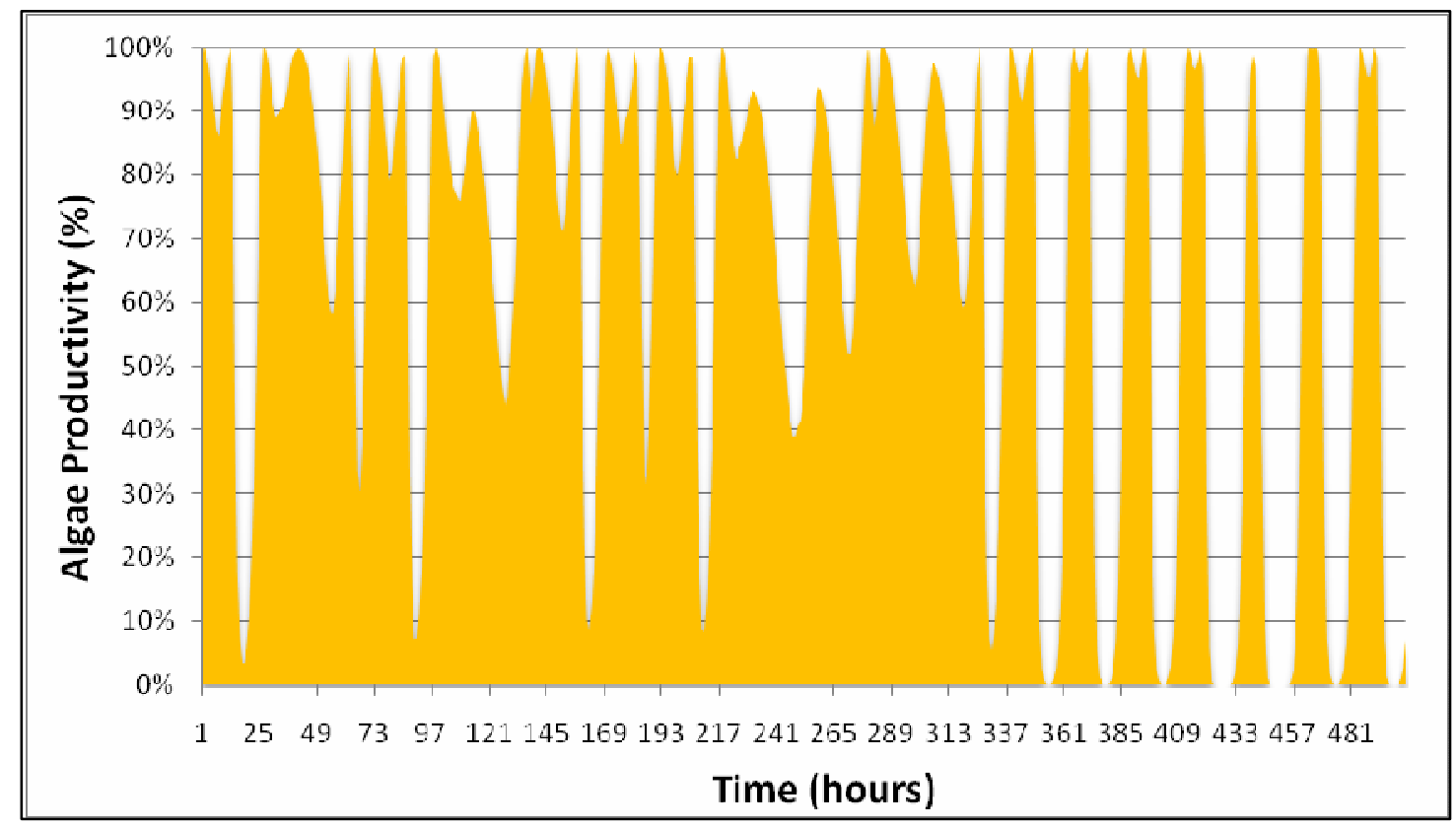

Figure 47. Algae productivity with respect to the temperature in each hour in the indoor PBR operation. 
For visualization purposes, it was now assumed that overheating would not cause productivity losses. Figure 48 shows the impressive productivity rate averaging at $90 \%$. Consequently, two different strategies for controlling the temperature in outdoor and indoor operations were considered: Cooling the greenhouse and PBR for indoor operation; and heating the PBR for the outdoor operation.

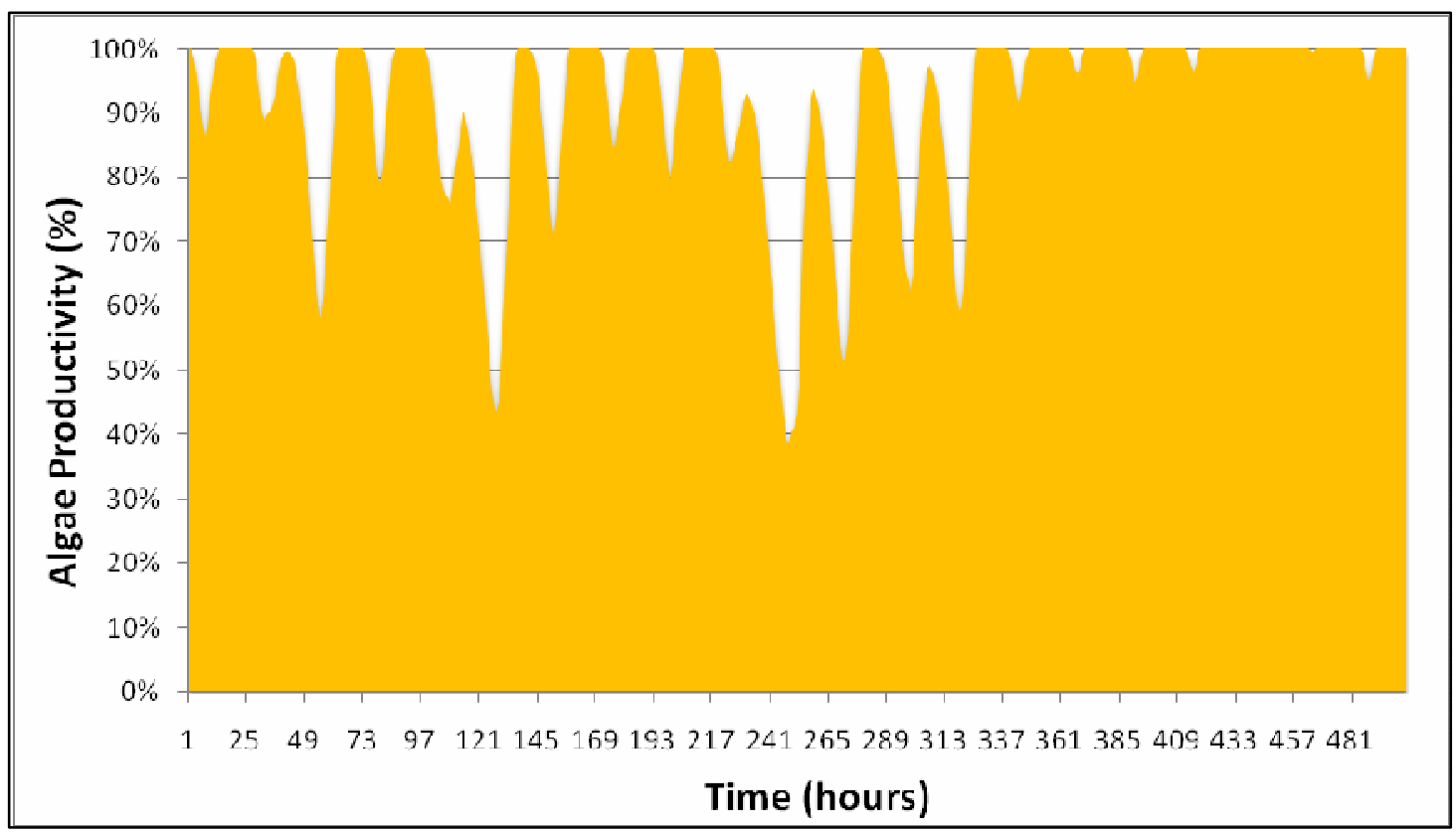

Figure 48. The hypothetical algae productivity with respect to the temperature in each hour for indoor PBR operation, when losses due to overheating were ignored.

As the next step, the actual amount of energy needed for heating and cooling was determined. The heating and cooling loads were calculated and presented separately because the technology and therefore the energy prices for heating and cooling are different. Generally speaking, heating is cheaper than cooling a system. Heat is a byproduct of many industrial processes, and can either be purchased for moderate prices or produced easily with a burner. Therefore, reducing the cooling loads in the first place is always the major goal. Appendix A presents the heating and cooling loads for indoor 
and outdoor operations for each day. The daily figures were the sums of the hourly heating and cooling loads calculated. Average values per day and the total sum for the period studied (here 21 days) were shown in Appendix A. As discussed previously, the total cooling load for outdoor conditions (593 MJ for the period of 21 days) could be neglected. However, an average heating load of 90,212 MJ per day and a total heating load of 2,338,000 MJ for the entire period of 21 days was determined. Heating loads for the indoor PBR operation of 14,091 MJ (average per day) and 411,580 MJ for the entire period of 21 days were determined. However, in the case of indoor operation, the cooling loads were very high (12,097 MJ average per day, and 266,320 MJ total for the entire period). Figure 49 shows the heating and cooling loads for the indoor operation graphically.

The easiest way to reduce cooling loads is to reduce solar radiation. The simplest way to reduce the solar gains is to provide shading with a shading cloth, curtain, or whitening the greenhouse glazing. Simulations were performed with a curtain or whitening having transmissivities of $60 \%$ and $80 \%$, and findings were presented in Appendices B and C, respectively. For a cover with $60 \%$ transmissivity, the cooling loads were significantly reduced (1,228 MJ average per day, 25,790 MJ total for the entire period). This was only about $10 \%$ of the cooling needed in a greenhouse without shading. However, heating loads increased in this scenario to $30,990 \mathrm{MJ}$ on a daily basis, and to $837,320 \mathrm{MJ}$ in total for the entire period (about 203\% more than the base scenario), which was still small compared to outdoor operation. 
In a third scenario, the energy needs using a whitening or curtain with an $80 \%$ transmissivity was simulated. The cooling loads decreased further compared to the first scenario by 55\% (5,420 MJ based on daily basis, $115,610 \mathrm{MJ}$ total for the entire period). The heating loads increased by $148 \%$ (20,902 MJ based on daily basis, 585,170 MJ total for the entire period).

With the knowledge of heating and cooling costs, the best scenario could be determined to minimize operational costs. Obviously, it would be different for each analyzed project. The previous comparison of scenarios was done for the change of cover transmissivities just to show the effect of a single variable on heating and cooling requirements. In addition to that, many other variables, for instance, tube diameter, number of tubes, number of PBRs, etc. could be examined as well. Dozens of parameters could be optimized for energy consumption, which would be the topics for future studies.

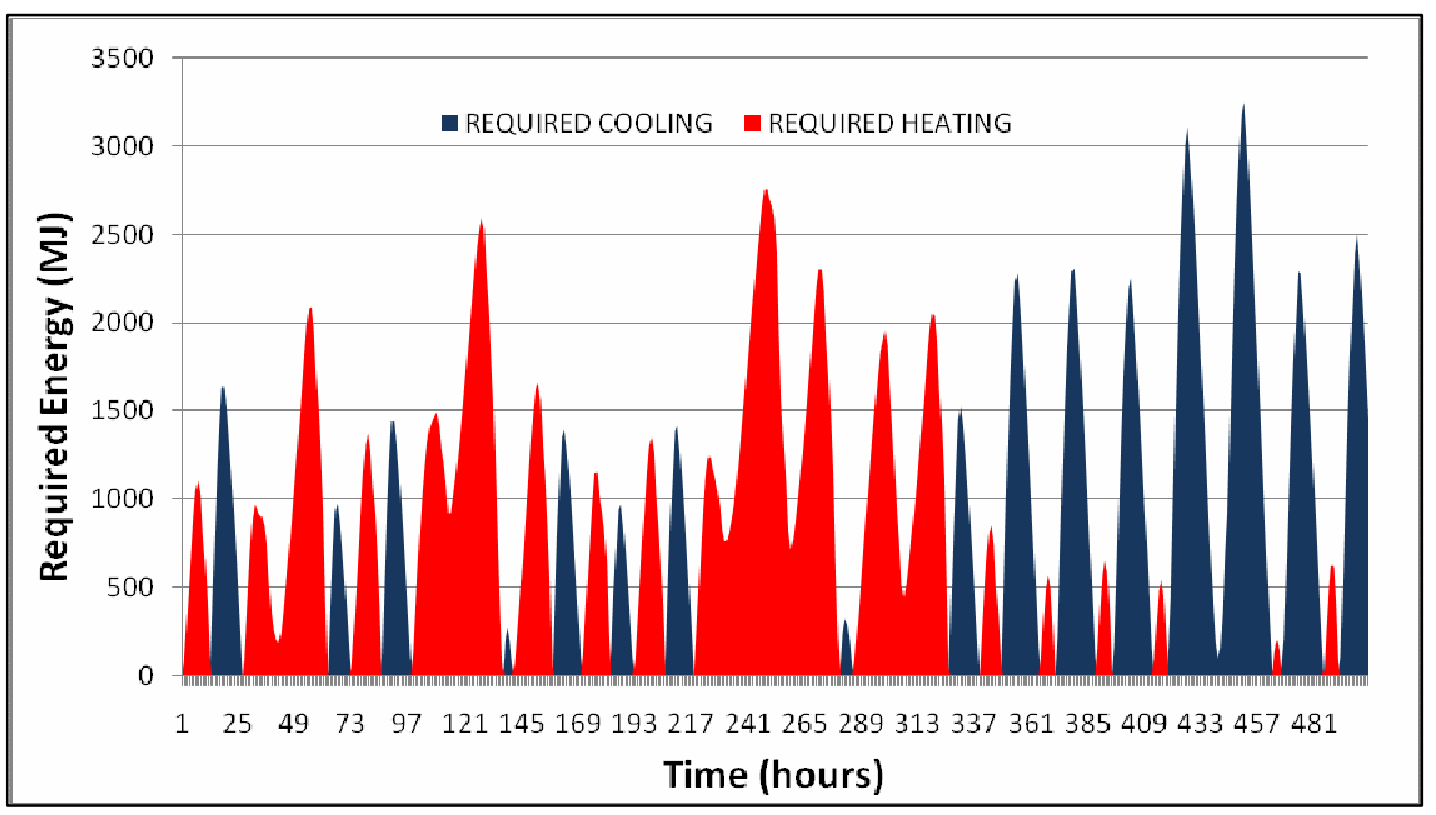

Figure 49. Required heating and cooling loads for the indoor PBR operation. 


\section{CHAPTER V}

\section{CONCLUSIONS}

\subsection{Temperature Experiments}

A procedure was developed and used for Chlorella algae to determine the growth dependency on temperature. The experimental data was needed to develop a mathematical model for heat management purposes. Besides a literature review for common strains, this was another method to provide the necessary data. For the Chlorella strain, the developed method resulted in a similar maximum growth rate as previously presented in the literature; i.e. 1.44 doublings per day versus 1.0 to 2.0 doublings per day. In this study, it was not required to reach the maximum growth rate, rather to monitor the growth distribution as a function of temperature. The important outcome was the percent losses and gains with respect to the observed maximum growth rate. This goal was fulfilled, and the data was successfully incorporated into the simulation model.

Some weaknesses of the procedure included the measurement of the nutrient content in the algae water. The multimeter operated based on the transmittance of a specific wavelength. At higher densities $(>25 \%)$, the green algae water caused misreadings and errors. The accuracy of the measurements decreased subsequently. However, for this study, an exact measurement was not essential. The nutrient availability was critical and maintained at high nutrient levels. Even with a large tolerance band of the nutrient measurement, the minimum requirements were always maintained. The nutrients (fertilizer) in this study were chosen only based on the N-P-K 
ratio. For further experiments, micronutrients, vitamins and silicon additions should be considered at proper concentrations.

The sensitivity of the spectrophotometer played an important role. Especially for small transmittance readings $(<20 \%)$, a slight difference of only $1 \%$ had an impact on the calculated growth rate of up to 0.3 doublings per day. A more precise spectrophotometer with digital readings and PC control would provide better accuracy and more reliable data, as well as the possibility of long term data storage.

The room where the experiments took place was not fully darkened, so the daylight probably had a small impact on the growth rate as well. Since the daily radiation fluctuated during the experiments, it could have impacted the results slightly.

The density range of 5\% to $85 \%$ transmittance was very large. Especially for high densities, optimal algae growth could be harmed. For future research, it is recommendable to keep the cell density low (transmittance $>15 \%$ ), which would lead to better growth conditions, but the frequency of diluting the broth would decrease consequently. A more frequent dilution would cause more lag (adaption) phases and would extend the time of research.

The sample sizes were relatively small due to an enormous amount $(>50 \%)$ of void measurements. For future experiments, a longer period of time or more parallel PBRs should be considered. With the experimental improvements mentioned above, the amount of void measurements could be reduced. 


\subsection{Heat Management Model}

The developed heat management model delivered good results for the temperature regime in greenhouses and PBRs, comparable to experiences made for the same location at the same time of the year in the Cal Poly campus greenhouse. From the temperature data, the heat management requirements for any specific location could be estimated. Using the model could in advance (i.e. in a planning stage of a project) precisely estimate its future heating or cooling loads, or estimate the productivity without heating or cooling. This simulation model is a fundamental tool and guidance in the economical decision making processes related to algae growth in photobioreactors.

Sensitivity analyses for outside air temperature, solar radiation, ground reflectivity, PBR column distance, transmissivity of the shading material, and ventilation rate were performed on the model. It took the system roughly two days to adjust to an outside temperature step change of $15{ }^{\circ} \mathrm{C}$. As expected, the storage components with smaller thermal mass (i.e. greenhouse air) reacted faster to environmental influences than components with larger thermal mass (i.e. ground). Therefore, the daily temperature peaks of the greenhouse air temperature, $\mathrm{PBR}$ temperature, and ground temperature had a gap of 1 to 4 hours. The sensitivity analysis for the ground reflectivity showed that the energy requirements rose with higher reflectivity. The algae productivity dropped with higher reflectivity. The sensitivity analysis for the PBR column distance showed a dependency of energy requirement on the distance. The wider the PBR columns were

placed apart, the more energy was consumed. However, the algae productivity was the highest at $0.75 \mathrm{~m}$ column distance. This led to the conclusion that there is an optimal 
distance between PBR columns for any specific PBR design, where the productivity rate peaks. The transmissivity of the shading material had a major impact on the energy requirements as well as the productivity rate. The heating needs increased by over $300 \%$ when putting any kind of shading with a transmissivity of $20 \%$ on the greenhouse. However, cooling requirements can be reduced to zero just by changing the shading. This gives a huge optimization potential for photobioreactor operators. The ventilation rate had hardly influence on the algae productivity, however, can reduce cooling loads of the photobioreactor.

A simulation of a hypothetical tubular photobioreactor in San Luis Obispo, California, U.S.A. with a volume of about 100,000 liter capacity showed the potential of the model exemplary. Average algae productivity rates of $23 \%$ and $67 \%$ for outdoor and indoor PBR operations, respectively, were obtained. Changing parameters (e.g. diameter, distance, reflectivity, number of PBRs, etc.) in the model had direct impact on the algae productivity rate and could be compared easily to the base case. Actual energy loads (heating and cooling) needed to maintain the PBR at optimal temperature were determined and compared, too. With the knowledge of the actual energy requirements, photobioreactor operators will be able to estimate their operational costs in advance and see what changes to their system would decrease their costs.

The developed model is only a mathematical estimation tool. An experimental validation of the model is still to be performed in future studies, in order to see the deviations to the real case. The validation could be carried out in the Cal Poly greenhouse after the commercial PBR is installed. 
The model itself can be optimized as well. Instead of using one-hour time intervals, the true interval could be reduced to minutes, which would provide better estimates of energy consumptions.

In addition to the presented analyses, many other parameters could be examined. Since all greenhouse and PBR dimensions are variable, heat requirements for different greenhouse types or PBRs could be compared easily.

Later on, the model could be extended to estimate all energy needs; for example, the pumping energy requirements for the specific PBR; the energy and productivity of artificial lighting; or the energy required for harvesting (centrifuge, drying, ultrasonic, pressing, etc.). All operational costs could be estimated and optimized accordingly.

Eventually, a complete production facility could be simulated with all inputs and outputs. Entire economical studies could be performed using selling prices for algae cake, algae oil or biodiesel directly in the model. Furthermore, doing a reverse analysis by introducing the desired price of a liter or gallon of biodiesel/ethanol could also be performed. The model would estimate the production plant size; suggest the location based on its latitude and required solar radiation, and give out the operational costs.

An all-in-one application for the the planning and operation of photobioreactors is the target. 


\section{BIBLIOGRAPHY}

Acien Fernandez, F., Garcia Camacho, F., Sanchez Perez, J. A., and Molina Grima, E. (1998). Modeling of Biomass Productivity in Tubular Photobioreactors for Microalgal cultures: Effects of Dilution Rate, Tube Diameter, and Solar Irradiance. Biotechnol. Bioengin., 605-616.

Akhter, M. P., G. E. Meyer and J. A. DeShazerv .(1988). -Evaluation of a passively heated and cooled Alpine greenhouse-simulation studies. Unpublished. University of Nebraska-Lincoln, Nebraska, U.S.A.

Alberts, B. (2002). Molecular Biology of the Cell. Garland Science.

Aldrich, R., and Bartok, J. W. (1992). Greenhouse Engineering. Ithaca, NY: Northeast Regional Agricultural Engineering Service.

AlgaeLink. (2007). (ALGAELINK) Retrieved from: http://www.algaelink.com.

Antoni, D., Zverlov, V. V., and Schwarz, W. H. (2007). Biofuels from microbes. Applied Microbiology and Biotechnology, 77 (1), 23-35.

Aqua Medic GmbH. (2007). Retrieved from www.aquamedic.com.

ARD. (2004). Erstes Deutsches Fernsehen. Retrieved from www.ard.de.

Arinze, E. A., G. J. Schoenau, R. W. Besant. (1984). A dynamic thermal performance simulation model of an energy conserving greenhouse with thermal storage. Transactions of the ASAE 27: 508-519.

Avissar, R. and Y. Mahrer. (1982). Verification study of a numerical greenhouse microclimate model. Transactions of the ASAE. 711-1720.

Barbera, E., Thomas, X., Moya, M., Ibanez, T., and Molins, M. (1993). Significance tests in the study of the specific growth rate of Haematococcus lacustris: influence of carbon source and light intensity. Ferment. Bioeng., 5, 403-405.

Barbosa, M. J. (2003). Microalgal photobioreactors: Scale-up and optimisation. Ph.D. Dissertation. Wageningen University.

Becker, E. (1994). Microalgae: biotechnology and microbiology (Vol. 10). (J. Baddiley, Ed.) Cambridge, New York: Cambridge Univ. Press. 
Bischoff, H., and Bold, H. (1963). Some algae from Enchanted Rock and related algal species. In Phycological studies IV. The University of Texas. Publ. 6318.

Boussiba, S., and Vonshak, A. (1991). Astaxabthin accumulation in the green algae Haematococcus pluvialis: cellular phycolohy and stress response. Plant Cell Physiology, 5, 1077-1082.

Chen, F. (1996). High cell density culture of microalgae in heterotrophic growth.

Chisti, Y. (2007). Biodiesel from microalgae. Biotech Advances, 25, 294-306.

Climatechange CA. (2005). Retrieved from http://www.climatechange.ca.gov.

Cooper, P. I. (1969). The Absoption of Solar Radiation in Solar Stills. Solar Energy, 12 (3).

Darley, W. M. (1982). Algal Biology: a physiological approach. Oxford, UK: Blackwell Scientific Publications.

Dauta, A., Devaux, J., Piquemal, F., and L., B. (1990). Growth rate of four freshwater algae in relation to light and temperature. Hydrobiologia, 207, 221-226.

Degen, J. (2003). Entwicklung eines Photobioreaktors mit verbesserter Lichtnutzung für Mikroalgen. Ph.D. Dissertation. Stuttgart: Fraunhofer IRB Verlag.

Del Campo, J. A., Garcia-Gonzalez, M., and Guerrero, M. (2007). Outdoor cultivation of microalgae for caotenoid production: current state and perspectives. Applied Microbiology and Biotechnology, 74, 1163-1174.

Dietz, A. G. (1963). Introduction to the Utiliyation of Solar Energy. New York: McGraw-Hill.

Dominguez-Bocanegra, A., Legarreta, I. G., and Jeronimo, F. M. (2004). Influence of environmental and nutritional factors in the production of astaxanthin from Haematococcus pluvialis. Bioresource Technology, 92, 209-214.

Duffie, J. A., and Beckman, W. A. (2006). Solar Engineering of Thermal Processes. Hoboken, New Jersey: John Wiley and Sons, INC.

Eppley, R. (1972). Temperature and phytoplankton growth in the sea. Fishery Bulletin , 70, 1063-1085. 
Eppley, R., and Renger, E. (1974). Nitrogen assimilation of an oceanic diatom in nitrogen-limited continuous culture. (10), 15-23.

Esapub. (2006). Retrieved from www.esapub.esrin.esa.it.

Eskandari, S. (2008). Temperature Coefficient (Q10). Retrieved from California State Polytechnic University, Pomona: http://www.csupomona.edu/ seskandari/physiology/physiological_calculators/Q10.

Espinasse, M. (1962). Robert Hooke. Berkeley and Los Angeles: University of California Press.

Fabregas, J., Dominguez, A., Regueiro, M., Maseda, A., and Otero, A. (2000). Optimization of culture medium for the continuous cultivation of the microalga Haematococcus pluvialis. Applied Microbioly and Biotechnooly, 53, 530-535.

Feng, C. (2007). A pilot plant two-phase anaerobic digestion system for bioenergy recovery from swine wastes and garbage. Waste Management.

Fraunhofer IGB. (2002). http://www.igb.fraunhofer.de.

Gate. (1999). Biogas technology in India. Eschborn, Germany: Deutsches Zentrum fur Entwicklungstechnologien.

GGMP. (2007, 01 31). The International Research Consortium on Continental Margins. Retrieved from International University Bremen: http://www.irccm.de/greenhouse.

Goldman, J., and Carpenter, E. (1974). A kinetic approach to the effect of temperature on algal growth. Limnology and Oceanography , 19 (5), 756-766.

Green Car Congress, (2006). Retrieved from www.greencarcongress.com.

GreenFuel Technologies Corporation. (2008). Retrieved from http://www.greenfuelonline.com/index.html

Grima, E. M., Fernandez, F. A., Camacho, F. G., Rubio, F. C., and Chisti, Y. (2000). Scale-up of tubular photobioreactors. J. Appl. Phycol., 12, 355-368.

Grote, K.-H., and Feldhusen, J. (2003). Dubbel: Taschenbuch für den Maschinenbau. Springer Verlag.

Glaub, Jefand G. J. Trezek. (1981). Heat and mass transfer analysis of greenhouse. ASAE Paper No: 81-4031, ASAE, St. Joseph, Ml 49085, U.S.A. 
Health From The Sun. (2006). Essential Fatty Acids and Herb FAQ's: What are the hazards of Hexane?". Retrieved from www.healthfromthesun.com.

Heubeck, S. (2007). Influence of CO2 scrubbing from biogas on the treatment performance of a high rate algal pond. Water Science and Technology, 55 (11), 193200.

Hielscher, T. (2005). Ultrasonic production of nano-size dispersions and emulsions. ENS'05. Paris, France.

Hinrichs, R., and Kleinbach, M. (2006). Energy: Its Use and the Environment (Fourth ed.). Belmont: THOMSON Higher Education.

Hoek, C. v., Mann, D., and Jahns, H. (1995). Algae An introduction to phycology. Cambridge: Cambridge University Press.

Huntley, M. E., and Redalje, D. G. (2007). CO2 Mitigation and Renewable Oil from Photosynthetic Microbes: A new Appraisal. Mitigation and Adaption Strategies for Global Change, 573-608.

Hurlbert, G. (n.d.). Penn State University. Retrieved from http://www.slic2.wsu.edu:82/hurlbert/micro101/pages/101lab3.html

Incropera, F., Dewitt, D., Bergman, T., and Lavine, A. (2007). Introduction to Heat Transfer. Hoboken, NJ: John Wiley and Sons.

Institute for Applied Environmental Economics. (2006). Aqueous Enzymatic Extraction of Oil from Rapeseeds. Retrieved from http://www.p2pays.org/ref/10/09365.htm

Iqbal, M. (1983). An Introduction to Solar Radiation. Toronto: Academic Pub.

Jonathan, B., Mason, K. A., and Singer, S. R. (2007). Biology. McGraw-Hill.

Kirk, J. (1994). Light and photosynthesis in aquatic systems. Cambridge: Cambridge University press.

Kindelan, M. (1980). A dynamic modeling of greenhouse environment.. Transactions of the ASAE 23 (5): 1232-1239.

Kulessa, M. E., Bode, S., Oberthür, S., Anderson, J., Walz, R., Schade, W., et al. (2007). The Climate Policy of the European Union. Intereconomics, 42 (2). 
Laval, A. (2004). Alfa Laval - disc stack centrifuge technology.

Lee, Y.-K., Ding, S.-Y., Low, C.-S., Chang, Y.-C., Forday , and Chew, P.-C. (1994).

Design and performance of an $\alpha$-type tubular photobioreactor for mass cultivation of microalgae. J. Appl. Phycol., 47-51.

Lehman, J., Botkin, D., and Likens, G. (1975). The assumptions and rationales of a computer model of phytoplankton population dynamics. Limnology and Oceanography, 20, 343-364.

Li, A., Antizar-Ladislao, B., and Khraisheh, M. (2007). Bioconversion of municipal solid waste to glucose for bio-ethanol production. Bioprocess and Biosystems Engineering, 30 (3), 189-196.

Luening, K. (1981). Light. In C. Lobban, and M. J. Wynne, The Biology of Seaweeds. Berkeley and Los Angeles: Univ. Calif. Press.

Molina-Grima, E., Fernandez, F. A., and Medina, A. R. (2004). Downstream processing of cell-mass and products. In A. Richmond, Handbook of microalgal culture (pp. 215-251). Oxford, UK: Blackwell Science.

Molhave, K. (2006). http://kristian.molhave.dk/index.htm.

Nichols, H., and Bold, H. (1969). Trichsacina polyinorpha gene. et sp. nov. Phycology, 1, 34-38.

Nishino, H. (1998). Cancer prevention by carotenoids. Mutat. Res. (402), 363-366.

NREL. (1998). A Look Back at U.S. Department of Energy's Aquatic Species Program: Biodiesel from Algae. National Renewable Energy Laboratory. Golden, Colorado, USA: John Sheehan, Terri Dunahay, John Benemann, Paul Roessler.

Ogbonna, J., Yada, H., and Tanaka, H. (1995). Light Supply Coefficient: a new Engineering parameter for Photobioreactor Design. J. Ferment. Bioengin., 369-376.

Oilgae. (2006). Retrieved from htttp://www.oilgae.com.

Olaizola, M. (2000). Commercial production of astaxanthin from Haematococcus pluvialis using 25,000-liter outdoor photobioreactor. Applied Phycology, 12, 499-506.

P. E. (2004). Beta Test Set for Emission-Fighting Algae Bioreactor. Retrieved from http://pepei.pennnet.com/. 
Pirt, S. J., Lee, Y., Walach, M., Pirt, M., Balyuzi, H., and Bazin, M. (1983). A Tubular Bioreactor for photosynthetic production of Biomass from Carbon Dioxide: Design and Performance. J. Chem. Tech. Biotechnol., 35-58.

PFW. (n.d.). Pressed for Wine. Retrieved from www.pressedforwine.com.

Prince Edwards Island Government Food Technology Centre. (2006). Sonochemistry. Retrieved from http://www.gov.pe.ca/ftc/index.php3?number=1006554andlang=E.

Provasoli, L., and F., C. A. (1974). Vitamins and growth regulators. In W. Stewart, Algal Physiology and Biochemistry (pp. 741-787). Oxford: Blackwell Scientific Publications.

Pulz, O. (2007). Evaluation of GreenFuel's 3D Matrix Algae Growth Engineering Scale Unit.

Pulz, O. (2001). Photobioreactors: production systems for phototrophic microorganisms. Applied Microbiology and Biotechnology, 57, 287-293.

Pulz, O., and Gross, W. (2004). Valuable products from biotechnology of microalgae. Applied Microbiology and Biotechnology, 65, 635-648.

Pulz, O., and Scheibenbogen, K. (1998). Photobioreactors: Design and performance with respect to light energy input. In Bioprocess and Algae Reactor Technology, Apoptosis (Vol. Volume 59/1998).

Raven, J., and Geider, R. (1988). Temperature and algal growth. New Phytol., 110, 441-461.

Renouables. (2007). energies-renouvelables. http://www.energies-renouvelables.org.

Reynolds, C. (1984). The Ecology of Freshwater Phytoplankton. Cambridge University Press.

Richmond, A. (2000, 12). Microalgal biotechnology at the turn of the millennium: A personal view. Applied Phycology, 441-451.

Rudloff, M. (2005). Biomass-to-Liquid Fuels (BtL) - Made by CHOREN - Process, Environmental Impact and Latest Developments. Automobile and Environment at Belgrade EAEC Congress, May 2005. CHOREN.

Schulz, T. (2006). The economics of micro-algae production and processing into biodiesel. Farming Systems, Department of Agriculture Western Australia.

Seambiotic. (2008). Retrieved from www.seambiotic.com. 
Shuler, M., and Kargi, F. (2002). Bioprocess Engineering. Upper Saddle River, NJ, USA: Prentice Hall PTR.

Soetaert, W. (2006). The impact of industrial biotechnology. Biotechnology Journal, 1, $756-769$.

Sparknotes. (2007). http://www.sparknotes.com.

Spicher, D. (2008). Auswirkungen von Retrofit im deutschen Kraftwerkspark: Implementierung im GEMS-Modell des Energiewirtschaftlichen Instituts Köln. Cologne: University of Cologne.

Stryer, L. (1975). Biochemistry. W. H. Freeman and Company.

Sullivan, C. (1977). Diatoms mineralization of silicic acid. J. Phycology, 13, 86-91.

Supercritical Fluid Technologies. (2006). How Do Supercritical Fluids Work? Retrieved from http://www.supercriticalfluids.com/faqs.htm.

Suslick, K. (1998). In J. W. Sons, Kirk-Othmer Encyclopedia of Chemical Technology; 4th ed. (pp. 517-541). New York.

Swinbank, W. C. (1963). Long-Wave Radiation From Clear Skies. J. Roy. Meteorol. Soc.

Takakura, T. K., A. Jordan, and L. L. Boyd. (1971). Dynamic simulation of plant growth and environment in the greenhouse. Transactions of the ASAE 14 (5): 964-971.

Thomas, D. (2002). Seaweeds. London: The Natural History Museum.

Vargaftik, N. (1975). Tables of thermophysical Properties of Liquids and Gases. New York: Hemisphere Publishing.

Varicon Aqua Solutions Ltd. (2004). Retrieved from http://www.variconaqua.com.

Weiland, P. (2000). Anaerobic waste digestion in Germany - Status and recent developments. Biodegradation, 6 (6), 415-421.

Wu, X., and Merchuk, J. C. (2002). Simulation of Algae Growth in a Bench Scale Bubble Column Reactor. Biotechnol. Bioengin., 156-1568.

Wu, Y., Jenkins, T., Blunden, G., von Mende, N., and Hankins, S. (1998). Suppression of fecundity of the root-knot nematode, Meloidogyne javanica, in monoxenic cultures of Arabidopsis thaliana treated with an alkaline extract of Ascophyllum nodosum. Applied Phycology, 10, 91-94. 
Yildiz, I. (1993). Simulation of greenhouse microclimates and environmental control strategies using a Rankine cycle heat pump. Ph.D. Dissertation. The Ohio State University. Columbus, Ohio, U.S.A., 63-65.

Yun, Y., and Park, J. (2001). Attenuation of Monochromatic and polychromatic lights in Chlorella culgaris suspensions. Appl. Microbiol. Biotechnol., 765-770.

Zeta-Meter, I. (1993). Everything you want to know about Coagulation and Flocculation.

Zumft, W. (1997). Cell biology and molecular basis of denitrification (Vols. In: Microbiol. Mol. Biol. Rev. Bd. 61, Nr. 4, ). Cologne, Germany. 
Appendix A: Energy requirements per day for standard transmissivity. 


\section{ENERGY REQUIREMENTS}

Standard conditions

\begin{tabular}{|c|c|c|c|c|}
\hline Day & $\begin{array}{c}\text { Outdoor PBR } \\
\text { HEATING }\end{array}$ & $\begin{array}{c}\text { Outdoor PBR } \\
\text { COOLING }\end{array}$ & $\begin{array}{l}\text { Indoor PBR } \\
\text { HEATING }\end{array}$ & $\begin{array}{c}\text { Indoor PBR } \\
\text { COOLING }\end{array}$ \\
\hline $4 / 10 / 2007$ & $79,589.92$ & - & $7,597.61$ & $12,851.42$ \\
\hline $4 / 11 / 2007$ & $98,322.68$ & - & $12,629.32$ & 763.38 \\
\hline $4 / 12 / 2007$ & $96,634.68$ & - & $21,271.53$ & $5,719.14$ \\
\hline 4/13/2007 & $89,956.91$ & - & $10,624.42$ & $10,509.83$ \\
\hline $4 / 14 / 2007$ & $102,787.00$ & - & $24,379.18$ & 450.80 \\
\hline $4 / 15 / 2007$ & $101,199.15$ & - & $30,602.05$ & 756.65 \\
\hline $4 / 16 / 2007$ & $85,740.59$ & - & $15,004.92$ & $9,751.53$ \\
\hline $4 / 17 / 2007$ & $97,253.60$ & - & $8,775.14$ & $6,196.31$ \\
\hline $4 / 18 / 2007$ & $99,619.53$ & - & $10,506.93$ & $9,976.65$ \\
\hline $4 / 19 / 2007$ & $109,223.92$ & - & $22,219.41$ & 255.85 \\
\hline $4 / 20 / 2007$ & $100,427.18$ & - & $44,149.25$ & - \\
\hline $4 / 21 / 2007$ & $97,909.99$ & - & $25,425.36$ & $1,199.59$ \\
\hline 4/22/2007 & $95,193.49$ & - & $27,498.19$ & - \\
\hline $4 / 23 / 2007$ & $89,170.67$ & - & $20,266.23$ & $10,658.66$ \\
\hline $4 / 24 / 2007$ & $82,469.53$ & - & $4,757.31$ & $19,913.38$ \\
\hline $4 / 25 / 2007$ & $89,421.30$ & - & $2,306.41$ & $22,779.33$ \\
\hline 4/26/2007 & $85,181.94$ & 593.36 & $2,766.19$ & $21,630.42$ \\
\hline $4 / 27 / 2007$ & $61,340.37$ & - & $2,109.29$ & $31,100.81$ \\
\hline 4/28/2007 & $67,170.55$ & - & - & $39,278.31$ \\
\hline 4/29/2007 & $85,013.27$ & - & 487.20 & $26,264.15$ \\
\hline $4 / 30 / 2007$ & $80,819.91$ & - & $2,545.04$ & $23,979.76$ \\
\hline $\begin{array}{l}\text { SUM (total per } \\
\text { period) (MJ) }\end{array}$ & $2,337,613.10$ & 593.36 & $411,579.99$ & $266,324.63$ \\
\hline $\begin{array}{l}\text { AVG per day } \\
\text { (MJ) }\end{array}$ & $90,211.72$ & 28.26 & $14,091.48$ & $12,096.95$ \\
\hline
\end{tabular}


Appendix B: Energy requirements per day for $60 \%$ transmissivity. 


\section{ENERGY REQUIREMENTS}

Curtain with 60\% transmissivity

\begin{tabular}{|c|c|c|c|c|}
\hline Day & $\begin{array}{c}\text { Outdoor PBR } \\
\text { HEATING }\end{array}$ & $\begin{array}{c}\text { Outdoor PBR } \\
\text { COOLING }\end{array}$ & $\begin{array}{c}\text { Indoor PBR } \\
\text { HEATING }\end{array}$ & $\begin{array}{c}\text { Indoor PBR } \\
\text { COOLING }\end{array}$ \\
\hline $4 / 10 / 2007$ & $79,589.92$ & - & $23,100.57$ & 11.46 \\
\hline $4 / 11 / 2007$ & $98,322.68$ & - & $34,451.33$ & - \\
\hline $4 / 12 / 2007$ & $96,634.68$ & - & $39,522.03$ & - \\
\hline $4 / 13 / 2007$ & $89,956.91$ & - & $29,693.19$ & - \\
\hline $4 / 14 / 2007$ & $102,787.00$ & - & $44,615.92$ & - \\
\hline $4 / 15 / 2007$ & $101,199.15$ & - & $50,984.23$ & - \\
\hline $4 / 16 / 2007$ & $85,740.59$ & - & $34,122.66$ & - \\
\hline $4 / 17 / 2007$ & $97,253.60$ & - & $30,166.12$ & - \\
\hline $4 / 18 / 2007$ & $99,619.53$ & - & $29,972.24$ & - \\
\hline $4 / 19 / 2007$ & $109,223.92$ & - & $45,082.24$ & - \\
\hline $4 / 20 / 2007$ & $100,427.18$ & - & $61,289.32$ & - \\
\hline $4 / 21 / 2007$ & $97,909.99$ & - & $48,762.33$ & - \\
\hline $4 / 22 / 2007$ & $95,193.49$ & - & $48,424.85$ & - \\
\hline $4 / 23 / 2007$ & $89,170.67$ & - & $36,670.19$ & - \\
\hline $4 / 24 / 2007$ & $82,469.53$ & - & $19,401.91$ & $1,332.84$ \\
\hline $4 / 25 / 2007$ & $89,421.30$ & - & $15,180.09$ & $1,425.13$ \\
\hline $4 / 26 / 2007$ & $85,181,94$ & 593.36 & $16,555.04$ & $1,120.14$ \\
\hline $4 / 27 / 2007$ & $61,340.37$ & - & $13,686.10$ & $7,161.18$ \\
\hline $4 / 28 / 2007$ & $67,170.55$ & - & $5,735.42$ & $9,707.42$ \\
\hline 4/29/2007 & $85,013.27$ & - & $9,046.35$ & $2,573.50$ \\
\hline $4 / 30 / 2007$ & $80,819.91$ & - & $14,319.17$ & $2,460.28$ \\
\hline $\begin{array}{l}\text { SUM (total per } \\
\text { period) (MJ) }\end{array}$ & $2,337,613.10$ & 593.36 & $837,316.94$ & $25,791.96$ \\
\hline $\begin{array}{l}\text { AVG per day } \\
\text { (MJ) }\end{array}$ & $90,211.72$ & 28.26 & $30,989.59$ & $1,228.19$ \\
\hline
\end{tabular}


Appendix C: Energy requirements per day for $80 \%$ transmissivity. 


\section{ENERGY REQUIREMENTS}

Curtain with $80 \%$ transmissivity.

\begin{tabular}{|c|c|c|c|c|}
\hline Day & $\begin{array}{c}\text { Outdoor PBR } \\
\text { HEATING }\end{array}$ & $\begin{array}{c}\text { Outdoor PBR } \\
\text { COOLING }\end{array}$ & $\begin{array}{c}\text { Indoor PBR } \\
\text { HEATING }\end{array}$ & $\begin{array}{c}\text { Indoor PBR } \\
\text { COOLING }\end{array}$ \\
\hline $4 / 10 / 2007$ & $79,589.92$ & - & $13,607.92$ & $5,072.29$ \\
\hline $4 / 11 / 2007$ & $98,322.68$ & - & $22,757.03$ & - \\
\hline $4 / 12 / 2007$ & $96,634.68$ & - & $27,743.44$ & 476.61 \\
\hline $4 / 13 / 2007$ & $89,956.91$ & - & $17,570.73$ & $3,041.81$ \\
\hline $4 / 14 / 2007$ & $102,787.00$ & - & $33,826.55$ & - \\
\hline $4 / 15 / 2007$ & $101,199.15$ & - & $40,188.62$ & - \\
\hline $4 / 16 / 2007$ & $85,740.59$ & - & $21,849.34$ & $2,499.91$ \\
\hline $4 / 17 / 2007$ & $97,253.60$ & - & $16,526.31$ & 552.91 \\
\hline $4 / 18 / 2007$ & $99,619.53$ & - & $17,409.52$ & $2,496.19$ \\
\hline $4 / 19 / 2007$ & $109,223.92$ & - & $33,095.87$ & - \\
\hline $4 / 20 / 2007$ & $100,427.18$ & - & $52,453.63$ & - \\
\hline $4 / 21 / 2007$ & $97,909.99$ & - & $36,214.24$ & - \\
\hline $4 / 22 / 2007$ & $95,193.49$ & - & $37,625.74$ & - \\
\hline $4 / 23 / 2007$ & $89,170.67$ & - & $25,837.47$ & $2,990.33$ \\
\hline $4 / 24 / 2007$ & $82,469.53$ & - & $10,644.48$ & $9,645.41$ \\
\hline $4 / 25 / 2007$ & $89,421.30$ & - & $6,680.27$ & $10,517.66$ \\
\hline $4 / 26 / 2007$ & $85,181.94$ & 593.36 & $7,548.84$ & $9,749.04$ \\
\hline $4 / 27 / 2007$ & $61,340.37$ & - & $6,208.18$ & $17,989.97$ \\
\hline $4 / 28 / 2007$ & $67,170.55$ & - & $1,251.18$ & $23,452.51$ \\
\hline $4 / 29 / 2007$ & $85,013.27$ & - & $3,184.60$ & $13,329.96$ \\
\hline $4 / 30 / 2007$ & $80,819.91$ & - & $6,718.56$ & $11,979.40$ \\
\hline \multicolumn{5}{|r|}{} \\
\hline $\begin{array}{c}\text { SUM (total per } \\
\text { period) (MJ) }\end{array}$ & $\mathbf{2 , 3 3 7 , 6 1 3 . 1 0}$ & $\mathbf{5 9 3 . 3 6}$ & $\mathbf{5 8 5 , 1 7 2 . 4 7}$ & $115,612.67$ \\
\hline $\begin{array}{c}\text { AVG per day } \\
\text { (MJ) }\end{array}$ & $90,211.72$ & $\mathbf{2 8 . 2 6}$ & $\mathbf{2 0 , 9 0 2 . 0 2}$ & $\mathbf{5 , 4 1 8 . 7 6}$ \\
\hline
\end{tabular}


Appendix D: Effects of different Nitrogen concentrations on the chemical composition of various algae strains. 


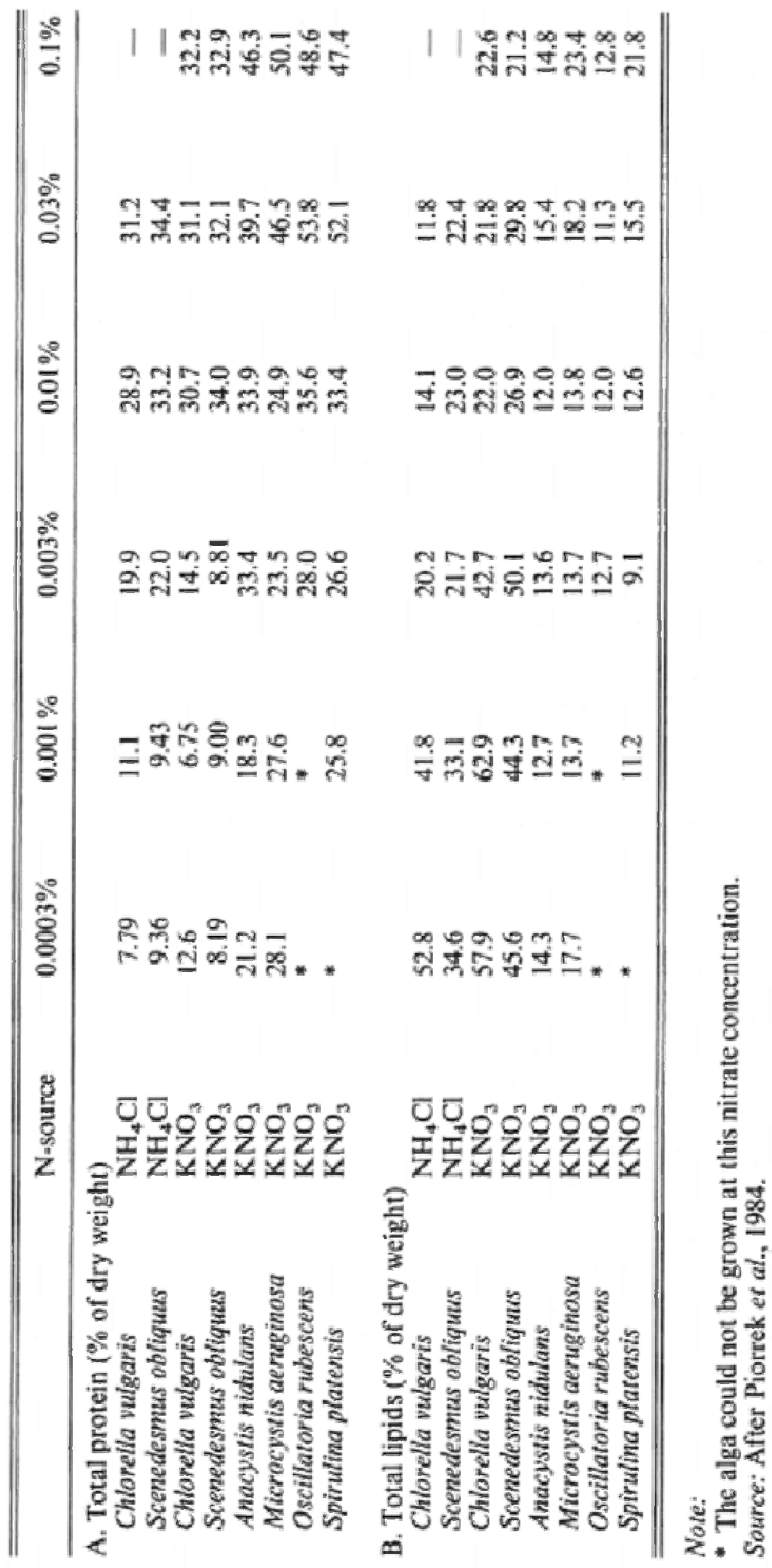

